Alain MARCHANDISSE

\title{
Un prince en faillite. Jean de Flandre, évêque de Metz (1279/80-1282), puis de Liège (1282-1291)
}

BRUXELLES

PALAIS DES ACADÉMIES

Rue Ducale, 1 


\title{
Un prince en faillite. Jean de Flandre, évêque de Metz (1279/80-1282), puis de Liège (1282-1291)
}

\author{
par Alain MARCHANDISSE \\ Chargé de recherches du F.N.R.S. \\ Docteur en Philosophie et Lettres
}

Au Professeur André Joris

On peut être en même temps un brillant homme d'Église et un politique exécrable, ou inversement, une situation pour le moins embarrassante lorsque l'on détient des responsabilités à la fois politiques et religieuses. Tel est bien le cas du prince-évêque de Liège - précisons-le

' Les différents sigles employés dans ce travail sont les suivants : A.C.H.S.B.A. : ANNALES dU CERCLE HUTOIS DES SCIENCES ET BEAUX-ARTS; A.H.L. : ANNUAIRE D'HistoIre lúgeoise; A.P.A.É. : ANCIENS Pays ET Assemblées d'États; A.S.A.N. : ANNAles de LA Société aRchélogique de NAMUR; B.C.R.H. : Bulletin de la COMMisSion royale D'HISTOIRE; B.I.A.L. : BULLETIN DE L'INSTTTUT ARCHÉOLOGIQUE LIEGGEOIS; B.I.H.B.R. : BULLETIN DE L'INSTITUT HISTORIQUE BELGE DE ROME; B.N. : BIOGRAPHIE NATIONALE DE Belgique; D.H.G.E. : DictionNaire d'Historre et de Géographie eCclésiastiques; C.S.L. : St. Bormans, É. Schoolmeesters, É. PonCelet, Cartulaire de l'église SaintLambert de Liège, t. 1-6, Bruxelles, 1893-1933; L.D.M. : LeXIKON DES MrTTELALTERS; M.Â. : Le Moyen Âge; R.B.P.H. : Revue Belge de PhILOLOGIE et D'Historre; R.C.L. : É. FaIron, Régestes de la Cité de Liège, t. 1, Liège, 1933; R.H.D. : Revue D'Historre du DROIT; R.O.P.L. : St. BORMANS, Recueil des ordonnances de la principauté de Liège. Première série. 974-1506, Bruxelles, 1878. Nous tenons à remercier vivement MM. A. JORIS, J.L. KUPPER, L. MILIS et C. WYFFELS, qui ont accepté cette publication dans les collections de la Commission royale d'Histoire et l'ont enrichie de leurs suggestions. Notre gratitude va tout particulièrement à MM. A. JORIS et J.L. KUPPER, respectivement Professeur honoraire et Professeur ordinaire aux Universités de Liège et de Luxembourg, Membres de la Commission royale d'Histoire, ainsi qu'à MM. P. JODOGNE, Professeur à l'Université de Liège, et R.C. VAN CAENEGEM, Professeur émérite à l'Université de Gand, Membre de la Commission royale d'Histoire, qui, à des titres divers, nous ont apporté une aide précieuse dans la rédaction de cette contribution. 
d'emblée - et tel est également le paradoxe qu'ont cultivé quelquesuns des chefs d'État liégeois au cours du moyen âge. Jean de Flandre ${ }^{2}$ fait incontestablement partie de ceux-là.

Évêque de Metz durant peu de temps, puis de Liège, entre 1282 et 1291, ce prince de l'Église a laissé pour l'essentiel l'image d'un canoniste de première force. On lui doit en effet la première codification véritable des procédures synodales liégeoises (1288), des statuts dont chacun reconnaît aujourd'hui l'importance'. S'il apparaît comme un excellent pasteur, il fut en revanche un bien piètre gestionnaire politique, tout particulièrement en ce qui concerne les finances de l'État liégeois. Le titre que nous avons choisi de donner à cette contribution traduit d'ailleurs assez bien, en des termes quelque peu imagés, il est vrai, les difficultés à la fois récurrentes et exponentielles que connut ce cadet de Flandre dans l'administration de ses finances. Pour en montrer l'exacte ampleur, nous proposons ici un ensemble de chartes notamment un grand nombre de reconnaissances de dettes - inégalement réparties entre les Fonds des chartes des comtes de Flandre, aux Archives de Gand, et la Chambre des Comptes, aux Archives fran-

${ }^{2}$ Sur cet évêque, on nous permettra de renvoyer à nos travaux : A. MARCHANDISSE, La fonction épiscopale à Liège, aux XIIIe et XIVe siècles. Étude de politologie historique (= MARCHANDISSE, Fonction épiscopale), Thèse de doctorat d'État en Philosophie et Lettres, Liège, Université de Liège, 1994-1995, spéc. p. 151-161, 263-265, 300-301, 419-422, 533-534 (sous presse; nous renvoyons donc aux p. de la version dactylographiée).- ID., Art. Jean IV de Flandre-Dampierre, D.H.G.E., sous presse. En outre, efr M. DussarT, Jean de Flandre, évêque de Liège. 1282-1291, Mem. de Lic. en Histoire dactyl., Liège, Université de Liège, 1977-1978.- J. LeJEuNE, L'enlèvement de Jean de Flandre, évêque de Liège. Ou comment on écrit l'histoire et comment un droit se constitue (= LEJEUNE, Enlèvement Jean de Flandre), A.P.A.É., t. 3, 1952, p. 69-89.- J. PYCKE, Répertoire biographique des chanoines de Notre-Dame de Tournai, 1080-1300 (= PYCKE, Répertoire), Louvain-la-Neuve-Bruxelles, 1988, p. 92-93.- Chr. RENARDY, Les maîtres universitaires du diocèse de Liège. Répertoire biographique (1140-1350) (= RENARDY, Répertoire), Paris, 1981, p. 342-343 et, surtout, J.L. KUPPER, Herzog Johann I. von Brabant und das Fürstentum Lüttich vor und nach der Schlacht bei Worringen (= KUPPER, Herzog Johann I. von Brabant und Lüttich), BLÄTTER FÜR DEUTSCHE LANDESGESCHICHTE, t. 125,1989 , p. $87-97$ (réimpr. dans LE LUXEMBOURG EN Lotharingie. LuXemburg im lotharingischen Raum. Mélanges Paul Margue. Festschrift PaUl Margue, Luxembourg, 1993, p. 345-355).

${ }^{3}$ En attendant les travaux annoncés de J. Avril, cfr, sur ce texte: É. SCHOOLMEESTERS, Les statuts synodaux de Jean de Flandre, évêque de Liège, le 16 février 1288 (= SCHOOLMEESTERS, Statuts synodaux), Liège, 1908.- J.P. DELVILLE, Les statuts synodaux de l'ancien diocèse de Liège, A.H.L., t. 20, 1979, p. 39-78.M. LAVOYE, Le texte original des statuts synodaux de Jean de Flandre, BULLETIN DE LA

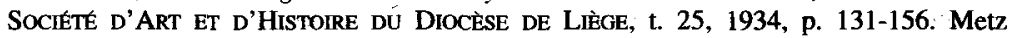
(France, dép. Moselle). 
çaises du département du Nord, un dossier documentaire qui, certes, n'est probablement pas exhaustif mais dont l'intérêt ne peut être nié. En effet, celui-ci, qui ne prend toute son importance que dans sa globalitée, supplée quelque peu les comptes épiscopaux dont la carence, à Liège, amoindrit considérablement notre connaissance du fonctionnement de l'institution épiscopale 5 . Par ailleurs, ces actes nous permettent de mieux saisir le drame que connurent nombre de dynastes médiévaux : vivre la banqueroute au quotidien. Mais avant d'exposer plus avant le contenu de ces documents et afin de leur donner un éclairage satisfaisant, quelques mots sur le personnage central de cet article : Jean de Flandre.

Né en $1250^{6}$, Jean de Flandre ou de Dampierre était le troisième fils du comte de Flandre Guy de Dampierre $(1278-\dagger 1305)^{7}$ et de sa première épouse, Mahaut de Béthune $(\dagger 1263)^{8}$. Très rapidement, le comte mit tout en oeuvre afin que s'ouvre à son fils cadet une carrière prestigieuse au sein de l'Église. Vers 1268, le jeune prince de Flandre obtint le titre de decretorum doctor de l'Université de Bologne', spécialisée dans l'enseignement du droit, tandis que, dans le même temps, il multipliait prébendes et dignités : à douze ans, la prévôté de Saint-Donatien

${ }^{4}$ C'est bien la raison pour laquelle nous avons choisi d'éditer l'ensemble des documents même si certains d'entre eux l'ont déjà été par le passé. Ces éditions sont d'ailleurs, on le remarquera, particulièrement dispersées et comportent, en outre, nombre d'erreurs de transcription, voire carrément des omissions.

${ }^{5}$ Les comptes de l'hôtel épiscopal semblent pourtant avoir existé, sous Jean de Flandre tout au moins. En effet, d'après le document 29, le prélat assume les dépenses de son hồtel « si comme il apert plus plainement par les contes des dis despens de nostre hosteil ».

- J. GLISSEN, Les légistes en Flandre aux XIII et XIV siècles, BULLETIN DE LA COMMISSION ROYALE DES ANCIENNES LOIS ET ORDONNANCES, t. 15, 1948, p. 131-132.RENARDY, Répertoire, p. 342.- PYCKE, Répertoire, p. 92.- MARCHANDISSE, Fonction épiscopale, p. 552,556 n. 34.

7 À son propos, en l'absence d'une biographie véritable, cfr M. VANDERMAESEN, Art. G. III., L.D.M., t. 4, Munich-Zurich, 1989, col. 1767 (et bibliog.).- ID., Art. Dampierre, L.D.M., t. 3, Munich-Zurich, 1986, col. 487-488 (et la bibliog.).- ID., Vlaanderen en Henegouwen onder het huis van Dampierre (1244-1384), ALGEMENE GESCHIEDENIS DER

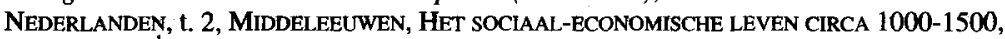
HET STEDELIJK LEVEN CIRCA 1000-1400, POLITIEKE ONTWIKKELING CIRCA 1100-1400, Haarlem, 1982, p. 403-414 et bibliog., p. 554-557.- H. NowÉ, Art. Guy de Dampierre, B.N., t. 30 (SUPPLÉMENTS, t. 2), Bruxelles, 1959, col. 424-446, et les propos de J. Bovesse, dans Jean Ire, comte de Namur (1276-1330). Notes biographiques, A.S.A.N., t. 45, 19491950, p. 1-2, 11, 12, 18-20, 24, 58.

${ }^{8}$ Cfr n. 7.- E. WARLOP, De vlaamse adel voor 1300 (= WARLoP, Vlaamse adel), t. 2,1, Handzame, 1968, p. 69, 77.

${ }^{9}$ Renardy, Répertoire, p. 342.- PyCKe, Répertoire, p. 92. Bologne (Italie, Émilie- 
de Bruges et, par là même, la chancellerie de Flandre ${ }^{10}$, la trésorerie de Notre-Dame de Tournai (1265-1278) et la prévôté de Saint-Pierre de Lille ${ }^{11}$, qui lui est confirmée en 1272 par Grégoire $\mathrm{X}^{12}$, sur les instances de son père et de sa grand-mère, la comtesse de Flandre Marguerite de Constantinople ${ }^{13}$. En 1279/1280, il est élu évêque de Metz $^{14}$ avant de recueillir, le 9 juin $1282^{\prime 1}$, la succession de l'évêque de Liège Jean d'Enghien ${ }^{16}$. Nous avons montré ailleurs que loin d'être, comme on l'a parfois dit, un épisode banal de la querelle des d'Avesnes et des Dampierre, l'avènement liégeois de Jean de Flandre relève incontesta-

${ }^{10} \mathrm{Cfr}$, par exemple, W. Prevenier, La chancellerie des comtes de Flandre dans le cadre européen à la fin du XIF siècle, BIBLIOTHËQUE DE L'ÉCOLE DES CHARTES, t. 125, 1967, p. 35 et n. 1, 58.- Th. DE HeMPTINNE, W. PreVenier, M. VANDERMAESEN, La chancellerie des comtes de Flandre $\left(12^{e}-14^{c}\right.$ siècle), LANDESHERRLICHE KANZLEIEN IM SPÄtmitTElalter : Referate ZUM VI. InTERnationale Kongreb fUR DiPlomatiK, MüNCHEN, 1983, éd. G. SILAGI, t. 1, Munich, 1984, p. 434, 445. Cfr encore Th. LuYKs, De strijd om het kanselierschap in Vlaanderen tussen Philips van Savoye en Jan van Vlaanderen, MisCELLANEA J. GeSSLER, t. 2, s.l., 1948, p. 767-779. Bruges (Belgique, pr. Flandre occidentale, arr. Bruges, comm. Bruges).

" Renardy, Répertoire, p. 342.- PyCKe, Répertoire, p. 92. Tournai (Belgique, pr. Hainaut, arr. Tournai, comm. Tournai), Lille (France, arr. Nord).

$121271-\uparrow 1276$.

${ }^{13}$ É. HaUtCoEUR, Cartulaire de l'église collégiale de Saint-Pierre de Lille (= Hautcoeur, Cartulaire Saint-Pierre Lille), t. 1, Lille-Paris, 1894, p. 429-430.- J.B.M.C. KERVYN DE LETtENHOVE, Codex Dunensis sive diplomatum et chartarum medii aevi amplissima collectio, Bruxelles, 1875, p. 364.- É. HAUTCOEUR, Histoire de l'église collégiale et du chapitre de Saint-Pierre de Lille (= HaUTCOEUR, Histoire Saint-Pierre Lille), t. 1, Lille-Paris, 1896, p. 113-115. Sur Marguerite de Constantinople, comtesse de Flandre (1244-1278), cfr Th. LuYKs, De grafelijke financiële bestuursinstellingen en het grafelijk patrimonium in Vlaanderen tijdens de regering van Margareta van Constantinopel (12441278), Bruxelles, 1961.

${ }^{14}$ Renardy, Répertoire, p. 342.- PYCKE, Répertoire, p. 93.- B. MORRET, Stand und Herkunft der Bischöfe von Metz, Toul und Verdun im Mittelalter, Dusseldorf, 1911, p. 38. On trouvera quelques éléments sur le règne messin de Jean de Flandre, dans M. DEPOUX, La seigneurie épiscopale de Metz. Ses variations territoriales de 962 à 1415, t. 2, Thèse de 1 'École des Chartes, 1954, p. 454-456 (Aimable communication de Madame Line SKORKA, Conservateur en chef du Patrimoine des Archives pour la région de Lorraine, Directeur des Archives départementales de la Moselle, que nous remercions chaleureusement).

${ }^{15}$ Les registres de Martin $I V$ (1281-1285), éd. ÉCOLE FRANÇAISE DE ROME, t. 1, Paris, 1901-1935, p. 63.- C.S.L., t. 6, p. 29.

${ }^{16}$ Sur ce prélat (1274- $\uparrow 1281$ ), cfr MARCHANDISSE, Fonction épiscopale, p. 145-151, 299-300.- J. Closon, Un évêque de Liège peu connu de la fin du XIIr siècle : Jean d'Enghien (1274-1281), B.I.A.L., t. 57, 1933, p. 41-82.- RENARDY, Répertoire, p. 341342.- PYCKE, Répertoire, p. 298-299. 
blement de la haute politique internationale ${ }^{17}$. On peut penser en effet qu'en le désignant, Martin IV ${ }^{18}$, pape français, voulut donner satisfaction au comte de Flandre et à son fils afin de les allier durablement aux princes qui avaient permis son accession au souverain pontificat, à savoir le roi de France Philippe III le Hardi ${ }^{19}$ et son oncle, Charles I ${ }^{\text {er }}$ d'Anjou, roi de Sicile ${ }^{20}$, en vue notamment de la croisade menée par ces derniers contre l'Aragon (1282-1285) ${ }^{21}$. Investi au temporel alors qu'il régnait à Metz (mai 1281) ${ }^{22}$, Jean de Flandre fit son entrée à Liège en octobre $1282^{23}$ et jura peut-être, à cette occasion, la première capitulation épiscopale de l'histoire de Liège ${ }^{24}$. De la politique étrangère liégeoise sous son règne, on retiendra surtout une succession d'alliances

17 Nous exposons l'ensemble des événements liés à l'avènement de Jean de Flandre dans Marchandisse, Fonction épiscopale, p. 151-161. Sur la querelle des d'Avesnes et des Dampierre, qui mit aux prises, tout au long du XIII' siècle, les descendants des deux unions de Marguerite de Constantinople, cfr l'ouvrage classique de Ch. Duvrvier, La querelle des d'Avesnes et des Dampierre, jusqu'à la mort de Jean d'Avesnes (1257), 2 vol., Bruxelles-Paris, 1894.

${ }_{18} 1281-\uparrow 1285$.

$191270-\uparrow 1285$.

${ }^{20}$ Sur ce roi de Sicile (1266- $\left.\uparrow 1285\right)$, fils cadet des rois de France Louis VIII et Blanche de Castille, cfr P. Herde, Art. K. I. v. Anjou, L.D.M., t. 5, Munich-Zurich, 1991, col. 983985 et la bibl. de ce spécialiste de la question.

${ }^{21}$ Cfr R. FAwTIER, L'Europe occidentale de 1270 à 1380 , 1' part., De 1270 à 1328 , Paris, 1940, p. 266-284.- Ch.V. LangloIs, Le règne de Philippe III le Hardi, Paris, 1887, p. 44, 96-166.- L. LECLĖRE, Les rapports de la papauté et de la France sous Philippe III (1270-1285), Bruxelles, 1889, p. 96-116.- J.R. STRAYER, The crusade against Aragon, SPECULUM, t. 28, 1953, p. 102-113.

22 J.Fr. BöHMER, O. REDLICH, Die Regesten des Kaiserreiches unter Rudolf, Adolf, Albrecht, Heinrich VII. (I273-1313), $1^{\mathrm{e}}$ part., Innsbruck, 1898, p. 318, $\mathrm{n}^{\circ} 1299$.

${ }^{23}$ Chronique liégeoise de $1402(=1402)$, éd. E. BACHA, Bruxelles, 1900, p. 223.- JEAN DE HoCsem, Chronicon (= JEAN DE HoCsem, Chronicon), éd. G. KuRTH, Bruxelles, 1927, p. 69.- CoRneille de ZanTfliet, Chronicon (= CoRneIlle De ZanTFliet, Chronicon), éd. E. Martène et U. DuRAND, Amplissima Collectio, t. 5, Paris, 1729, col. 120. Sur ces chroniques, cfr JEAN DE HocseM, Chronicon, p. XXXVII-LXIII- S. BALAU, Les sources de l'histoire de Liège au moyen age. Étude critique (= BALAU, Sources), Bruxelles, 1903, p. 499-513, 533-538, 605-619.- R. FEENSTRA, Les Flores utriusque iuris de Jean de Hocsem et leur édition au XV' siècle, R.H.D., t. 31, 1963, p. 487-499.- P. AvoNDS, Jan van Hocsem en Leuven, R.H.D., t. 38, 1970, p. 191-194.- R.C. VAN CAENEGEM, Art. Hocsem, Jan van, NATIONAAL BIOGRAFISCH WOORDENBOEK, t. 1, Bruxelles, 1964, col. 611-615.- RENARDY, Répertoire, p. 349-351.- F. VeRCAUTtEREN, Gilles de la Marcelle, chanoine de Liège, trésorier de l'empereur Henri VII, STUDI IN ONORE DI ARMANDO SAPORI, t. 1, Milan, 1957, p. 429-431 (réimpr. dans ID., Études d'histoire médiévale. Recueil d'articles du Professeur Vercauteren publiés par le Crédit communal de Belgique, Bruxelles, 1978, p. 477-489).- J. LeJeUne, La * Chronique liégeoise de 1402 * et Henri de Dinant (1253-1256), MÉlanges Félix RousSEAU. ÉTUDES SUR L'HISTOIRe du PaYS MOSAN AU MOYEN ÂGE, Bruxelles, 1958, p. 413-432.- ID., À propos de l'art mosan... Renier, l'orfèvre et les fonts de Notre-Dame, A.P.A.É., t. 3, 1952, p. 3-27 et spéc. p. 11-15.- ID., Enlèvement Jean de Flandre, p. 71-89 et spéc. p. 71-74.- J.L. KuPPER, Note sur Henri de Dinant, B.I.A.L., t. 98, 1986, p. 339-349.

${ }^{24}$ C.S.L., t. 2, p. 348-352 (date erronée, à ramener au 18 septembre 1281). 
et de conflits avec le duc Jean ${ }^{\text {er }}$ de Brabant $^{25}$, en particulier le soutien épiscopal au Brabançon lors de la célèbre bataille de Worringen $(1288)^{26}$ et le siège de la forteresse de Cornillon par les troupes ducales $(1291)^{27}$. Dans ses États, le prélat liégeois s'efforça de pacifier les relations entre le clergé et la bourgeoisie liégeois; et annula une excommunication jadis fulminée par Jean d'Enghien contre les chapitres de la ville $^{28}$. Certaines dissensions avec la Cité le forcèrent à gagner Huy (1284/1285-1287 $)^{29}$ mais, en fin de compte, l'évêque parvint à réconcilier clergé et bourgeoisie de la Cité par la célèbre Paix des Clercs

${ }^{25}$ Sur ce prince (1267- $\dagger$ 1294), beau-frère de Jean de Flandre, cfr P. Avonds, Art. J. I., L.D.M., t. 5, Munich-Zurich, 1991, col. 506-507 (et bibl.).

${ }^{26} 1402$, p. 228.- JEAN De Hocsem, Chronicon, p. 77-78.- JEAN DE Warnant, Chronique (Extraits) (= Tongerlo), éd. S. BALAU et É. FAIRON, Chroniques liégeoises, t. 1, Bruxelles, 1913, p. 39.- JEAN D'OUTREMEUSE, Chronique en bref (= JEAN D'OUTREMEuse, Chronique en bref), BiBLiothèQue DE LA VILLE DE LIĖGE (CHIROUXCroisiers), Salle Ulysse CaptTaine, ms. $133, \mathrm{f}^{\circ} 90 \mathrm{v}^{\circ}$. Sur ces chroniques, cfr J. LEJEUNE, Jean d'Outremeuse, le quatrième livre du "Myreur des histors " et la "Chronique en bref ", A.H.L., t. 4, 1951, spéc. p. 522 n. 3.- ID., Une source méconnue : la "Chronique en bref » de Jean d'Outremeuse, R.B.P.H., t. 34, 1956, p. 985-1020. A. JoRIs, Politique monétaire et difficultés commerciales : un procès contre Huy en 1310, A.C.H.S.B.A., t. 24, 1953, p. 195 et n. 7. Les rapports tumultueux entre Jean $\mathrm{I}^{\text {er }} \mathrm{de}$ Brabant et Jean de Flandre sont décrits en détail par KUPPER, Herzog Johann I. von Brabant und Lüttich, p. 87, 91-97. Cfr encore J. LeJEUNE, Liège et son Pays. Naissance d'une patrie (XIII'-XIV' siècles) (= LeJEUNE, Liège et son Pays), Liège, 1948, p. $85-87$ et J. BAERTEN, La bataille de Worringen (1288) et les villes brabançonnes, limbourgeoises et liégeoises, ViLles et CaMpagnes aU moyen ÂGe. Mélanges Georges Despy, éd. A. DierKens et J.M. Duvosquel, Liège, 1991, p. 83. Worringen (R.F.A., L. RhénanieWestphalie).

27 JEAN DE HocSEM, Chronicon, p. 82-83.- Tongerlo, p. 40.- JEAN D' OUTREMEUSE, $L y$ Myreur des histors (= JEAN D' OUTREmEuSE, Myreur), éd. A. Borgnet et St. Bormans, t. 5, Bruxelles, 1867, p. 477-478 (sur cette oeuvre et son auteur, cfr JEAN D'OUTREMEUSE, Myreur, t. 7:- G. KuRTH, Étude critique sur Jean d'Outremeuse, MÉmOIRES dE LA ClaSSE Des LeTtres de L'ACAdémIE Royale de BelgiQue, $2^{2}$ sér., t. 7, 1910, p. 1-107.- BalaU, Sources, p. 559-574.- ID., Comment Jean d'Outremeuse écrit l'histoire, B.C.R.H., t. 71, 1902, p. 227-259.- F. VerCAUTEREN, Luttes sociales à Liège (XIII et XIV siècles), $2^{\mathrm{e}}$ éd., Bruxelles, 1946, p. 114-115).- A. WAUTERS, Le duc Jean $l^{\text {er }}$ et le Brabant sous le règne de ce prince (1267-1294) (= WAUTERS, Jean $I^{2}$ ), Bruxelles-Liège, 1862, p. 202-203.- M. Josse, Le domaine de Jupille, des origines à 1297 (= JossE, Domaine Jupille), Bruxelles, 1966, p. 78 n. 161.- R. DEPREZ, La politique castrale dans la principauté épiscopale de Liège du Xe au XIV siècle, M.Â., t. 65, 1959, p. 519.

${ }^{28}$ C.S.L, t. 2, p. 355-356, 377-380.- St. Bormans, Notice d'un cartulaire du clergé secondaire de Liège, Bruxelles, 1873, p. 21-22 (extr. de B.C.R.H., $3^{e}$ sér., t. 14, 1872).R.C.L., t. 1, p. 106-107.- G. KuRTH, La Cité de Liège au moyen âge (= KuRTH, Cité de Liège), t. 1, Bruxelles-Liège, 1909, p. 231-232.

${ }^{29}$ C.S.L., t. 2, p. 384-385, 397-398.- R.C.L., t. 1, p. 107.- JEAN DE HoCSEM, Chronicon, p. 74-75.- 1402, p. 225-226.- JEAN D'OUTREMEUSE, Chronique en bref, $\mathrm{f}^{\circ} 90 \mathrm{v}^{\circ}$.- ID., Myreur, t. 5, p. 442-443, 446.- KuRTh, Cité de Liège, t. 1, p. 232. Huy (Belgique, pr. Liège, arr. Huy, comm. Huy). 
(7 août 1287$)^{30}$, prélude à l'élaboration d'un véritable code pénal à l'usage des chanoines et des bourgeois, connu sous le nom de Loi muée ( 8 août et 9 octobre 1287$)^{31}$. Jean de Flandre s'éteignit le 14 octobre $1291^{32}$.

Ces quelques faits étant posés, venons-en à présent à la situation financière de l'évêque de Liège.

À quelques très rares exceptions, les quelque trente documents édités en annexe présentent un point commun: ils concernent, à des degrés divers, des emprunts contractés par Jean de Flandre. Or, tout emprunt suppose un manque d'argent ou, à tout le moins, des ressources insuffisantes au regard du train de vie que l'on mène. Dès lors et avant d'étudier les emprunts proprement dits, leurs modalités et l'identité des prêteurs, plusieurs questions se doivent de trouver une réponse : 1) les ressources de l'État liégeois étaient-elles à ce point infimes et 2) quelles furent les raisons qui poussèrent Jean de Flandre à emprunter?

À la première interrogation et pour ne parler ici que de la fonction épiscopale liégeoise, celle que Jean de Flandre exerça le plus longtemps, la réponse est incontestablement négative. L'Église de Liège fut toujours particulièrement opulente ${ }^{33}$ et ce n'est pas la moindre des raisons pour lesquelles son siège épiscopal fut tellement convoité. À preuve, le montant des services communs acquittés par le prélat liégeois - en substance, le prix à payer pour que la papauté lui concède le trône de saint Lambert -, soit 7200 florins, dès la fin du $\mathrm{XIII}^{\mathrm{e}}$ siècle $^{34}$. Ces services représentant traditionnellement le tiers des

${ }^{30}$ C.S.L., t. 2, p. 409-422.- R.O.P.L., p. 64-74.- R.C.L., t. 1, p. 114.

${ }^{31}$ C.S.L., t. 2, p. 422-426.- R.O.P.L., p. 74-85.- R.C.L., t. 1, p. 115-116.- KuRTH, Cité de Liège, t. 1, p. 231-242.

${ }^{32}$ Historia insignis monasterii Sancti Laurentii Leodiensis, éd. E. MARTèNE et U. Durand, Amplissima Collectio, t. 4, Paris, 1729, col. 1107.- JeAn De Hocsem, Chronicon, p. 83 (année erronée).- 1402, p. 231 (id.).- Annales Laubienses, éd. G.H. PERTZ, M.G.H., SS., t. 4, p. 27 (id.).- Annales Sancti Jacobi Leodiensis minores, éd. J. ALEXANDRE, Liège, 1874, p. 24 (id.) (sur ces diverses annales, cfr BalaU, Sounces, p. 256-258, 260.- A. PoTTHAST, Repertorium Fontium Historiae Medii Aevi, t. 2, 1967, p. 296.- J. STIENNON, Étude sur le chartrier et le domaine de l'abbaye de Saint-Jacques de Liège (1015-1209), Paris, 1951, p. 71-76, 179-180).- É. PonCELET, Guy de Hainaut, élu de Liège (= PONCELET, Guy de Hainaut), B.C.R.H., 5' sér., t. 8, 1898, p. 501-504.

${ }^{33} \mathrm{Cfr}$ les informations données par J.L. KUPPER, Liège et l'Église impériale (XIk-XII siècle) (= KuPPER, Liège et l'Église impériale), Paris, 1981, p. 453, pour la période antérieure à 1200 .

${ }^{34}$ H. HOBERG, Taxae pro communibus servitiis ex libris obligationum ab anno 1295 usque ad annum 1455 confectis, Rome, 1949, p. 68, 374. 
revenus annuels de la charge pour laquelle ils sont réclamés ${ }^{35}$, l'épiscopat liégeois devait donc normalement rapporter, grosso modo, 21600 florins par an, soit l'un des plus importants revenus de la Chrétienté. Comme ce chiffre le laisse supposer, l'évêque de Liège détenait en fait quantité de moyens pour faire de l'argent.

Mentionnons tout d'abord les recettes d'origine publique. Celles provenant de la mense épiscopale, qui, théoriquement, représentait un tiers des alleux de l'Église de Liège ${ }^{36}$, devaient être considérables, quel que soit d'ailleurs le type de faire-valoir qui lui était appliqué et malgré une gestion parfois peu rationnelle ${ }^{37}$. Aux revenus de la mense venaient s'ajouter ceux issus de l'inféodation du second tiers des alleux, en l'espèce les droits des reliefs de fiefs, une fortune si l'on pense que la totalité des terres féodales de la principauté relevait exclusivement du prélat ${ }^{38}$. L'exercice des droits régaliens, de ces parcelles de l'autorité suprême que l'empereur conférait lors de l'investiture épiscopale, était également particulièrement lucratif pour le prélat. Parmi eux, on trouve l'ensemble des prérogatives liées au ius monetae, en particulier les amendes encourues pour atteinte à ce droit et surtout les revenus de la frappe de la monnaie ${ }^{39}$, ce seigneuriage que l'évêque se réserva toujours jalousement, n'hésitant pas à prendre des mesures drastiques contre tous ceux qui cherchaient à briser son

35 J. GAUDEMET, Le gouvernement de l'Église à l'époque classique (= GAUDEMET, Gouvernement), $2^{c}$ part., Le gouvernement local, Paris, 1979, p. 70.- U. BERLIËR, Inventaire analytique des Libri obligationum et solutionum des Archives Vaticanes, au point de vue des anciens diocèses de Cambrai, Liège, Thérouanne et Tournai (= BERLIĖRE, Libri obligationum), Rome-Bruges-Paris, 1904, p. VII-XVII.- G. KURTH, Liège et la cour de Rome au XIVe siècle, B.I.H.B.R., t. 2, 1922, p. 15-18.

${ }^{36}$ KUPPER, Liège et l'Église impériale, p. 434-435. Le document 6, mentionnant d'innombrables biens sur lesquels Jean de Flandre garantit le payement d'une dette, serait particulièrement utile pour une éventuelle étude consacrée à la mense épiscopale liégeoise. Cfr d'ailleurs J.L. KuPPER, Raoul de Zähringen, évêque de Liège, 1167-1191. Contribution à l'histoire de la politique impériale sur la Meuse moyenne (= KUPPER, Raoul de Zähringen), Bruxelles, 1974, p. 73 n. 38.

${ }^{37}$ Sur les diverses incapacités dont fut frappée la mense épiscopale, cfr MARCHANDISSE, Fonction épiscopale, p. 256 et n. 138.

${ }^{38}$ KUPPER, Liège et l'Église impériale, p. 434-435.

${ }^{39}$ Sur toutes ces questions, cfr ID., Liège et l'Église impériale, p. 454.- H. FRÈRE, Le droit de monnaie de l'évêque de Liège (= FRÈRE, Droit de monnaie), REVUE NUMISMATIQUE, 6c sér., t. 8, 1967, p. 70-88, spéc. p. 70-73, 82-85, 88.- ID., Introduction à la numismatique liégeoise, REVUE DE LA BANQUE, t. 33, 1969, p. 285-286.- J. BAERTEN, Les droits des empereurs et des évêques en matière monétaire dans la principauté de Liège $\left(\mathrm{X}^{e} \sim \mathrm{XII}^{c}\right.$ siècles), CERCLES D'ÉTUDES NUMISMATIQUES, t. 29, 1992, p. 49-59.- J.L. KuPPER, Otbert de Liège : les manipulations monétaires d'un évêque d'Empire à l'aube du XII' siècle (= KUPPER, Otbert), M.Â., t. 86, 1980, p. 353-385, spéc. p. 355. 
monopole ${ }^{40}$. L'exploitation du droit de monnaie se doublait de celle des marchés et des tonlieux ${ }^{41}$. Cependant, la perception de taxes indirectes sur la circulation et la vente des marchandises, de même que les sanctions pécuniaires $y$ afférentes, ne constituent que quelques exemples parmi les multiples impôts et amendes que l'évêque était en droit de réclamer ${ }^{42}$.

Les revenus liés à la fonction épiscopale sont également loin d'être négligeables. Outre la dîme dont il est encore question dans les sources même si, souvent, elle est inféodée ${ }^{43}$, l'évêque perçoit les jura episcopalia ou synodalia, terme générique désignant les taxes liées à la juridiction synodale de l'évêque. Celui-ci insiste tout particulièrement sur le strict maintien du cathedraticum ${ }^{44}$, ce tribut payé par chaque église paroissiale à son évêque en signe de sujétion et afin qu'il puisse subvenir aux besoins de sa charge ${ }^{45}$. C'est dire combien il devait grossir le budget du prélat, un budget qui, de prime abord et si l'on s'en tient aux seules recettes légales, aurait dû être largement bénéficiaire. Cependant, il n'en est rien, tant s'en faut. À l'inverse, l'évêque de Liège apparaît constamment comme un homme criblé de

40 En 1307, Thibaut de Bar détruisit un château appartenant à Thibaut II, duc de Lorraine, parce que ce dernier avait battu monnaie dans la seigneurie de Florennes, qu'il tenait en fief de l'évêché [C.S.L., t. 3, p. 74-76.- JEAN DE HoCSEM, Chronicon, p. 125.1402, p. 254.- Tongerlo, p. 61.- MathIAS DE LewIS, Chronicon (= MATHIAS DE LewIS, Chnonicon), éd. St. BoRmans, Liège, 1865, p. 87 (sur cette chronique, cfr Balau, Sources, p. 538-546.- P. AvoNDS, Politieke propaganda in de XIV de-eeuw : de leenhulde van Jan II van Brabant aan Thibaut van Bar in Lewis's "Chronicon Leodiense », B.C.R.H., t. 135, 1969, p. 91-132)]. En 1298, le seigneur de Durbuy renonça à frapper de la monnaie dans cette localité suite à des réclamations, notamment de la part de l'évêque de Liège (C.S.L., t. 2, p. 554-555).

${ }^{41}$ KUPPER, Liège et l'Église impériale, p. 454.- FRÈRE, Le droit de monnaie, p. 82. KuPPER, Otbert, p. 370.

${ }_{42}$ Pour un aperçu de ces revenus nombreux et lucratifs, cfr MARCHANDISSE, Fonction épiscopale, p. 258-259.

${ }^{4.3} \mathrm{Cfr}$, entre autres, É. Poncelet, Actes des princes-évêques de Liège. Hugues de Pierrepont, 1200-1229, Bruxelles, 1941, p. 61-62, 242-243, 272.- ID., Chartes du prieuré d'Oignies de l'ordre de Saint-Augustin, t. 1, Namur, 1913, p. 165.- C.S.L., t. 1, p. 346; t. 3, p. 129-131.- Chr. RENARDY, L'influence des juridictions sur le mouvement de restitution des dîmes dans le diocèse de Liège (XI'-XIV siècle), R.H.D., t. 41, 1973, p. 347.

44 KUPPER, Liège et l'Église impériale, p. 455.- A. Munsters, Het "Cathedraticum " in het oude bisdom luik, DE MAAsgouw. LimbURGS TudDSCHRIFT VOOR Geschiedenis, TAal EN Kunst, t. 66, 1952, p. 17-20.- M. Lalmant, Art. Cathedraticum, Dictionnaire de Drott CanoniQue, t. 2, Paris, 1937, col. 1436-1437.

${ }^{45}$ Nombreux exemples dans MARCHANDIssE, Fonction épiscopale, p. 259-260 et $\mathrm{n}$. 152. 
dettes, au bord du gouffre financier, véritablement aux abois ${ }^{46}$. Sans doute les raisons de ce paradoxe doivent-elles être cherchées du côté des dépenses, dont les motifs, multiples, apparaissent très clairement sous le règne de Jean de Flandre, au travers des actes que nous éditons ici.

À l'aube de son règne, nous l'avons vu plus haut, l'évêque de Liège se trouvait déjà passablement endetté. Il est en effet invité à payer aux divers services de la papauté des services communs d'un montant de 7 200 florins $^{47}$. Le prince entame donc son règne avec un passif d'autant plus encombrant qu'il doit encore éventuellement acquitter, en sus, le solde débiteur de son ou de ses prédécesseurs ${ }^{48}$. Ce qui est vrai pour les droits d'accession au siège épiscopal ne l'est pas moins pour les dettes laissées par le précédent souverain liégeois. Ainsi, le 22 septembre 1284, Jean de Flandre se voit-il obligé de payer 6000 livres tournois, montant des dîmes non acquitté par feu Jean d'Enghien, ainsi qu'une dette que ce dernier n'avait pas honorée envers le duc de Brabant, soit quelque 1000 marcs liégeois ${ }^{49}$.

Arrivé à Liège, l'évêque ne pouvait guère compter sur une situation économique florissante. En effet, quelles qu'en soient la durée et les raisons, la vacance du pouvoir est tout saüf propice au remplissage des coffres épiscopaux. La période précédant l'avènement de Jean de Flandre ne fait pas exception à la règle. Le 27 décembre 1281, le chapitre de Saint-Lambert déclarait, impassible, qu'à la mort de l'évêque, il a toute latitude pour lever les revenus de l'évêché et en faire son profit $^{\mathrm{t}^{0}}$. De l'évêque en devenir, il ne se préoccupe guère : "ita quod creato episcopo, residuum si quod fuerat ultra expensas et custodiam factas circa premissa in dictis redditibus, revertebatur seu cedebat ipsi

${ }^{45}$ Au dire de JeAn DE Hocsem, Chronicon, p. 171.- 1402, p. 307, 317, les évêques de Liège étaient souvent endettés jusqu'au cou. En 1347, Englebert de la Marck (1345-1364) déclare d'ailleurs : " occasione premissorum simus mole debitorum oppressi » (C.S.L., t. 4, p. 67).

47 À ces services communs venaient s'ajouter tout un ensemble de taxes (menus services, sacra, subdiaconum, annates) décrites dans GAUDEMET, Gouvernement, p. 70. Promesses et quittances de paiement des services dans BERLIÈRE, Libri abligationum, p. $1,4,5,21-23,25,68-70,72,73,75,78-80,103,104$.

${ }_{48}$ Id., p. XIII.

${ }^{49}$ Document 11. En 1275, Jean d'Enghien écrivait au roi des Romains Rodolphe de Habsbourg : "Sane cum ad creditum mihi episcopatum de novo personaliter advenissem, in novo adventu novum debitorum ingressus labyrinthum, a furore creditorum adeo undequaque sum oppressus, importune lacessitus, ut vix sufficiant tempora consiliis, vix reditus suppetant, quibus fauces inhiantibus compescere valeam, quibus possem clamores pestiferos reprimere creditorum " (É. SCHOOLMEESTERS, Rudolphe de Habsbourg et la principauté de Liège, B.I.A.L., t. 33, 1903, p. 7-8, 36).

${ }^{50}$ C.S.L., t. 2, p. 344-346. 
episcopo sic creato $^{51}$ ». Jean de Flandre protestera, certes, mais il semble qu'il n'ait obtenu ni modification des pratiques, ni dédommagement $^{52}$. Quant au mambour, ce laïc disposant de la régence temporelle durant l'interrègne ${ }^{53}$, s'il n'a pas profité de sa charge pour vider les caisses de l'État, il ne les remplira pas non plus car il a lui aussi le droit de disposer légalement des revenus épiscopaux durant toute la durée de sa mission ${ }^{54}$. Pourtant, il ne s'estimera pas rétribué pour autant. En effet, dès le 14 janvier 1283 et en mai de la même année ${ }^{55}$, pour prix des services rendus durant le sede vacante, Jean de Flandre versa de très fortes sommes à l'ancien mambour Henri de Louvain ${ }^{56}$. Il est dès lors à peine besoin de préciser que, de par leur ampleur, les dettes auxquelles Jean de Flandre a dû faire face, avant même d'avoir pu percevoir le moindre copé des revenus de sa charge, l'ont littéralement mis « sur la paille ».

Et pourtant, loin de s'amenuiser, les dépenses vont se multiplier à longueur de règne. Signalons tout d'abord ce que nous appellerons les frais de fonctionnement du pouvoir épiscopal. Même s'il semble que l'évêque ne soit pas intervenu outre mesure dans la rétribution de ses conseillers et de ses officiers ${ }^{57}$, les dépenses nécessaires au vivre et au

si Id., p. 345.

${ }_{52}$ Id., p. 354-355; t. 6, p. 34-35, 272-273.

${ }^{53}$ La vacance du pouvoir épiscopal fait l'objet d'un chapitre entier de MARCHANDISSE, Fonction épiscopale, p. 536-546.

${ }^{54}$ R.C.L., t. 1, p. 128-131.- JACQueS DE HEMRICOURT, Le Patron de la Temporalité, éd. A. Bayot, dans Jacques de Hemricourt, Oeuvres, éd. C. de Borman, A. Bayot, É. Poncelet, t. 3, Bruxelles, 1931, p. 66. Sur cette oeuvre de la fin du XIV ${ }^{\epsilon}$ siècle et sur son auteur, cfr É. PONCELET, Introduction historique. Notes complémentaires et tables générales (= PonCELET, Introduction), dans JACQUeS DE HEMrICoURT, Oeuvres, éd. C. de Borman, A. Bayot, É. Poncelet, t. 3, Bruxelles, 1931, p. I-LXXVI.- BalaU, Sources, p. 546-559.- J. CUVELIER, Notes pour servir à la biographie et à l'étude critique de l'auvre de Jacques de Hemricourt, B.C.R.H., t. 71, 1902, p. 260-274.

${ }^{55}$ Documents 5 et 6. Id. à l'égard de Gérard de Durbuy en septembre 1284 (document 11).

${ }^{56}$ Henri de Louvain, seigneur de Herstal $(1253-\dagger 1285)$, est le fils de Godefroid, comte de Louvain ( $\uparrow 21$ janvier 1253), et de Marie de Baucignies, fille d'Arnould IV d'Audenarde ( $†$ après le 24 août 1293), ainsi que le petit-fils du duc Henri I ${ }^{\text {* }}$ de Brabant. Cfr M. YANS, Le destin diplomatique de Herstal-Wandre, terre des Nassau, en banlieue liégeoise, A.H.L., t. 6, 1958-1962, p. 491.- É. PONCELET, Une paix de lignage au duché de Brabant en 1264, B.C.R.H., t. 105, 1940, p. 209-210.- A. COLLART-SACRÉ, La libre seigneurie de Herstal. Son histoire, ses monuments, ses rues et ses lieux-dits, t. 1, Liège, 1927, p. 37.- D. LEQUARRE, La terre franche de Herstal et sa cour de justice, B.I.A.L., t. 29, 1900, p. 86.- W.K. VoN ISENBURG, Stammtafeln zur Geschichte der europäischen Staaten (Europäische Stammtafeln) (= VoN IsENBURG, Stammtafeln), t. 2, Marbourg, 1965, tabl. 8. Il était mambour de l'évêché en septembre 1281 (C.S.L., t. 2, p. 341-342; t. 6, p. 28).

57 Sur la rétribution des officiers et conseillers épiscopaux, qui se fait essentiellement par octroi de charges et de dignités (canonicats, échevinats, mayorats), ainsi que de terres, cfr MARChANDISSE, Fonction épiscopale, p. 447-453. 
couvert du prélat et de son proche entourage ont absorbé, en revanche, de larges parts du budget épiscopa ${ }^{58}$. Jean de Flandre se procure tantôt des chevaux $(1280)^{59}$, tantôt de la paille $(1284)^{60}$ ou encore des plumes, des draps et des cendaus (1291) ${ }^{61}$. Les despens de boinre et de mengier pour nous et pour no propre osteil sont également explicitement mentionnées $(1291)^{62}$ : le blé et l'avoine ainsi que le vin doivent être acheminés régulièrement aux hôtels épiscopaux de Liège et de Huy ${ }^{63}$.

Viennent ensuite les frais dus au caractère itinérant de la monarchie épiscopale liégeoise. Quasi quotidiennement, entouré d'une escorte dont il est rarement possible de préciser la composition, le prince arpente ses terres et change constamment de domicile ${ }^{64}$. Tout ceci engendre de lourdes dépenses, en particulier pour l'entretien des demeures épiscopales. Sous le règne de Jean de Flandre, Huy et Anhaive firent tout spécialement l'objet de la sollicitude princière. Située dans un site réputé inexpugnable, la première de ces villes ne deviendra pas seulement le lieu de séjour par excellence de l'évèque des $\mathrm{XIII}^{e}$ et $\mathrm{XIV}^{e}$ siècles $^{65}$, elle sera également le refuge dans lequel il

${ }^{58}$ En 1347, Englebert de la Marck délègue tous ses pouvoirs au chapitre de SaintLambert afin qu'il puisse l'aider efficacement dans sa lutte contre les bonnes villes. C'est lui qui gérera les finances épiscopales et Englebert demande seulement reservata nobis solum [...] congrua portione pro vite nostre et familiarium nostrorum necessariis. (C.S.L., t. 4, p. 67-69).

s9 Document 1.

${ }^{60}$ Document 11.

${ }^{61}$. Documents 23, 24, 28. Le « cendal » est l'étoffe de soie la moins coûteuse. Utilisée pour doubler les vêtements de soie ou de drap de laine, elle sert à confectionner les accessoires de parure et les coussins. Cfr E. GODEFROID, Dictionnaire de l'ancienne langue française et de tous les dialectes $d u I X^{*}$ au $X V^{*}$ siècle, t. 2, Paris, 1883, p. 12.- Fr. PIPONNIER, P. Mane, Se vêtir au Moyen Âge, Paris, 1995, p. 30.- A. PAGE, Vêtir le Prine. Tissus et couleurs à la Cour de Savoie (1427-1447), Lausanne, 1992, p. 33.

${ }^{62}$ Documents 25, 29.

${ }^{63}$ Document 28.

4 Cfr nos propos relatifs à l'itinérance du pouvoir épiscopal liégeois dans MARChANDISSE, Fonction épiscopale, p. 521-528.

${ }^{65}$ Sur Huy, résidence épiscopale, et son château, cfr A. JoRIs, La ville de Huy au moyen âge. Des origines à la fin du XN" siècle, Paris, 1959, p. 140-141, 143-144, 460.- ID., A propos de * burgus " à Huy et à Namur, DiE STADT IN DER EUROPÄISCHEN GESCHICHTE. FESTSChrift EDTTH ENNEN, Bonn, 1972, p. 193-196 (réimpr. dans ID., Villes. Affaires. Mentalités. Autour du pays mosan, éd. Cl. Gafer, J.L. KuPPer, A. MARChandisse, Bruxelles, 1993, p. 139-148).- ID., Le visage de Huy. Choix et commentaire de documents iconographiques anciens (XV'-XIX' siècles), Bruxelles, 1976, p. 12-27,- J.L. KUPPER, Aux lisières de l'Empire. L'évêque Notger de Liège et l'élection de Hugues Capet, POUvoIrS ET LIBERTÉs au temps des PREMiers CapétIens, éd. É. MaGnou-NorTIER, Paris, 1992, p. 97 , $101-103$. 
s'engouffre lorsque quelque soulèvement urbain le force à quitter Liège $^{66}$. C'est donc à Huy que Jean de Flandre, accompagné de sa curia et de tout le clergé liégeois, se réfugia lorqu'il rompit toute relation avec le patriciat liégeois. Il y séjournera, semble-t-il, durant les années 1284/1285-128767. Il y entamera des travaux afin de « moderniser » sa demeure : in castro fecit Hoyensi novam aulam magnis sumptibus fabricari et vastam turrim Basini scaliis operiens mansiones infra distinxit ${ }^{68}$. On lui doit encore citernes et celliers ${ }^{69}$. Quant à Anhaive, cette bourgade proche des États de son père, qu'il gagnait en bateau parce que sa santé ne lui permettait plus de monter à cheval, il la fit fortifier ${ }^{70}$.

Autres dépenses à caractère répétitif : toutes celles liées à la pratique de la guerre. Sans s'être lui-même illustré par quelque fait d'armes d'envergure, Jean de Flandre apporta un soutien militaire de poids à Jean I ${ }^{\text {er }}$, duc de Brabant, au cours de la guerre de succession de Limbourg et notamment lors de la bataille de Worringen ${ }^{71}$. Nul doute que, de ce contingent qu'il délégua à son beau-frère, l'évêque dut régler une partie des frais ${ }^{72}$. Cependant, le prélat liégeois ne se borne pas à soutenir financièrement les hommes combattant sous sa ban-

${ }^{66}$ Jean d'Eppes (1229-1238) s'y réfugie au début de son règne (MARCHANDISSE, Fonction épiscopale, p. 112) et Adolphe de la Marck (1313-1344) fait de même en 13251330 [JEAN DE HOCSEM, Chronicon, p. 172, 176.- 1402, p. 286, 294, 304.- LeVOLD DE NORTHOF, Chronica comitum de Marka (= LeVold DE NORTHOF, Chronica), éd. F. ZsChaeCK, $2^{c}$ éd., M.G.H., SS.Rer.German.N.S., t. 6, Berlin, 1955, p. 70 (sur cette dernière chronique, cfr LEVOLD DE NORTHOF, Chronica, p. IX-XLVII.- J. STINISSEN, Levoldi de Northof chronica comitum de Marka. Een kritische studie, HET OUDE LAND VAN LOON, t. 43, 1988, p. 148-187.- BALAU, Sources, p. 524-527.- RENARDY, Répertoire, p. 384-386)].

${ }^{67}$ Cfr supra n. 29.

68 JEAN DE HoCSEM, Chronicon, p. 79.

69 Ibid. - 1402, p. 229.- Tongerlo, p. 40.- MATHIAS DE LEWIS, Chronicom, p. 81.- CoRnelle DE ZANTFLIET, Chronica, col. 124.- JEAN D'OUTREMEUSE, Myreur, t. 5, p. 475.

${ }^{70}$ 1402, p. 230-231.- JeAn De Hocsem, Chronicon, p. 83.- Mathias de Lewis, Chronicon, p. 81.- PONCELET, Guy de Hainaut, p. 504, 528-529.- C. BADOT, Anhaive et son castel, Bulletin de LA Société ROYALE « LE VIEUX-LièGE », t. 4, 1951-1955, p. 18-19.É. PONCELET, Le livre des fiefs de l'Église de Liège sous Adolphe de la Marck, Bruxelles, 1898, p. XIII.- R. DEPREZ, Les châteaux, tours et maisons fortifiées de l'Église de Liège d'Éracle à Jean d'Arckel. Caractères de la politique castrale du X'a au XIV' siècle, Mém. de Lic. en Histoire dactyl., Liège, Université de Liège, 1954-1955, p. 6. Anhaive (Belgique, pr. Namur, arr. Namur, comm. Jambes). Illustration des vestiges du donjon, dans FONDATION RoI BAudouin, périodique trimestriel, $\mathrm{n}^{\circ} 32,1996, \mathrm{p} .10$ (Aimable communication de M. J.L. KUPPER).

${ }^{71} \mathrm{Cfr}$ n. 26.

${ }^{72} \mathrm{Cfr} \mathrm{Cl}$. GAIER, Analysis of military forces in the principality of Liège and the county of Looz from the twelfth to the fifteenth century, STUDIES IN MEDIEVAL AND RENAISSANCE History, t. 2, 1965, p. 212-213.- PonCELET, Introduction, t. 3, p. CLXV-CLXVI. 
nière. Encore faut-il protéger l'évêché de toute forme d'agression et bien sûr reconstruire les bâtiments détruits à l'occasion de l'une ou l'autre bataille. De fait, de telles dépenses sont de temps à autre mentionnées dans nos actes. Jean de Flandre ne négligea pas la défense du pays $(1289)^{73}$ et se préoccupa tout particulièrement de la citadelle de Cornillon. Rappelons à ce propos qu'en 1291, illustrant ainsi toute l'ambiguitté de ses rapports avec Jean de Flandre, le duc de Brabant lança ses hommes à l'assaut de Cornillon ${ }^{74}$. Certains d'entre eux prirent la fuite; la plupart furent capturés, en grande partie grâce au courage du châtelain, Wautoule de Jupille ${ }^{75}$. Jean de Flandre n'oubliera pas cet officier fidèle et valeureux. Il empruntera afin de le rétribuer dignement pour la défense et le gouvernement de la forteresse ${ }^{76}$, et aussi, très probablement, afin de financer les réparations à apporter au complexe défensif de la principauté ${ }^{77}$. Il apparaît cependant qu'à la mort du prélat liégeois, Wautoule de Jupille émargeait encore au budget épiscopal. En effet, le comte de Flandre lui réglera une partie de ce qui lui restait $d \hat{u}^{78}$. S'ils ne se résolvent pas nécessairement par une guerre, certains différends peuvent en revanche aboutir à des pertes territoriales, lesquelles constituent autant de revenus qui disparaissent. Ainsi le duc de Brabant, par des procédés cauteleux, parviendra-t-il à récupérer les terres de Rolduc et Simpelveld ${ }^{79}$. Quant au comte de Looz $^{80}$, il privera Jean de Flandre de trois avoueries ${ }^{81}$. Parmi les

${ }^{73}$ Document 18.

${ }^{74}$ Cfr n. 27.

75 Wautoule de Jupille était bailli du Pont d'Amercoeur et maire de la cour de Jupille les 14 mai 1304 et 3 mars 1305. Cfr C.S.L., t. 3, p. 44.- Josse, Domaine Jupille, p. 113 et n. 34.

${ }^{76}$ Document 27.

7 Document 28.

78 Document 30.

79 C.S.L., t. 2, p. 363.- JEAN De HoCSEM, Chronicon, p. 77-79.- JEAN D'OUTREMEuse, Myreur, t. 5, p. 472-473.- KUPPER, Herzog Johann I. von Brabant und Lüttich, p. 91, 95. Simpelveld (Pays-Bas, Limbourg); Rolduc (Kloosterrade) (Pays-Bas, Limbourg). En 1288, Jean Ir céda la haute justice de Hoegaarden (Belgique, pr. Brabant flamand, arr. Louvain, comm. Hoegaarden), Beauvechain (Belgique, pr. Brabant wallon, arr. Nivelles, comm. Beauvechain) et Tourinnes-la-Grosse (Belgique, pr. Brabant wallon, arr. Nivelles, comm. Beauvechain) à Jean de Flandre, mais contre tous les droits épiscopaux sur Herewaarden (Pays-Bas, Gueldre), Kessel (Pays-Bas, Limbourg), Deurne (Pays-Bas, Brabant septentrional) et Maren (C.S.L., t. 2, p. 437-441).

* Arnould V (1279-1323). Cfr J. BAERTEN, La politique liégeoise d'Arnoul V, comte de Looz (1279-1323), M.Â., t. 63, 1957, spéc. p. 484.

${ }^{81}$ Il s'agit des avoueries de Tongres (Belgique, pr. Limbourg, arr. Tongres, comm. Tongres), Alken (Belgique, pr. Limbourg, arr. Tongres, comm. Alken) et Oreye (Belgique, pr. Liège, arr. Waremme, comm. Oreye) (C.S.L., t. 2, p. 365-367). Cfr encore n. précédente. 
dépenses liées aux dissensions politico-militaires, signalons encore que Jean de Flandre dut également débourser quelque argent afin de sceller un accord avec Gérard de Luxembourg ${ }^{82}$, seigneur de Durbuy ${ }^{83}$, lequel, s'il fut, semble-t-il, mambour de la principauté durant quelque temps ${ }^{84}$, n'en porta pas moins régulièrement atteinte aux droits épiscopaux, notamment sous Henri de Gueldre, Jean d'Enghien et Hugues de Chalon $^{85}$. En 1290, Guy de Dampierre se portera garant en faveur de son fils du paiement d'une amende de 2000 marcs de Liège, en cas de non-respect du pacte scellé entre les belligérants ${ }^{86}$.

À côté de dépenses plus pacifiques, comme l'acquisition de quelque terre ${ }^{87}$, le rachat de la forteresse de Franchimont en $1291^{88}$ ou la féodalisation de quelque alleu $(1283)^{89}$, il est enfis une dernière circonstance qui dut très certainement grever le budget de l'évêque, c'est l'enlèvement dont il fut victime à une date difficilement identifiable mais qui

${ }_{82}$ Gérard de Durbuy est le fils cadet d'Ermesinde, comtesse de Luxembourg (1198$\uparrow 1247)$, et le frère du comte Henri V le Blondel $(1247-\dagger 1281)$, qui, à la mort de sa mère, lui céda notamment Durbuy, son premier apanage. À son propos cfr A. de LEUzE, L'arrondissement de Marche, dans É. TANDEL, Les communes luxembourgeoises, t. 5, Arlon, 1892, p. 204-205.- Terre de Durbuy. Catalogue de l'exposition. Durbuy. Halle aux blés (20 aốt-26 septembre 1982), Bruxelles, 1982, p. 142-143.- La formation territoriale du pays de Luxembourg depuis les origines jusqu'au milieu du XV' siècle. Exposition documentaire. Catalogue, Luxembourg, 1963, p. 87, 98.- G.J. NiNANE, L'ancienne terre de Durbuy et sa structuration paroissiale, ANNALES DE L'INSTITUT ARCHÉOLOGIQUE DE LUXEMBOURG, t. 29, 1968, p. 72.

${ }^{83}$ C.S.L., t. 2, p. 462-463.- Document 19.

${ }^{84}$ Document 11.

${ }^{85}$ C.S.L., t. 2, p. 315-316, 338-339 (Jean d'Enghien), 554-555 (Hugues de Chalon).J. HALKIN, C.G. RolAND, Recueil des chartes de l'abbaye de Stavelot-Malmedy, t. 2, Bruxelles, 1930, p. 49-52 (Henri de Gueldre). Sur Henri et Hugues, princes-évêques de Liège (1247-1274 et 1295-1301), cfr MARCHANDISSE, Fonction épiscopale, p. 136-148, 171-173, 301-302, 311-315, 411-417, 422-423.- J.Cl. DETROUX, Henri de Gueldre, princeévêque de Liège, 1247-1274, Mém. de Lic. en Histoire dactyl., Liège, Université de Liège, 1971-1972.- H. PIRENNE, Art. Henri de Gueldre, B.N., t. 9, Bruxelles, 1886-1887, col. 193202.- P. De SpIEgeler, Art. Henri de Gueldre, D.H.G.E., t. 23, Paris, 1990, col. $1142-$ 1143.- A. Joris, Art. Hugues de Chalon, D.H.G.E., t. 25, Paris, 1994, col. 203-205.RENARDY, Répertoire, p. 310-312.- É. SCHOOLMEESTERS, Hugues de Châlon, évêque de Liège, LeOdIUM, t. 5, 1906, p. 47-52.- D. BoERMANS, Hugues de Chalon, évêque de Liège, 1296-1301, Mém. de Lic. en Histoire dactyl., Liège, Université de Liège, 1973-1974.P. Roman D' Amat, Art. Chalon (Hugues de), DictionnaIRE DE BIOGRAPHIE FRANÇAise, t. 8 , Paris, 1956, col. 217-218.

86. Document 19.

${ }^{87}$ C.S.L., t. 6, p. 34.

${ }^{88}$ Document 25. Franchimont (Belgique, pr. Liège, arr. Verviers, comm. Theux).

${ }^{89}$ Documents 5, 6, 11. 
doit se situer vers avril $1289^{\circ}$. On se souviendra qu'il fut séquestré durant de longs mois, probablement à l'instigation de la seconde épouse de Guy de Dampierre, Isabelle de Luxembourg ( $\dagger 1298)^{91}$, et qu'il ne recouvra la liberté qu'après payement d'une très lourde rançon ${ }^{22}$.

Voilà donc brièvement décrits les divers départements dans lesquels fut englouti, selon toute vraisemblance, l'essentiel des ressources épiscopales. Pour accroître ses capacités financières, Jean de Flandre recourut, nous l'avons vu, aux emprunts de toutes sortes. À l'évidence, cela doit susciter notre étonnement. En effet, quant bien même l'Église oblitéra quelque peu les interdits fulminés contre le commerce de l'argent, tolérant voire cautionnant certaines formes de prêts ${ }^{93}$ celui à gratification tarifée $e^{94}$ notamment, qui, pourtant, reste usuraire, moralement tout au moins - et réprimant surtout l'usure occulte et sauvage, Jean de Flandre, pour sa part, dans les statuts synodaux qu'il promulgua en 1288, condamna les usuriers avec la plus extrême vigueur. Il leur promet notamment l'excommunication, la nullité de leurs offrandes et de leurs testaments, et leur refuse en outre la communion $^{95}$. Le paradoxe est donc total : le prêt à intérêt se voit valorisé par celui qui, de prime abord, aurait dû y être le moins enclin, un prélat liégeois qui fut un évêque, un prêtre davantage qu'un prince, un juriste formé à l'école de Bologne, très au fait des arguties du droit canonique et, qui plus est, un homme qui, dans les statuts de 1288 , se

90 Analyse dans Lejeune, Enlèvement Jean de Flandre.- MARCHANDISSE, Fonction épiscopale, p. 533. Les remarques de M. MARGUE et M. PAULY, Luxemburg vor und nach Worringen, JAHRBUCH FÜR WESTDEUTSCHE LANDESGESCHICHTE, t. 16, 1990, p. 152 n. 238 et surtout p. 157 et n. 272 , à propos de LEJEUNE, Enlèvement Jean de Flandre et KUPPER, Herzog Johann I. von Brabant und Lüttich, p. 95, nous paraissent, par rapport à ces études, marginales et pour le moins cavalières.

${ }_{91}$ Fille d'Henri V le Blondel, comte de Luxembourg (cfr n. 82)

92 JEAN DE Hocsem, Chronicon, p. 75-76.- 1402, p. 226.- Tongerlo, p. 39.- JEAN D'Outremeuse, Myreur, t. 5, p. 466, 472.- ID., Chronique en bref, $\mathrm{f}^{\circ} 90 \mathrm{v}^{\circ}-91 \mathrm{r}^{\circ}$.

${ }_{93}$ Sur cette question, la littérature est bien évidemment foisonnante. Nous nous bornerons donc à renvoyer à l'étude de synthèse de B. SCHNAPPER, La répression de l'usure et l'évolution économique (XIIF-XVK siècles) (= SCHNAPPER, Répression usure), R.H.D., t. 37, 1969, p. 47-75 et la bibl., p. 48 n. 1, et aux remarques particulièrement éclairantes de C. WyFfels, Deux emprunts de 1288 consentis par des bourgeois de Liège à Warnier, seigneur de Dave, agissant pour le compte de Gui de Dampierre, comte de Flandre et marquis de Namur (= WYFFELS, Deux emprunts), A.H.L., t. 9, 1966, p. 268272 et ID., L'Usure en Flandre au XIII' siècle (= WYFFELS, Usure en Flandre), R.B.P.H., t. 69,1991 , p. 853-871.

${ }^{94}$ Distinction entre ce type de prêt et celui à intérêt établie par Ibid.

${ }^{95}$ SchOOLMEESTERS, Statuts synodaux, p. 33-34, 127-128. Les statuts furent modérés quelque peu par la suite (1288) (Id., p. 90-95, spéc. p. 91-92). 
pose en champion de la lutte contre l'usure. Certes, à propos des emprunts que contracte Jean de Flandre, il n'est jamais fait mention d'un quelconque intérêt. Il prétend en revanche, selon le voeu du chapitre de Saint-Lambert d'ailleurss ${ }^{96}$, bénéficier de prêts sans cous, sans usure et sans vilain marchiet ${ }^{97}$. Et pourtant. Que Guy de Dampierre, comte de Flandre, les bourgeois douaisiens ou les banquiers siennois et florentins, qui tiraient leur fortune des bénéfices réalisés sur les emprunts consentis, aient fait oeuvre de philanthropes à l'égard du prélat liégeois nous semble bien improbable. De plus, il est attesté que ce dernier recourut aux services des Lombards ${ }^{98}$, ceux-là mêmes que, à peine dix ans plus tard, l'évêque Adolphe de Waldeck chassera de Liège à grand fracas, en raison des crimes d'usure dont ils étaient coupables $^{99}$. Il faut dès lors se rendre à l'évidence : soutenu par un chapitre cathédral qui préfère se voiler la face, Jean de Flandre a violé une cause dont il se faisait le chantre, qu'il ait simplement obtenu des prêts à gratification tarifée ou, pire, à intérêt, celui-ci étant dissimulé dans le montant à acquitter. Si, de jure, il s'opposa à l'usure, de par sa fonction et peut-être aussi de par ses convictions, il ne put résister, de facto, aux pressions exercées par ses fournisseurs et ses créanciers. Au spectre de la faillite, il préfère substituer une politique pragmatique, fût-elle en complète opposition avec les préceptes qu'il entendait voir appliquer par ses sujets ${ }^{100}$.

Évoquons à présent, au travers d'actes qui sont tantôt des lettres de foire, tantôt des lettres obligatoires, tantôt des reconnaissances de plège ou tout à la fois, les caractéristiques des prêts accordés à Jean de

96 Document 18.

${ }^{97}$ Document 10.

98 Document 28. Sur les Lombards, dans nos régions, nous épinglerons simplement W. REICHERT, Lombarden zwischen Rhein und Maas. Versuch einer Zwischenbilanz, RHEINISCHE VIERTELJAHRSBLÄTTER, t. 51, 1987, p. 188-223.- J. SCHNEIDER, Les Lombards en Lorraine, ANNUAIRE DE LA SOCIETÉ D'Histoire ET D'ARChÉlogie DE LA LORRAINE, t. 79, 1979, p. 65-98. - F. VERCAUTEREN, Document pour servir à l'histoire des financiers lombards en Belgique (1309), B.I.H.B.R., t. 26, 1950-1951, p. 43-67.- C. TIHON, Aperçu sur l'établissement des Lombards dans les Pays-Bas aux XIIK et XIV' siècles, R.B.P.H., t. 39, 1961, p. 334-364. Sur un sujet connexe, cfr C. WyFfELs, Les Cahorsins en Flandre au XIIF siècle, ANNALES DU MIDI, t. 103, 1991, p. 307-321.

99 JeAN DE Hocsem, Chronicon, p. 108-109.- 1402, p. 247.- MATHIAS DE LeWIS, Chronicon, p. 86.- Tongerlo, p. 55. Sur Adolphe de Waldeck (1301-1302), cfr RENARDY, Répertoire, p. 167-168.- A. JoRIS, Art. Adolphe de Waldeck, B.N., t. 32 (SuPPLÉMENTS, t. 4), Bruxelles, 1964, col. 751-756.- MARCHANDISSE, Fonction épiscopale, p. 173-175.

${ }^{100}$ Cfr les propos de WyFFELS, Deux emprunts, p. 271-272.- ID., Usure en Flandre, p. 870-871. «On pèche mais on se repent ", comme le dit très bien SCHNAPPER, Répression usure, p. 75. 
Flandre ${ }^{101}$. Les sommes empruntées, tout d'abord : elles sont considérables. Après avoir perçu 2000 marcs de Liège et 4000 livres de Flandre en $1283^{102}$, le prélat liégeois se reconnaît débiteur, en 1284 , de 24.000 livres tournois, de 8168 livres de Flandre et de 5000 livres parisis $^{103}$. Les derniers moments de la vie de l'évêque (1291) témoignent également de besoins particulièrement dispendieux, avec divers emprunts d'un montant global de 23000 livres tournois, 1700 livres parisis, 1650 livres de Louvain et 400 marcs liégeois ${ }^{104}$. Toutes les sommes consenties étaient remboursables soit à un terme strictement précisé - dans les lettres de foire, notamment ${ }^{105}$, soit dans un délai plus ou moins long, consécutif à la semonce du créancier ${ }^{106}$. Nous l'avons dit, les taux d'intérêts frappant ces divers emprunts ne sont jamais précisés. En revanche, un certain nombre de précautions sont prises afin d'assurer le remboursement des sommes empruntées, et ce dans les meilleures conditions. Nous constatons tout d'abord la présence, seules ou en combinaison, de toutes les formes de sûretés à la disposition du débiteur et du créancier ${ }^{107}$. Néanmoins, la solidarité (sûreté personnelle) - en 1280, Guy de Dampierre et ses fils, Robert ${ }^{108}$ et Jean, s'obligent, et cascuns pour le tout, envers leurs créanciers ${ }^{109}$ - et le gage (sûreté réelle mobi-

${ }^{101}$ Sur les rapports entre les princes belges et l'argent, l'ouvrage de base reste G. BIGwooD, Le régime juridique et économique du commerce de l'argent dans la Belgique du moyen âge (= Bigwood, Commerce de l'argent), 2 vol., Bruxelles, 19211922. Cfr encore, par comparaison, M. WERnER, Prälatenschulden und hohe Politik im 13. Jahrhundert. Die Verschuldung der Kölner Erzbischöfe bei italienischen Bankiers und ihre politischen Implikationen, KöLN, STADT UND BISTUM IN KIRCHE UND REICH DES Mittelalters. Festschrift für Odllo Engels, zum 65. Geburtstag, éd. H. VollRath et St. WeinfurTer, Cologne-Weimar-Vienne, 1993, p. 511-570.

102 Documents 6-8.

${ }^{103}$ Documents 9-14

${ }^{104}$ Documents 21-25, 27-29.

${ }^{105}$ Documents 1, 9-10 (remboursements prévus à la foire de Provins, en mai 1280 et mai 1284).

${ }^{106}$ Document 2. Certains emprunts consentis par Guy de Dampierre doivent être remboursés à sa volonté (Documents 21, 22, 24, 25, 27). Sur cette expression, cfr WYFFELS, Usure en Flandre, p. 855-858.

107 Sur les modalités des emprunts, cfr Bigwood, Commerce de l'argent, t. 1, p. 438-606, spéc., pour les sûretés, p. 462-506.

${ }^{108}$ Robert, comte de Flandre (Robert de Béthune) (1305- $\left.\uparrow 1322\right)$, qui, dans nos documents (notamment document 1), est titré comte de Nevers, seigneur de Béthune et de Termonde. La première appellation lui vient de son second mariage, en 1272, avec Yolande de Nevers, la seconde, de l'héritage maternel (Robert, seigneur de Béthune et de Termonde, père de Mahaut de Béthune). Cfr W. Prevenier, Art. R. III., L.D.M., t. 7, fasc. 4, MunichZurich, 1994, col. 895-896.- D. MASURE, Robrecht van Bethune en Ieper, IEPERS KWARTIER, t. 9, $\mathrm{n}^{\circ}$ 2-3 (Robrecht van Bethune, de leeuw van Vlaanderen), 1973, p. 75-102.- Th. LuYKs, Robrecht van Bethune en zijn tijd, Id., p. 117-129.

109 Document 1. 
lière), sont nettement moins usités que l'engagère (sûreté réelle immobilière) et la caution (sûreté personnelle). Si cette dernière est, semble-til, quasiment automatique dans les emprunts contractés par Jean de Flandre ${ }^{110}$, celui-ci n'a manifestement pas recouru à un grand nombre de plèges différents. En effet, hormis Jean $I^{\text {er }}$ de Brabant, qui se porte caution pour son beau-frère en juin $1287^{\prime \prime \prime}$, l'évêque n'eut jamais qu'un seul et unique plège : son père, le comte Guy de Dampierre ${ }^{112}$. C'est d'ailleurs principalement à lui qu'il cédera des terres en engagère ${ }^{113}$. Parmi celles-ci, il en est certaines dont la possession temporaire, par le créancier, ne dispense pas le débiteur de rembourser son emprunt. En revanche, pour d'autres, c'est le revenu qu'elles produisent et qui est perçu par le prêteur qui permet d'éteindre la dette, ce type d'engagère s'identifiant, en quelque sorte, à une assignation en payement. Dans le cas de l'évêque de Liège, il est parfois assez malaisé de distinguer les deux types de transactions. Quoi qu'il en soit, parmi les nombreux biens que Jean de Flandre offrit en garantie, il semble bien que la terre de Bouillon ait eu sa préférence ${ }^{114}$. Ce n'est guère étonnant. En effet, de tout temps, l'évêque de Liège engagea des biens situés à la périphérie du pays de Liège, excentriques voire enclavés dans d'autres principautés. De la sorte, il évitait de subordonner l'assise foncière de ses États à ses difficultés financières ${ }^{115}$. Même si elles n'offrent guère d'originalité, quelques clauses, présentes en grand nombre dans les actes édités en annexe, méritent encore d'être signalées. La clause de non-préjudice ${ }^{116}$, cet engagement à rembourser au créancier ou au plège les dommages et intérêts suscités par le non-réglement de la dette au terme fixé, est présente dans chaque acte ${ }^{17}$. Il en va pratiquement de même ${ }^{118}$ de la clause au porteur, qui prévoit le remboursement au représentant du créancier ou du plège, et qui, très souvent, consacre la valeur légale de l'écrit ${ }^{119}$.

${ }_{110}$ Documents 2, 7, 8, 10, 11, 12, 13, 17, 19, 29.

"I' Document 17. La même année, il avait promis à Jean de Flandre de décider le chapitre cathédral liégeois à lui autoriser un emprunt, de 8000 livres parisis selon l'acte épiscopal (Jean van Heelu, Rijmchroniek, Bruxelles, 1836, Cod. dipl., p. 449-451 et spéc. p. 450), de 20000 livres parisis selon l'acte ducal (C.S.L., t. 2, p. 403-406, spéc. p. 404), ainsi que de l'aider à trouver cet argent et encore 7000 livres en supplément.

$1{ }^{12}$ Documents 2, 7, 8, 10, 11, 12, $13,19$.

${ }_{113}$ Documents 2, 7, 8, 11, 12, 13, $25,27$.

${ }^{114}$ Documents 7, 8, 12, 13. Bouillon (Belgique, pr. Luxembourg, arr. Neufchâteau, comm. Bouillon).

${ }^{115}$ MARCHANDISSE, Fonction épiscopale, p. 240-241.- E. PONCELET, Les droits souverains de la principauté de Liège sur le duché de Bouillon, B.C.R.H., t. 108, 1943, p. 133-134.

116 Bigwood, Commerce de l'argent, t. 1, p. 554-557.

117 Documents 1, 2, 7, 10, 11, 12, 13, 14, 16, 19, 25, 27.

${ }^{118}$ Documents 1, 2, 7, 10, 11, 12, 13, 14, 16, 22, 25, 27.

119 Bigwood, Commerce de l'argent, t. 1, p. 507-515. 
Sont encore mentionnés de temps à autre équivalences et ordres de payement au cours du jour ${ }^{120}$, lesquels visent d'une part à réduire les inadéquations entre les mentions en monnaie de compte et les remboursements en espèce, d'autre part les désagréments causés par la fluctuation des monnaies ${ }^{121}$. Enfin, parmi les sanctions prévues lorsque les dettes ne sont pas honorées, si le quint-denier n'apparaît que très rarement ${ }^{122}$, en revanche les clauses de renonciation à toute forme d'exception permettant au débiteur de se soustraire à ses obligations, sont souvent particulièrement développées ${ }^{123}$.

Après avoir décrit les diverses modalités des emprunts consentis à Jean de Flandre, tournons-nous à présent vers ses créanciers, en clair tous ceux qui, d'une manière ou d'une autre, assurèrent la survie financière du prélat liégeois. Parmi ceux-ci, on trouve tout d'abord diverses sociétés italiennes. Florentins ${ }^{124}$, Lucquois ${ }^{125}$, Siennois notamment les membres de la compagnie des Salimbeni ${ }^{126}$, ils firent office de banquiers, tant pour Jean de Flandre que pour Guy de Dampierre, son père ${ }^{127}$. Si l'on voit parfois apparaître, parmi les créan-

${ }^{120}$ Id., p. 515-519.

${ }^{121}$ Documents 6, 18, 25.

${ }^{122}$ Document 16. Sur cette sanction, cfr Id., p. 562-563.

${ }^{123}$ Documents $1,10,14,16$. Cfr surtout les documents 3 et 4 , relatifs à un emprunt contracté en faveur de Guy de Dampierre par Jean de Flandre. On y trouve notamment les exceptions suivantes : dolus in factum, conditio sine causa et ex injuste causa, restitutio in integrum, constitutio De duabus dictis, epistula divi Adriani... auxquelles s'ajoute le privilège de la croix etc. Sur lesdites clauses, cfr F. VERCAUTEREN, Note sur l'apparition des renonciations aux exceptions de droit romain dans les principautés belges au XIIt siècle,

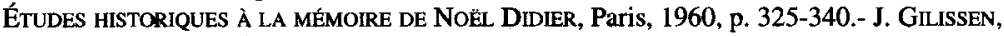
L'apparition des renonciations aux exceptions de droit romain dans le droit flamand au XIII' siècle, Revue internationale des Droits de l'antiQuité, t. 4 (Mélanges F. De VISSCHER, t. 3), 1950, p. 513-550.

${ }^{124}$ Document 1 (Oldebrant Lapo, Brunet frères, Gérard Compaigne, Henri Millac).

${ }_{125}$ Document 11 (Ghet et Digne Bertremieu).

${ }^{26}$ Documents 3 et 4 (plusieurs membres de la compagnie Salimbeni et Renier Alberti), 9 et 10 (id.), notamment.

${ }^{127}$ Les comtes de Flandre eurent surtout recours à des compagnies siennoises et florentines (BIGwood, Commerce de l'argent, t. 1, p. 179), ce que confirment nos actes. Le commerce italien a inspiré des générations d'historiens, tout spécialement celui de l'argent. Pour notre part, nous nous référons principalement à BIGWOOD, Commerce de l'argent, ouvrage aujourd' hui encore pratiquement incontournable, ainsi qu'à Y. RENOUARD, Les hommes d'affaires italiens du Moyen Âge, nlle éd., Paris, 1968, spéc. p. 107-122, 152-216.- R. DE ROOVER, Money, banking and credit in medieval Bruges, Cambridge Mass., 1948, et, pour Sienne, dont il est plus particulièrement question ici, à E. Von RoON-BASSERMANn, Sienische Handelsgesellschaften des XIII. Jahrhunderts mit besonderer Berïcksichtigung ihres internationalen Handels (= VON ROON-BASSERMANN, Sienische Handelsgesellschaften), Mannheim-Leipzig, 1912, p. 55-61 et E.D. ENGLISH, Enterprise and liability in Sienese banking, 1230-1350, Cambridge Mass., 1988, p. 22-25 et passim. 
ciers du prince, quelque membre d'une famille patricienne flamande, comme le douaisien Jean de France ${ }^{128}$, l'évêque de Liège n'avait en revanche que bien peu à attendre de son chapitre cathédral. Certes, ce dernier qui, en vertu du droit canonique, devait être consulté avant que le prélat ne puisse engager quelque parcelle d'un patrimoine épiscopal réputé inaliénable ${ }^{129}$, donnera son aval à deux emprunts épiscopaux ${ }^{130}$. Toutefois, les tréfonciers ne débourseront jamais rien et, qui plus est, auront soin d'exclure la mense capitulaire de toute initiative épiscopale. En fait, de même qu'il s'efforça d'oeuvrer en faveur de ses proches - le prélat obtint en cour de Rome et de la part de marchands siennois un important emprunt pour son père ${ }^{131}-$, c'est de sa famille que Jean de Flandre recevra le soutien le plus efficace. Ainsi, à de nombreuses reprises, son cousin Nicolas de Condét ${ }^{132}$ qui, pourtant, contracta, lui aussi, des emprunts ${ }^{133}$, notamment envers Jean de Flandre ${ }^{134}$, à ce qu'il paraît - le fait est suffisamment étonnant pour

${ }^{128}$ Mentionné dès 1252, peut-être décédé avant 1298.et, en tout cas, avant janvier 1304, huit fois échevin de Douai entre 1252 et 1292, prêteur occasionnel en faveur de Guy de Dampierre et de Marguerite de Constantinople, entre 1269 et 1283. Cfr BIGwood, Commerce de l'argent, t. 1, p. 32.- G. EsPINAS, Les origines du capitalisme, 2, Sire Jean de Flandre, patricien et rentier douaisien. Sire Jacques le Blond, patricien et drapier douaisien (seconde moitié du XIII siècle), Lille, 1936, p. 95-99.- ID., La vie urbaine de Douai au moyen âge (= ID., Vie urbaine de Douai), t. 3, Paris, 1913, p. 395-396. Sur la bourgeoisie douaisienne et le commerce de l'argent, cfr ID., Vie urbaine de Douai, t. 2, p. 144-169.

${ }^{129}$ Gaudemet, Gouvernement, p. 127 n. 83, 141-144.- MARCHANDISSE, Fonction épiscopale, p. 239-240.

${ }^{130}$ Documents 5, 18.

${ }^{131}$ Documents 3 et 4.

132 Nicolas II de Condé, fils de Jacques de Condé, seigneur de Morialmé, lequel est le demi-frère de Mahaut de Béthune, mère de Jean de Flandre. Cfr, à ce propos, C.G. RoLAND, Les seigneurs de Morialmé avant le quinzième siècle, A.S.A.N., t. 35, 1922, p. 38, 46-52, 54-55, 57-61.- J. DE SAINT-GENOIS, Inventaire analytique des chartes des comtes de Flandre avant l'avènement des princes de la Maison de Bourgogne autrefois déposées au chateau de Rupelmonde, et conservées aujourd'hui aux archives de la Flandre orientale, précédé d'une notice historique sur l'ancienne trésorerie des chartes de Rupelmonde et suivi d'un glossaire, de notes et d'éclaircissements ( $=$ DE SAINT-GENOIS, Inventaire Rupelmonde), Gand, 1843-1846, p. 76, 77, 81, 200.- Abbé DeHAISNES, J. FINOT, Inventaire sommaire des archives départementales antérieures à 1790. Nord. Archives civiles. Série B. Chambre des Comptes de Lille (= DeHAISNES-FinOT, Imventaine), t. 9, s.l.n.d., p. 78-80, 82, 83, 95, 97, $n^{\circ} B$ 4033-4035, 4038, 4039, 4049, 4052. Compte tenu du volume des transactions financières entre Nicolas de Condé et Guy de Dampierre, on peut à bon droit se demander si Nicolas ne rétrocédait pas à Jean de Flandre l'argent que lui concédait le comte ou celui pour l'emprunt duquel ce dernier se portait caution.

${ }^{133}$ Notamment envers la bourgeoisie arrageoise : G. BIGWOOD, Les financiers d'Arras. Contribution à l'étude des origines du capitalisme moderne, R.B.P.H., t. 3, 1924, p. 774, 788 ; t. 4, 1925, p. $394,396$.

${ }^{134}$ Document 26. 
être noté -, prêta de l'argent à l'évêque de Liège ${ }^{135}$. Il en va de même, semble-t-il, du frère du prélat, le futur comte de Flandre Robert de Béthune $^{136}$. Cependant, il est clair que Jean de Flandre n'obtint jamais aide plus grande que de la part de son père, Guy de Dampierre.

En ce sens, les reconnaissances de dettes que nous éditons ici apportent un témoignage majeur sur les rapports entre un père et fils qui, au gré de la politique et de ses caprices, se trouvaient être également deux chefs d'État. On le sait, Guy de Dampierre fut à la base du transfert à Liège de Jean de Flandre ${ }^{137}$. Lui qui détenait également la terre de Namur, voisine de la principauté, estima sans doute devoir tirer un profit maximum de ses succès diplomatiques. Favorisé en cela par un fils malingre, aux abois ou absent pour cause d'enlèvement, le comte exerça une emprise totale sur l'État liégeois, agissant à la fois directement et indirectement. À certains moments, on le voit très bien, Guy de Dampierre, présent à Liège, tire toutes les ficelles. Episcopo decumbente, il agit comme s'il était mambour de la principauté1 ${ }^{138}$. C'est d'ailleurs lui qui scelle le sort des prisonniers brabançons pris au piège lors de l'attaque de la forteresse de Cornillon ${ }^{139}$ et c'est également sous les règnes parallèles de Jean et de Guy de Dampierre que les traités, arbitrages et autres conciliations entre Liège et la Flandre sont les plus nombreux ${ }^{140}$. Cependant, le comte de Flandre a parfaitement compris qu'il est un motif, supérieur à tout autre, qui lui permet à chaque instant d'agir sur les décisions du souverain liégeois : le manque d'argent, cette hémorragie financière dont

135 Documents 6, 7, 13, 14, 16, 17.

${ }_{136}$ Document 31. Sur ce personnage, cfr n. 108.

137 JEAN DE Hocsem, Chronicon, p. 68.- 1402, p. 223.- JEAN D'Outremeuse, Myreur, t. 5, p. 428.- Mathias de Lewis, Chronicon, p. 80.

138 JeAn de Hocsem, Chronicon, p. 82-83.- Tongerlo, p. 41.- JEAN d'OUTREMEuSE, Myreur, t. 5, p. 479.

${ }^{139}$ Cfr supra et n. 138.

${ }^{140}$ Confirmation par évêque et duc de tous les traités d'alliance entre comte de Namur et évêque de Liège (1290) [Fr. DE REIFFENBERG, Monuments pour servir à l'histoire des provinces de Namur, de Hainaut et de Luxembourg (= DE REIFFENBERG, Monuments), t. 1, Bruxelles, 1844, p. 109.- É. PONCELET, La guerre dite « de la Vache de Ciney» (= PONCELET, Vache), B.C.R.H., 5c sér., t. 3, 1893, p. 391]; désignation de deux arbitres pour terminer leurs différends à propos de leurs domaines (1290) (DE REIFFENBERG, Monuments, t. 1, p. 29-30); traité d'alliance entre les deux princes (1290) (PonCElET, Vache, p. 391-393). L'évêque et le chapitre de Saint-Lambert, d'une part, le comte, d'autre part, établissent des arbitres pour faire le partage des biens possédés indivis (1290) (DE REIFFENBERG, Monuments, t. 1, p. 32-33). Jean de Flandre promet de respecter une sentence arbitrale dans un différend territorial avec son père (1290) (C.S.L., t. 2, p. 467-468); la sentence est prononcée (1290) (DE REIFFENBERG, Monuments, t. 1, p. 237-238). L'évêque et le chapitre de Saint-Lambert d'une part, le comte, de l'autre, s'en remettent à des arbitres pour terminer des contestations à propos des limites de leurs États, du côté de Moha et du Condroz (1291) (C.S.L., t. 2, p. 472-474). 
Jean de Flandre déplore chaque jour les tourments. Ainsi voyons-nous le comte renflouer sans cesse les caisses de l'évêché. Il consent de nombreux prêts à son fils ${ }^{141}$ et, à plusieurs reprises, se pose en caution du prélat dans le cadre de ses emprunts ${ }^{142}$ ou pour le payement d'amendes éventuelles ${ }^{143}$. Que ce soient les membres de son personnel ou certains de ses officiers - le maire ${ }^{144}$ ou le receveur de $\mathrm{Namur}^{145}$, le receveur général de Flandre $^{146}$, un Siger de Bailleul ${ }^{147}$, par exemple - qui remettent l'argent à l'évêque de Liège ne doit pas nous induire en erreur. Ils ne seront jamais

141 Documents 20, 21, 22, 24, 25, 27, 29.

${ }_{142}$ Documents 2, 7, 8, 9, 10, 11, 12, 13 .

${ }_{143}$ Document 19.

144 Documents 20 (20 septembre 1290), 24 (27 mai 1291). Henri de Revin est maire de Namur le 5 avril 1289 [D.D. BrouwERs, L'administration et les finances du comté de Namur du XIII au XV' siècle, t. 4, Chartes et réglements (= BrouwERs, Chartes et réglements), t. 1, Namur, 1913, p. 224] mais ne l'est plus en 1294 (ID., L'administration et les finances du comté de Namur du XIIF au XVe siècle, t. 5, Cens et rentes, t. 1, Namur, 1910, p. 209.- J. Borgnet, St. BoRmans, Cartulaire de la commune de Namur, t. 1, Namur, 1873, p. 120). Quant à Stassart de Hemptinne, il est maire au moins entre le 4 octobre 1291 et le 30 juillet 1297 [BRouwers, Chartes et réglements, t. 1, p. 248, 249, 262, 276, 292.- DE ReIfFenBerg, Monuments, t. 1, p. 35-37.- V. BARBIER, Histoire de l'abbaye de Floreffe de l'ordre de Prémontré, $2^{e}$ éd., t. 2, Namur, 1892, p. 216.- Ch. PIoT, Inventaire des chartes des comtes de Namur, anciennement déposées au chateau de cette ville (= PIOT, Inventaire Namur), Bruxelles, 1890, p. 68-69]. Châtelain de Golzinnes et bailli de Douaire, il est un administrateur de carrière au service de Guy de Dampierre. Cfr D.E. QuELLER, Diplomatic personnel employed by the counts of Flanders in the thirteenth century (= QUELLER, Diplomatic personnel), R.B.P.H., t. 34, 1956, p. 399.- H. DE RADIGUES DE CHENNEVIERE, Les échevins de Namur, A.S.A.N., t. 25, 1905, p. 8-9.

${ }^{145}$ Document 24 (27 mai 1291). Jakemon Branche devint receveur de Namur après le 12 avril 1279 (BROUwERs, Chartes et réglements, t. 1, p. 174) et avant le 11 avril 1280 (Id., p. 175). Il le reste, semble-t-il, jusqu'en juin 1290 au plus tôt (Id., p. 230.- V. GAILLARD, Inventaire analytique des chartes des comtes de Flandre, autrefois déposées au château de Rupelmonde et récemment retrouvées aux archives de l'ancien Conseil de Flandre, à Gand (= GaIllaRD, Inventaire), Gand, 1857, p. 42, n³29.- DeHAISNES-FINOT, Inventaire, t. 9 , p. 93, $\mathrm{n}^{\circ} \mathrm{B} 4048$ ), et en tout cas ne l'est plus le 10 décembre 1292 (BRouWERs, Chartes et réglements, t. 1, p. 262). Sur les fonctions de receveur de Namur et sur le mayorat, dans ce comté, cfr J. BOVESSE, Le personnel administratif du comté de Namur au bas moyen âge. Aperçu général, REVUE DE L'UNIVERSITÉ DE BRUXELLES, t. 22, 1969-1970, p. 444-445, 454.

${ }^{146}$ Documents 15, 22, 24 (18 novembre 1286, 4 février 1291, 27 mai 1291). Les receveurs en question sont Siger de Bailleul (cfr n. suivante) et Gérard Lupichini, dit le Lombard (1289-1292) [cfr E.E. KITTELL From ad hoc to routine : a case study in medieval bureaucracy (= KITTELL, Medieval bureaucraty), Philadelphie, 1991, p. 207.- QuELLER, Diplomatic personnel, p. 395-396].

147 Siger de Bailleul (France, Nord), maréchal de Flandre (première mention, 12 novembre 1281$)$ et receveur général (1282-1283, 1285-1289), décédé avant 1300 [WARLOP, Vlaamse adel, t. 1, p. 350,371,421; t. 2,1, p. 60-61.- KITTELL, Medieval bureaucraty, p. 207, 209.- D.E. QUELLER, E.E. KMTELL, Jakemon of Deinze, general receiver of Flanders, 1292-1300: a study in administrative history (= QUELLER-KITTELL, Jakemon of Deinze), R.B.P.H., t. 61, 1983, p. 292-293]. 
que des intermédiaires; Guy de Dampierre est et restera le principal bailleur de fonds d'un évêque qui, de toute évidence, devait constamment se dire que la source pouvait se tarir à tout moment et que le prix à payer pour bénéficier des largesses de son père, c'était, chaque fois que cela était possible, de calquer sa politique sur celle de la Flandre.

S'il influa directement sur les décisions de Jean de Flandre, Guy de Dampierre trouva également un moyen très efficace pour le contrôler à distance. Il s'arrangea, en effet, pour être présent dans l'entourage de son fils par le biais de quelques personnes de confiance. À nouveau, nous trouvons un écho de cette réalité, des interventions de ces conseillers très spéciaux et d'ailleurs, plus généralement, de l'entourage épiscopal dans son ensemble, dans la plupart des textes publiés en annexe. Signalons, parmi d'autres, Hellin de Helemmes ${ }^{148}$ et Étienne de Harchicourt ${ }^{149}$, respectivement clerc et chapelain de l'évêque, que celui-ci avait dû rencontrer au sein du chapitre de SaintPierre de Lille ${ }^{150}$, ou encore Gérard de Ferlin ${ }^{151}$, clerc flamand, secrétaire de l'évêque puis du comte et intermédiaire entre les deux hommes : il honorera certaines dettes épiscopales et transmettra•au

${ }_{148}$ Document 21. Hellin de Helemmes (France, Nord), maître, clerc épiscopal (1291), est chargé de mission par l'abbé de Cornelimünster en 1281 et chanoine de Saint-Pierre de Lille en 1290 et 1297 (P1ot, Inventaire Namur, p. 38-39.- HAUTCOEUR, Cartulaire SaintPierre Lille, t. 1, p. 534, 563). Il accompagnait Jean de Flandre à Orvieto lorsque celui-ci contracta un emprunt en faveur de son père (document 4,1282 ). Il y a probablement identité entre notre personnage, chanoine de Notre-Dame de Huy, et le Hélin de Hillegem, magister, chanoine de Notre-Dame de Huy en 1286, proposé par L.Fr. GENICOT, Les chanoines et le recrutement du chapitre de Huy pendant le moyen age, A.C.H.S.B.A., t. 27, 1963-1964, p. 82.

${ }_{149}$ Document 9. Étienne de Harchicourt est chanoine (mars 1289) puis doyen de SaintPierre de Lille, du 29 novembre 1289 au 13 juin 1297, $\dagger 15$ décembre 1298. Cfr Hautcoeur, Cartulaire Saint-Pierre Lille, t. 1, p. 530, 532, 535-537, 541, 544, 549, 550, 553, 559, 561, 562.- ID., Histoire Saint-Pierre de Lille, t. 1, p. 469.

1so Cfr supra.

151 Maître, chanoine de Saint-Paul de Liège et coûtre de Fosses en 1291, prévôt de SaintPierre de Douai (1305), chanoine de Saint-Pierre de Lille et d'Andenne, il fut clerc des comtes Guy de Dampierre et Robert de Béthune (1292-1311) et mourut avant le 12 août 1312 (à ne pas confondre, semble-t-il, avec un homonyme, $\dagger$ fin XIV ${ }^{\mathrm{c}}$ siècle). Cfr RENARDY, Répertoire, p. 240.- DE SAINT-GENOIs, Inventaire Rupelmonde, p. 199, 244, 245, 256, 333334, 352-353.- GAILLARD, Inventaire, p. 14, 45, 47, 55-56, 91, 100, 111, 113, 114, $\mathrm{n}^{\circ} 47,54$, $360,384,462,465,660,704,770,783,789$.- DEHAISNES-FinOT, Inventaire, t. 9, p. $93, n^{\circ} B$ 4048.- C. WYFFELS, Inventaris van de oorkonden der graven van Vlaanderen. Chronologisch gerangschikt supplement (= WYFFELS, Inventaris), s.l.n.d., p. 56, 75.- HAUTCOEUR, Cartulaire Saint-Pierre Lille, t. 1, p. 557-558, 563.- O.J. THIMSTER, Cartulaire ou recueil de chartes et documents inédits de l'église collégiale de Saint-Paul, actuellement cathédrale de Liège, Liège, 1878, p. 127.- U. BERLièrE, Suppliques d'Innocent VI (1352-1362), RomeBnuxelles-Paris, 1911, p. 490 n. 1.- PONCELET, Guy de Hainaut, p. 508.- KITTEL, Medieval bureaucraty, p. 79. 
prélat diverses sommes $d^{\prime}$ argent à lui adressées par son père ${ }^{152}$. L'archidiacre Guillaume d'Arras ${ }^{153}$, probablement le plus proche collaborateur de l'évêque, est également l'un de ses créanciers ${ }^{154}$. Il est peut-être issu de toute cette bourgeoisie arrageoise si impliquée dans le commerce de l'argent. Quant à Grégoire ${ }^{i 55}$, coûtre de Fosses, s'il apparaît fréquemment dans l'entourage du prince de Liège, il n'en fait pas moins partie des gens de Guy de Dampierre ${ }^{156}$. C'est d'ailleurs chez lui que descendront les observateurs chargés par le comte de Flandre de faire en sorte que la succession du défunt évêque se fasse au mieux des intérêts flamands ${ }^{157}$. On l'aura compris, il ne fait guère de doute que par son action personnelle - sous-jacente et donc souvent invisible - et aussi, probablement, par celle des antennes qu'il avait installées à Liège, Guy de Dampierre parvint à verrouiller, durant dix ans, l'entourage de son fils et une bonne part de la politique épiscopale liégeoise.

Bien évidemment, le comte ne perdit pas tout intérêt pour la principauté de Liège avec la mort de Jean de Flandre. Nous l'avons vu, il exerça un travail de sape occulte afin que la succession au trône de saint Lambert soit réglée à son avantage ${ }^{158}$ et surtout au détriment de l'élu Guy de Hainaut ${ }^{159}$ et de la Maison d'Avesnes à laquelle celui-ci appartenait. En outre, Guy de Dampierre assuma l'ensemble des dépenses liées au décès de son fils ${ }^{160}$. C'est en effet lui qui acquitta les

${ }_{152}$ Documents 23-25.

153 Sur ce personnage bien connu, archidiacre de Condroz dès 1289 , conseiller et représentant de Jean de Flandre, notamment en 1285, 1289, 1290 et 1291, cfr J. PAQUAY, Cartulaire de la collégiale Notre-Dame à Tongres jusqu'au XV' siècle, t. 1, Tongres, 1909, p. 231-232.- V. BARBIER, Le chapitre noble de Moustier-sur-Sambre, Namur, 1885, p. 128131.- C.S.L., t. 2, p. 466-467, 469-472; t. 6, p. 272-273.- RENARDY, Répertoire, p. 270-271.

154 Document 28.

${ }^{155}$ Maître Grégoire, coûtre de Fosses, est mentionné avec ce titre dès 1288 (L. LAHAYE, Inventaire analytique des chartes de la collégiale de Saint-Jean l'Évangéliste à Liège, $\mathrm{t} .1$, Bruxelles, 1921, p. 113 n. 1.- RENARDY, Répertoire, p. 267.- PONCELET, Guy de Hainaut, p. 508). Un Georges (mauvaise lecture ? Identification hasardeuse d'une initiale ?) est également coûtre de Fosses en 1275 et 1285 (J. PAQUAY, La collégiale Saint-Barthélemy à Liège. Inventaire analytique des chartes, Liège, 1935, p. 126, 132).

${ }^{156}$ Documents 30 et 32.

${ }^{157}$ Document 30.- PoNCELET, Guy de Hainaut, p. 507-508. Lesdits observateurs (Jean de Mortagne, seigneur d'Espierres, Jacques de Deinze, Lotin de Bruges, Nicolas de Strée et Guyot de Namur) seront identifiés infra, n. 290, 313-316.

${ }_{158}$ Cfr supra et MARCHANDISSE, Fonction épiscopale, p. 168-169.

1.59 Sur ce personnage, élu de Liège (1291-1295) puis évêque d'Utrecht (1301- $\dagger 1317$ ), cfr MARChandisse, Fonction épiscopale, p. 165-171.- Poncelet, Guy de Hainaut.

${ }^{160}$ Document 30. 
frais occasionnés par l'embaumement ${ }^{161}$ et l'acheminement du corps, d'Anhaive à l'abbaye de Flines ${ }^{162}$, où l'évêque fut inhumé. Il rétribua également tous ceux qui veillèrent et accompagnèrent la dépouille mortelle vers sa dernière demeure, ainsi que l'officier chargé de rédiger le testament du défunt. Par ailleurs, Guy de Dampierre s'engagea à rembourser les dettes laissées par le prélat liégeois, notamment au préjudice d'Antonin de Fierin, un bourgeois namurois, de toute évidence $^{163}$.

Cette dernière remarque nous conduit à poser une ultime question d'importance : Jean de Flandre a-t-il jamais remboursé l'ensemble des emprunts qu'il contracta? À cette question, nous pensons devoir répondre par la négative, tout au moins partiellement. Nous savons en effet qu'Antonin de Fierin ne fut pas le seul à réclamer son dû. Guy de Dampierre lui-même se plaignit amèrement de ne pas rentrer dans ses fonds. Aussi entendit-il imposer l'ensemble de la principauté... en vain ${ }^{164}$. En 1294, avec insistance, il réclama aux Dinantais l'argent promis pour couvrir les dettes de son fils, une exigence qui, au dire du chroniqueur Jean de Hocsem, engendra une guerre entre le comte et la patrie liégeoise ${ }^{165}$. Au demeurant, la conservation de cet ensemble hété-

161 Il est intéressant de signaler l'embaumement de cette dépouille épiscopale en 1291, quelques années seulement avant que des mesures soient prises à l'encontre de certaines de ces pratiques par le pape Boniface VIII (1299). Nous comptons revenir prochainement sur toutes les questions liées à la mort et aux funérailles des évêques de Liège (des origines à la fin du $\mathrm{XV}^{\mathrm{e}}$ siècle), dans un article intitulé Prélude à l'éternité. Funérailles et sépultures des évêques de Liège au moyen âge, à paraître dans R.B.P.H. Sur ces propos, on se reportera aux travaux toujours excellents d'A. PARAVICINI-BAGLIAN, $l l$ corpo del papa. Turin, 1994.- ID., Medicina e scienze della natura alla corte dei papi nel duecento, Spolète, 1991, et sa synthèse rapide Démembrement et intégrité du corps au XIIr siècle, TERRAIN. CARNETS DU PATRIMOINE ETHNOLOGIQUE, $n^{\circ} 18$ (Le CORPS EN MORCEAUX), 1992, p. 26-32.

${ }_{162}$ En attendant l'article signalé à la n. précédente, cfr MARCHANDISSE, Fonction épiscopale, p. 319 et n. 417 . É. HAUTCOEUR, Histoire de l'abbaye de Flines, Paris-Lille-DouaiBruxelles, 1874, p. 80-81, 414-415. Flines-lès-Raches (France, Nord).

${ }^{163}$ Document 32.

${ }_{164}$ Tongerlo, p. 41 (Tunc idem comes venit in castrum Hoyense et, mandato coram se consilio totius patrie, dixit filium suum esse erretitum multis debitis; quare scottum unum volebat supra patriam ponere, scilicet infra villas bonas et extra, ita quod quodlibet hospitium solvere suum symbolum. Consilium autem patrie respondit quod hoc non pateretur. quia istud nunquam consueverant. Communitas vero ville Hoyensis hoc intelligens quasi in seditione commota est contra predictum comitem, sed quidam intermedii venientes eos pacaverunt, et ita comes recessit super hiis nichil agens).- JEAN D'OUTREMEUSE, Myreur, t. 5, p. 479, 482.- LeJeune, Liège et son Pays, p. 326. Remarquons la spécification apportée par Guy de Dampierre quant au type de taxe à lever : il s'agit d'un impôt que quodlibet hospitium doit acquitter, d'un impôt par feu, dont la mention à cette date est pour le moins précoce.

${ }^{165}$ JEAN DE Hocsem, Chronicon, p. 86.- Tongerlo, p. 44.- CoRneIlle DE ZanTfliet, Chronicon, col. 132. 
roclite de lettres obligatoires et de reconnaissances de plèges dans les coffres à chartes du comte de Flandre est tout à fait significative. En effet, on peut penser, à bon droit, que toutes ces chartes non cancellées par lequelles Jean de Flandre prend des engagements envers son père ou quelque prêteur étranger auraient dû lui être remises, accompagnées de quittances, dès lors que tout était réglé. Par suite, elles devraient être conservées dans les archives liégeoises. Manifestement, il n'en est rien et nous ne sommes pas loin de penser qu'hormis en de rares circonstances ${ }^{166}$, Jean de Flandre n'honora pas ses dettes ${ }^{167}$.

À dire vrai - et nous conclurons ainsi -, ces emprunts et surtout leur probable non-remboursement, une façon somme toute assez anodine de se procurer de l'argent, comparée aux moyens souvent malhonnêtes qu'employèrent nombre d'évêques de Liège - détournements, racket, escroquerie, pillage, amendes imposées aux villes, pots-de-vin... ${ }^{168}-$, nous incitent à penser que tout cet argent n'était pas destiné à financer quelque dépense somptuaire mais était proprement vital pour le souverain liégeois. Visiblement desservi par une réduction des recettes et un accroissement de ses dépenses, ainsi que par l'absence de toute vision budgétaire, condition d'une gestion rationnelle, l'évêque de Liège de la fin du XIII ${ }^{e}$ siècle connaît une situation financière qui est d'ailleurs celle de beaucoup d'autres princes territoriaux du temps ${ }^{169}$, c'est-à-dire une faillite ${ }^{170}$ perpétuelle, conséquence, à coup sûr, de la tendance écono-

${ }^{166}$ Par exemple document 10. La présence de ce document dans les archives flamandes et les notes dorsales en italien donnent à penser que l'acte, tout d'abord conservé par les banquiers italiens qui prêtèrent l'argent au prélat, fut restitué après remboursement.

167 Le 16 juillet 1292, Guy de Dampierre déclarait que son défunt fils avait contracté de grandes obligations envers lui et que lesdites obligations n'avaient pas encore été acquittées (DE SAINT-GENOIS, Inventaire Rupelmonde, p. 189-190, $\mathrm{n}^{\circ} 644$ ).

${ }^{168}$ MARCHandisSE, Fonction épiscopale, p. 255 et n. 136, 260-263, 265-267.

${ }^{169}$ Cfr les exemples donnés par B. GuENÉE, L'Occident aux XIV'et XVé siècles. Les États, $4^{c}$ éd., Paris, 1991, p. 176-179 (Philippe le Hardi, Frédéric III,...).

${ }^{170}$ Pour notre part, nous pensons qu'il faut oser parler de faillite. En effet, entre, d'une part, un prince médiéval comme Jean de Flandre (et d'ailleurs la plupart des évêques de Liège du bas moyen âge) ou un État contemporain tel la Belgique, qui sans un apport financier extérieur (divers prêteurs, dans le cas de Jean de Flandre, les banques, dans celui d'un État contemporain), aurait été ou serait en cessation de paiements, et, d'autre part, une entreprise en liquidation, il n'y a selon nous guère de différences. Certes, la faillite d'un souverain ou celle d'un État ne seront jamais prononcées juridiquement [ce fut parfois le cas dans le passé, cfr notamment la banqueroute de l'État à la fin du règne de Philippe II (information aimablement transmise par le Prof. R.C. van Caenegem)]. Dans le second cas, il est même de bon ton de taire la réalité des faits. Reste que rien ne peut empêcher quiconque de constater une situation de fait, à savoir, en ce qui concerne Jean de Flandre, une incapacité à subvenir aux besoins de sa charge avec ses seules sources traditionnelles de revenus et un recours systématique à des emprunts, qu'il ne rembourse que très rarement. Toutes les conditions sont donc réunies, nous semble-t-il, pour aboutir à une faillite qui, bien sûr, ne se traduira pas par un acte de justice mais qui n'en est pas moins présente, en particulier dans ses conséquences. 
mique générale ${ }^{171}$. Incapable d'assumer son règne avec ses seules sources traditionnelles de financement, le prélat se voit contraint de recourir à des procédés empiriques, à des expédients, comme si les structures de l'État médiéval étaient désormais anachroniques, en porte-à-faux par rapport aux besoins d'un État moderne en devenir ${ }^{172}$.

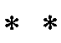

*

Conformément aux règles édictées par la Commission royale d'Histoire, les textes présentés en annexe ont été édités selon quelques principes stricts qu'il est bon d'expliciter ici. Les originaux ont été transcrits avec le plus grand soin. Tout particulièrement, nous nous sommes efforcé de coller le plus possible aux textes en ancien français, n'hésitant pas à admettre une leçon inhabituelle bien qu'attestée. Les dates ont été résolues selon le style de Pâques, qui était celui en usage durant la période qui nous occupe, tant à la chancellerie des comtes de Flandre ${ }^{173}$ qu'à celle des princes-évêques de Liège ${ }^{174}$. Les quelques éditions existantes ont été mentionnées. En cette matière, cependant, nous ne sommes pas sûr d'avoir atteint l'exhaustivité, la table de Wauters ${ }^{175} s$ 'avérant, en l'occurrence, d'une efficacité pour le moins limitée. Les notes dorsales n'offrant guère d'originalité, pour la plupart, nous avons jugé inutile de les signaler systématiquement ${ }^{176}$.

"7' Ph. Contamine, M. Bompaire, St. LebecQ, J.L. SARRazin, L'économie médiévale, Paris, 1993, p. 409.

${ }^{172}$ Il semble bien que la présente contribution participe de tout un courant de recherches actuel qui s'attache aux rapports entre haute finance et pouvoir politique ainsi qu'à la gestion financière des États médiévaux. À l'heure où nous corrigeons les épreuves de cet article, nous recevons en effet, sans malheureusement pouvoir en faire usage ici, deux ouvrages consacrés aux questions débattues dans notre étude : Hochfinanz im westen des Reiches : 1150-1500, sous la dir. de F. BURGARD, A. HAVERKAMP, Fr. IRSIGLER, W. REICHERT, Trèves, 1996.- J. RAUZier, Finances et gestion d'une principauté au XIV' siècle. Le duché de Bourgogne de Philippe le Hardi (1364-1384), Paris, 1996.

${ }^{173} \mathrm{Cfr} \mathrm{W}$. PrEvenIER, Un probleme de chronologie : la transition du style de Noël au style de Pâques dans la chancellerie des comtes de Flandre (1191-1205), R.B.P.H., t. 43, 1965 , p. 569.

${ }_{174}$ E. de MARnefFe, Styles et indictions suivis dans les anciens documents liégeois, Bruxelles, 1896, p. 38-43.

175 A. WaUters, St. Bormans, J. HalkIN, Table chronologique des chartes et diplômes imprimés concernant l'histoire de la Belgique, t. 6, Bruxelles, 1881; t. 7,2, Bruxelles, 1889; t. 11,2, Bruxelles, 1912.

176 Instructions pour la publication des textes historiques (= Instructions), Bruxelles, 1955, p. 11. 
Seules les marques en italien, importantes d'un point de vue proprement historique, ont été restituées, sous toute réserve, cependant, en raison de l'extrême complexité de leur lecture ${ }^{177}$. Enfin, plutôt que de présenter constamment des informations identiques, nous avons opté pour une description en appendice ${ }^{178}$ des divers sceaux de Jean de Flandre apposés à nos actes. Nous constatons la présence de deux contre-sceaux et de trois sceaux différents.

1 . Sceau de type 1 : datant de 1280 , sceau ante susceptum ${ }^{179}$ de Jean de Flandre, élu de Metz, en navette (hauteur : $72 \mathrm{~mm}$, largeur : $47 \mathrm{~mm}$ ) et en cire verte. On y voit, représenté en majesté, un clerc non mitré, en aube et amict (il semble porter quelque chose), debout dans une niche gothique, flanqué de deux lions. La légende semble être: [ ]O[ ] S(Ou E)LCI / METEN $\cdot \mathrm{Z} \cdot \overline{\mathrm{PPOSITI}}{ }^{180}$.

2. Sceaux des types 2 et 3 : Correspondant respectivement aux fonctions épiscopales messines et liégeoises de Jean de Flandre, ils sont identiques. D'une hauteur de $80 \mathrm{~mm}$ et d'une largeur de $55 \mathrm{~mm}$, ils sont en navette et représentent un évêque assis, mitré, crossé et bénissant. La légende du premier était vraisemblablement la suivante :

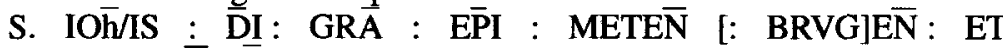

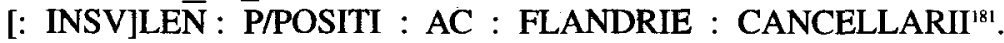
Voici celle du sceau épiscopal liégeois : + SI/GILLVM IOhANNIS / DEI GRATIA / LEODIENSIS * EPISCOPI *182.

3. Contre-sceaux des types 1 et 2 : d'un diamètre de $33 \mathrm{~mm}$, les deux contre-sceaux de Jean de Flandre élu puis évêque, ne comportent qu'une seule différence. En effet, si tous deux présentent un même écu à un lion dans un sextilobe, seul le sceau épiscopal porte l'écu surchargé d'une crosse posée en bande. La légende du contre-sceau de type 1 (élu de Metz) est la suivante : + SECRETVM : SIGILLI ${ }^{183}$. Quant à celui de type (évêque de Metz puis de Liège), la légende en est : + SECRETVM : SIGILLI : NOSTRI ${ }^{184}$.

17 Documents 3, 4, 10.

${ }^{178}$ Instructions, p. 14.

179 Vocabulaire international de la diplomatique, éd. M. Milagros Carcel OrTi, Valence, 1994, p. $124, n^{\circ} 523$.

180 Document 1.

${ }^{181}$ La légende proposée par DE SAINT-GENoIs, Inventaire Rupelmonde, p. $91, \mathrm{n}^{\circ} 93$, est confirmée par ce celles que nous lisons sur les sceaux apposés aux actes 2 et 3 .

${ }^{182}$ R. LAURENT, Sigillographie (= LAURENT, Sigillographie), Bruxelles, 1985, p. 72, n³43/23.- É. PONCELET, Les sceaux et chancelleries des princes-évêques de Liège (= PonCELET, Sceaux), Liège, 1938, p. 170, n 22.

${ }_{183}$ Document 1.

${ }^{184}$ LAURENT, Sigillographie, p. 72, n³43/24.- PONCELET, Sceaux, p. 170, n²2. 


\section{ANNEXES}

Guy, comte de Flandre et marquis de Namur, Robert, comte de Nevers, seigneur de Béthune et de Termonde, et Jean, élu de Metz, déclarent que divers marchands florentins leur ont prêté 1000 livres tournois, somme qu'ils promettent de rembourser lors de la prochaine foire de Provins, en mai.

\section{3 avril 1280}

A. ORIGINAL sur patchemin (hauteur, à gauche : $161 \mathrm{~mm}$, à droite : $165 \mathrm{~mm}$, dont un repli, à gauche, de $22 \mathrm{~mm}$, à droite, de $18 \mathrm{~mm}$; largeur, en haut : $217 \mathrm{~mm}$, en bas : $216 \mathrm{~mm}$ ), muni de trois sceaux, pendant sur double queue de parchemin : 1) sceau circulaire (diamètre : $92 \mathrm{~mm}$ ), en cire blanche et de type équestre à l'épée, de Guy de Dampierre, comte de Flandre (grand sceau équestre III); de la légende (+ $S$ ' . GVIDONIS : COMITI/S : FLANDRIE : ET : MAR/ChIONIS : NAMVCEN $\bar{N}$ cfr R. LAURENT, Les sceaux des princes territoriaux belges du $X^{e}$ siècle à 1482 (= LAURENT, Sceaux princes belges), t. 1,1, Bruxelles, 1993, p. 169; t. 2, Bruxelles, 1993, pl. 41-45), on peut lire [ ] NI [ ] S : NAMVCEN; contresceau circulaire (diamètre : $46 \mathrm{~mm}$ ), de type armorial (contre-sceau armorial III), portant pour légende : + SECRETV : GVIDON $\overline{\mathrm{N}}$ : COMITIS : FLANDRIE (Id., t. 1,1, p. 169; t. 2, pl. 41-43, 45); 2) sceau circulaire (diamètre : $84 \mathrm{~mm}$ ), en cire blanche et de type équestre à l'épée, de Robert, comte de Nevers, seigneur de Béthune et de Termonde (grand sceau équestre II, avant accession); de la légende (+ S' ROBERTI - PRIMOGENI/TI COMITIS FLANDRI/E - COMITIS NIVERNEN; cfr $I d$., t. 1,1, p. 171; t. 2, pl. 49), on peut lire [ ] ROBERTI - PRIMOGENI/TI - CO [ ]; contre-sceau circulaire (diamètre : $40 \mathrm{~mm}$ ), de type armorial (contre-sceau armorial II, avant accession), portant pour légende : + SECRETV ROB'TI - COMITIS - NIVERN (Id., t. 1,1, p. 171-172; t. 2, pl. 50); 3) sceau de Jean de Flandre, élu de Metz, de type 1, avec contre-sceau de type 1. Acte conservé aux ArChives De L'ÉTAT A GAND (= A.É.G.), Chartes des comtes de Flandre, Fonds Gaillard, n 518.

ÉdITION : G. DES MAREZ, La lettre de foire à Ypres au XII ${ }^{*}$ siècle. Contribution à l'étude des papiers de crédit (= DES MAREZ, Lettre de Foire), MÉMOIRES COURONNÉs ET AUTRES MÉMOIRES PUBLIÉs PAR L'ACADÉmie ROYALE DES Sciences, des LetTres et des BeauX-Arts de Belgique, Coll. IN-8 ${ }^{\circ}$, t. 60 , 1900-1901, p. 165-166, n 74 , d'après $A$. 
MENTIONS : V. GAILLARD, Inventaire analytique des chartes des comtes de Flandre, autrefois déposées au château de Rupelmonde et récemment retrouvées aux archives de l'ancien Conseil de Flandre, à Gand (= GAILLARD, Inventaire), Gand, 1857, p. $63, \mathrm{n}^{\circ} 518$.- $\mathrm{G}$. BIGwooD, Le régime juridique et économique du commerce de l'argent dans la Belgique du moyen âge (= Bigwoon, Commerce de l'argent), t. 1, Bruxelles, 1921, p. 66.- R. DAviDsoHN, Storia di Firenze, t. 6, Florence, 1965, p. 495 et n. 3.

Nous, Guis, cuens de Flandre et marchis de Namur ${ }^{185}$, Robers ${ }^{186}$, cuens de Nevers $^{187}$, sire de Bethune ${ }^{188}$ et de Tenremonde ${ }^{189}$, et Jehans, par le grace de Diu, eslius de $\mathrm{Mez}^{190}$, fil au devant dit conte de Flandre, faisons savoir a tous ke nous avons rechiut de nos chiers amis Oldebrant Lapo, Brimet freres, Gerart Compaigne, Henri Millac ${ }^{191}$ et leur compaignons, marcheans de Florenche ${ }^{192}$, en deniers contans, en chevaus et en autres marcheandises, des queles il ont finet pour nous iuskes a le summe de mil livres de tornois, et bien nous en tenons a sols et a paiet, les quels deniers nous prometons a paier, et cascuns pour le tout, as devant dis marcheans ou a l'un de aus ou a leur certain message ki ces lettres aporteroit, dedens le foire de Provins ${ }^{193}$ a le Saint Aioul ${ }^{194}$ prochaine ke

${ }^{185}$ Cfr n. 7. Namur (Belgique, pr. Namur, arr. Namur, comm. Namur).

${ }^{186}$ Cfr n. 108.

${ }^{187}$ Nevers (France, Nièvre).

188 Béthune (France, Pas-de-Calais).

189 Termonde (Dendermonde) (Belgique, pr. Flandre orientale, arr. Dendermonde, comm. Dendermonde).

${ }^{190}$ Cfr n. 2.

191 Ces marchands florentins posent de réels problèmes d'identification. Il existe de très nombreux Lapo, soit prénommés, soit nommés ainsi [G. BIGwood, Les livres des comptes des Gallerani (= BIGWOOD, Gallerani), éd. A. GRUNZWEIG, t. 2, Introduction et tables, Bruxelles, 1962, p. 79, 93, 99, 161, 169, 187, 235, 238, 241.- Y. RENOUARD, Les relations des papes d'Avignon et des compagnies commerciales et bancaires de 1316 à 1378, Paris, 1941, p. 675.- R. DAVIDsoHn, Storia di Firenze (= DAVIDSOHN, Storia di Firenze), t. 6, Florence, 1965, p. 525, 866]. Comme l'indique la suite du texte, il doit également être question des Brunetti, famille florentine (Id., p. 65, 364, 638, 893, 894.BIGWood, Commerce de l'argent, t. 1, p. 199). Gérard appartient à la famille des Compagni (Id., t. 1, p. 58; t. 2, p. 302.- DaviDsoHn, Storia di Firenze, t. 6, p. 495, 664 et n. 4). Aucune information dans la nomenclature dressée par Y. RENOUARD, Le compagnie commerciali fiorentine del Trecento (Dai documenti dell'Archivio Vaticano), ARCHIVIO STORICO TTALIANO, t. 16, 1938, p. 41-68, $163-179$ (réimpr. dans ID., Études d'histoire médiévale, t. 1, Paris, 1968, p. 511-545).

${ }^{192}$ Florence (Italie, Toscane, pr. Florence).

${ }^{193}$ Provins (France, Seine-et-Marne). Sur les foires de Champagne (Troyes, Provins, Bar-sur-Aube, Lagny), dont il est question ici, nous nous contenterons de renvoyer à l'étude de synthèse de R.H. BAUTIER, Les foires de Champagne. Recherches sur une évolution historique, RECUEILS DE LA SOCIETté JEAN BodIN, t. 5, 1953, p. 97-147, spéc. bibl. p. 97-101 n. 2 (réimpr. dans ID., Sur l'histoire économique de la France médiévale. La route, le fleuve, la foire, Hampshire-Brookfield, 1991, pag. orig.) et à l'article rapide et pourvu d'une riche bibl. de M. BuR, Art. Champagnemessen, L.D.M., t. 2, MunichZurich, 1983, col. 1685-1689.

19422 mai. 
nous atendons, et se lidit Oldebrant Lapo, Brunet frere, Gerart Compaigne, Henris Millac et leur compaignon, marcheans de Florenche, pour defaute de nostre paiement au termine devant nommei avoient coust ne damage, nous leur prometons aussi a rendre avoec le dette devant dite, sans le dette amenrir, et accroire sour leur plain dit ou sour le dit de l'un de eaus sans autre provance faire. Et a che fermement tenir et entirement acomplir, obligons nous, et cascuns pour le tout, nous, nos successeurs, et nos biens meubles et non meubles, ou ke il soient ne u ke on les puist trover, sans aler encontre, paisivlement en bone foi, et renuncons expresseement a toutes exceptions de droit et de fait, a tous privileges et a toutes indulgences donees et a doner, empetrees et a empetrer, a le constitution de deus jornees et a convention de juges, a tout benefice de crois prise et a prendre et a toutes autres bares et cavillations ki a nous poroient aidier et as devant dis marcheans grever u nuire. En tesmoingnage de la quel cose, nous, Guis, cuens de Flandre, Robers, cuens de Nevers, et Jehans, par le grace de Diu, eslius de Mez, deseure nommei, avons fait saeler ces presentes letres de nos propres saiaus, ki furent donees en l'an del Incarnation nostre Seingnour mil deus cens sissante dis et noef, le merkedi apres mi quaresme, el mois de avril.

Jean, évêque de Metz, prévôt de Saint-Donatien de Bruges et de Saint-Pierre de Lille, chancelier de Flandre, notifie qu'à l'instigation de son père Guy, comte de Flandre et marquis de Namur, des bourgeois de Douai ont emprunté à son intention aux collecteurs de la dîme de Cambrai 3000 livres de petits tournois noirs, emprunt dont le remboursement est garanti par le comte et gagé sur les revenus de la prévôté de Bruges et de la chancellerie de Flandre.

\section{0 juin 1281}

A. Original sur parchemin (hauteur, à gauche : $131 \mathrm{~mm}$, à droite : $136 \mathrm{~mm}$, dont un repli, à gauche, de $24 \mathrm{~mm}$, à droite, de $23 \mathrm{~mm}$; largeur, en haut : $232 \mathrm{~mm}$, en bas : $231 \mathrm{~mm}$ ), muni, pendant sur double queue de parchemin, du sceau de Jean de Flandre, évêque de Metz, de type 2, avec contre-sceau de type 2. Acte conservé aux A.É.G., Chartes des comtes de Flandre, Fonds de Saint-Genois, $\mathrm{n}^{\circ} 293$.

ÉDItIoN : G. EspinAs, La vie urbaine de Douai au moyen âge (= EspINAs, Vie urbaine de Douai), t. 3, Pièces justificatives. XI'-XIII siècles $\left(n^{\text {os }} 1-860\right)$, Paris, 1913, p. 519-520, d'après $A$.

MENTIONS : J. DE SAINT-GENOIS, Monuments anciens essentiellement utiles à la France, aux provinces de Hainaut, Flandre, Brabant, Namur, Artois, Liège, Hollande, Zélande, Frise, Cologne, et autres pays limitrophes de l'Empire 
(= De SAINT-Genois, Monuments), t. 1,2, Lille, s.d., p. 686.- J. De SAINTGENOIS, Inventaire analytique des chartes des comtes de Flandre avant l'avènement des princes de la Maison de Bourgogne autrefois déposées au château de Rupelmonde, et conservées aujourd'hui aux archives de la Flandre orientale, précédé d'une notice historique sur l'ancienne trésorerie des chartes de Rupelmonde et suivi d'un glossaire, de notes et d'éclaircissements (= DE SAINT-GENoIs, Inventaire Rupelmonde), Gand, 1843-1846, p. 91 , nº293.

Nous, Jehans, par la grace de Dieu, eveskes de Mes, prevos de Bruges ${ }^{195}$ et de Lille ${ }^{10 \%}$, et chanceliers de Flandres, faisons savoir a tous ke comme a la requeste et a la priiere de nostre tres chier signeur et peire Guy, conte de Flandres et marchis de Namur, nostre chier ami Rykars dou Marchiet ${ }^{197}$, Jehans de France ${ }^{198}$ et Simons Males ${ }^{199}$, bourgois de Dowai ${ }^{200}$, aient empruntei as collecteurs dou dizime de Cambrai ${ }^{201}$ troiz mil livres de petis tornois noirs en esterlins de Braibant des deniers dou dit dizime, a rendre as dis collecteurs dedens quarante iours apres lor semonset a Cambrai ${ }^{202}$, et comme li dit bourgois aient ces troiz mil livres devantdites, k'il avoient empruntees si ke dit est, sans faire mention d'autreie ke de eaus meismes, prestees a nous et delivrees a nostre requeste pour nostre tres grant besoing, et nostre tres chiers sires et peires devantdis ait as devantnoumeis bourgois ses lettres donnees par les queiles il a enconvent a eaus k'il les en aquitera avoec tous cous, frais et

${ }^{195}$ Cfr n. 10.

196 Cfr n. 11.

197 Bourgeois de Douai, échevin en 1272, 1274, 1275 et 1279, créancier de plusieurs Dampierre entre 1268 et 1283. Cfr Espwas, Vie urbaine de Douai, t. 3, p. 387, 395-396, 401-402.- J. BuNTINX, Het memoriaal van Jehan Makiel, klerk en ontvanger van Gwijde van Dampierre (1270-1275) (= BunTiNX, Memoriaal), Bruxelles, 1944, p. 88, 92.G. Espinas, H. PIRENNE, Recueil de documents relatifs à l'industrie drapière en Flandre (= ESPINAS-PIRENNE, Recueil documents industrie drapière), $1^{\mathrm{c}}$ part., Des origines à l'époque bourguignonne, t. 2, Deynze-Hurst, Bruxelles, 1909, p. 114, 124, 125, 140.Bigwood, Commerce de l'argent, t. 1, p. 31-32.

198 Cfr n. 128.

${ }^{199}$ Échevin de Douai entre 1288 et 1290 (1291 ?), il prêta de l'argent aux Dampierre à diverses reprises entre 1268 et 1283 . En 1286, il était au service de Guy de Dampierre (siergans). Cfr Espinas, Vie urbaine de Douai, t. 3, p. 387, 395-396, 401-402.- BunTINX, Memoriaal, p. 56, 86, 91.- EsPINAS-PIRENNE, Recueil documents industrie drapière, t. 2, p. 146, 147, 152, 154.- Bigwood, Commerce de l'argent, t. 1, p. 31-32, 146, 149.

200 Douai (France, Nord).

201 Il doit s'agir de l'abbé de Vaucelles (France, Nord) et de Jean de Bruières, doyen de Notre-Dame de Cambrai, collecteurs en 1283, 1287 et 1291, auxquels s'ajoute peut-être Renier de Paissi, lui aussi collecteur en 1283. Cfr L. GILlodTs-VAN SEVEREN, Inventaire des archives de la ville de Bruges. Inventaire des chartes, $1^{\bullet}$ sér., Treizième au seizième siècle, t. 1, Bruges, 1871, p. 15, n³0.- DE SAINT-GENoIs, Inventaire Rupelmonde, p. 128$129,175-176, n^{\circ} 425,426,599$.

202 Cambrai (France, Nord). 
damages $k$ 'il en aroient $u$ encourroient au dit de eaus $u$ del un de eaus sans autre prouvance faire et sans le dite summe amenrir, nous, ki le dite summe avons eve et recheve, avons enconvent a nostre tres chier signeur et peire ke nous de le dite summe et des cous, des frais et des damages k'il en aroit $u$ encourroit pour nous, l'en deliverrons et aquiterons entierement en boene foi et volons k'il s'en tiegne as fruis et as venues de nostre prevostei de Bruges et de nostre chancelerie de Flandres, dés la feste de la Nativitei saint Jehan Baptiste ${ }^{203} \mathbf{k i}$ vient prochainement en avant iusques adont $k$ 'il $\mathbf{i}$ ait repris plainement les dites troiz mil livres avoec les cous et les frais ki fait en seroient $u$ iusques adont ke nous l'en auriemes aquitei et deluivrei en autre maniere a son grei souffissamment. En tesmoingnage et seurtei de la queile chose nous avons fait mettre nostre saiiel a ces presentes lettres, dounees l'an del Incarnation nostre Signeur mil deuz cens quatre vins et un, le mardi apres les witaves de Penthecouste.

Regnier Tholomei de Florence, notaire apostolique et impérial, notifie que Jean, évêque de Metz, a emprunté, sur instance de son père Guy, comte de Flandre et marquis de Namur, à divers marchands siennois, la somme de 500 livres de petits tournois, somme que le comte et lui s'engagent à rembourser avant la Saint-André prochaine, renonçant à tout exception leur permettant de se soustraire à leurs obligations.

Orvieto, 22 mai 1282

A. ORIGINAL sur parchemin (hauteur : $330 \mathrm{~mm}$, dont un repli de $20 \mathrm{~mm}$; largeur : $469 \mathrm{~mm}$ ), muni de 2 sceaux, pendant sur double queue de parchemin : 1) sceau de Jean de Flandre, évêque de Metz, de type 2, avec contresceau de type 2; 2) fragment de sceau en cire rouge de Gérard, prévôt de Cassel (cfr infra, acte 4); de la légende, on peut lire [ ] GERARDI [ ] SLETE; contre-sceau circulaire (diamètre : $12 \mathrm{~mm}$ ), de type héraldique; de la légende, on peut lire : SIG[ ]. Acte conservé aux A.E.G., Chartes des comtes de Flandre, Fonds de Saint-Genois, $\mathrm{n}^{\circ} 310$. 
Au dos, en italien : Lettere di domino conte di Fiandola di $V^{c}$ libre di tornois a la Sant'Andrea apostolo in Paris overo in Tressi in anno ottantedue.

Mentions : De SAINT-Genols, Inventaire Rupelmonde, p. 96, $\mathrm{n}^{\circ} 310 .-\mathrm{G}$. BIGWOOD, Documents relatifs à une association de marchands italiens aux $\mathrm{XII}^{r}$ et XIV siècles (= BIGwoOD, Documents), B.C.R.H., t. 78, 1909, p. 209 et n. 2.- E. VON ROON-BASSERMAN, Sienische Handelsgesellschaften des XIII. Jahrhunderts mit besonderer Berücksichtigung ihres internationalen Handels $(=$ VON ROON-BASSERMANN, Sienische Handelsgesellschaften), Mannheim-Leipzig, 1912, p. 59-60.- BiGwood, Commerce de l'argent, t. 1, p. 66.- D.E. QUELLER, Diplomatic personnel employed by the counts of Flanders in the thirteenth century (= QUELLER, Diplomatic personnel), R.B.P.H., t. 34, 1956, p. 388-389 et n. 11.

Le document comporte, dans le coin inférieur gauche, le seing manuel du notaire impérial et apostolique, Regnier Tholomei de Florence.

In Dei nomine amen. Anno Nativitatis Eiusdem millesimo ducentesimo octogesimo secundo, indictione decima, die vigesimo secundo mensis maii, pontificatus domini Martini papae ${ }^{204}$ quarti anno secundo, in presentia mei Raynerii ${ }^{205}$, notarii, et testium infrascriptorum ad hoc vocatorum et rogatorum, reverendus pater dominus Johannes, Dei gratia Metensis episcopus, filius viri magnifici domini Guidonis, comitis Flandriae et marchionis Namurcensis, apud Sedem Apostolicam constitutus, habens ab eodem domino comite et marchione potestatem et mandatum speciale contrahendi mutuum pro eodem comite et marchione et eius nomine usque ad summam quingentarum librarum turonensis monete, obligandi et renuntiandi prout in litteris patentibus sigillo eiusdem domini comitis et marchionis munitis plenius continetur, procuratorio seu gestorio nomine pro eodem domino comite et marchione, auctoritate ac virtute litterarum dictarum, se obligans ad omnia et singula infrascripta, confessus est et recognovit, in veritate et non spe numerationis vel receptionis future, se in curia domini pape apud eandem sedem, pro eiusdem domini comitis et marchionis necessariis et utilibus negotiis in dicta curia procurandis et alibi atque gerendis et expediendis utiliter mutuo recepisse et habuisse a Bonaventura Johannis $^{206}$; cive et mercatore Senense ${ }^{207}$, de societate filiorum Salembeniorum de Senis, mutuante et numerante pro se ipso et joro Johanne domini Johannis

${ }^{204}$ Cfr n. 18.

${ }^{205}$ Personnage non identifié. Les Tolomei étaient une compagnie marchande siennoise.

${ }^{206}$ Membre de la société des fils Salimbeni, comme tous ceux mentionnés ici, Bonoventura Giovanni est signalé entre 1275 (reçoit l'autorisation de commercer en Angleterre) et 1282 (notre doc.). Cfr Von ROON-BASSERMANN, Sienische Handelsgesellschaften, p. 59-61.

${ }^{207}$ Sienne (Italie, Toscane, pr. Sienne). 
Salembenii ${ }^{208}$, Baldo Bonavollie ${ }^{209}$, Hugone Hugolini Gigonis ${ }^{210}$, Ciono Baroncelli ${ }^{211}$ et Raynerio Alberti ${ }^{212}$, sociis et concivibus suis et joro omnibus et singulis sociis societatis predicte et nomine cuiuslibet eorum in solidum, quingentas libras bonorum et computabilium turonensium parvorum de pura et vera sorte de turonis, de quibus idem dominus episcopus, procuratorio seu gestorio nomine pro dicto domino comite et marchione, se bene et integre pagatum et contentum vocavit et tenuit eamque pecunie summam totam in necessariam utilitatem dicti domini comitis et marchionis fore conversam manifeste confessus est, exceptioni non numerate et non recepte et non sic converse pecunie omnino et expresse renuntians. Quas quingentas libras bonorum turonentium parvorum de turonis predictorum, dictus dominus episcopus, procuratorio seu gestorio nomine quo supra, auctoritate ac virtute litterarum predictarum, convenit et promisit eidem Bonaventure, suo et dictorum aliorumque omnium sociorum dicte societatis nomine legitime stipulanti, se ipsum, gestorio seu procuratorio nomine quo supra, et predictum dominum Guidonem, comitem et marchionem, reddituros et soluturos integre mercatoribus supradictis aut uni cuicumque eorum in solidum aut eorum vel uni eorum certo ad hoc constituto procuratori usque ad proximum futurum festum beati Andree ${ }^{213}$ Parisius sive

${ }^{208}$ Giovanni di Giovanni Salimbeni, signalé entre 1263 et 1283 , notamment à la cour pontificale et comme prêteur en faveur de Marguerite de Constantinople (Ibid.Dehaisnes-Finot, Inventaire, t. 9, p. 79, $\mathrm{n}^{\circ} \mathrm{B}$ 4035.- WyFFELS, Inventaris, p. 35-36, $\left.n^{\circ} 117\right)$.

${ }^{209}$ Baldo Bonavollie est mentionné en 1278 et en 1282 dans le cadre de prêts accordés par les Salimbeni à Marguerite de Constantinople et à Jean, seigneur de ChâteauVilain et de Luzy. Cfr Ibid.- G. DES MAREZ, La lettre de foire à Ypres au XIIr siecle. Contribution à l'étude des papiers de crédit (= DES MAREZ, Lettre de foire), MÉMOIRES

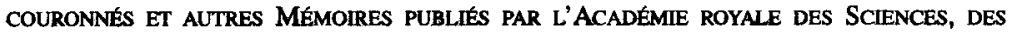
LeTtres et des BeAUX-ARTS DE BelgiQUe, COLL. IN-8 ${ }^{\circ}$, t. 60, 1900-1901, p. 183-184, $n^{\circ}$ 93.- DeHAisNes-Finot, Inventaire, t. 9, p. 79, n'B 4035.- Von ROON-BASSERMANN, Sienische Handélsgesellschaften, p. 59-61.- BIGwood, Commerce de l'argent, t. 1, p. 162.

${ }^{210}$ Ugo Ugolini Gigonis est signalé entre 1260 et 1282 . Il fut notamment le représentant de la compagnie pour toutes les affaires nouées par-delà les Alpes et le créancier de l'évêque de Beauvais (1263). Cfr Ibid.- Des MAREZ, Lettre de Foire, p. 183-184, n93.Von RoOn-BASSERManN, Sienische Handelsgesellschaften, p. 58-61.

${ }^{211}$ Cione (Uguictione) Baroncelli est signalé en 1278 et en 1282 . Cfr lbid.Dehaisnes-Finot, Inventaire, t. 9, p. $79, \mathrm{n}^{\circ} \mathrm{B} 4035$.

${ }^{212}$ Reniero Alberti est signalé entre 1275 et 1292 . Il fut notamment le créancier de Guy de Dampierre et des membres de sa famille en 1289, 1290 et 1292. Il fut également l'associé de Iacobo Sicherii, appartenant à la famille et compagnie des Gallerani. Cfr DE SAINT-Genols, Inventaire Rupelmonde, p. 194, n659.- Des MAREZ, Lettre de Foire, p. 183-184, n93.- VON ROON-BASSERMANN, Sienische Handelsgesellschaften, p. 59-61.BIGwoon, Commerce de l'argent, t. 1, p. 68-69, 162; t. 2, p. 295.- ID., Documents relatifs $\grave{a}$ une association de marchands italiens aux XIIK et XIV siècles (= BIGWOOD, Documents), B.C.R.H., t. 78, 1909, p. 209.- ID., Gallerani, t. 2, p. 60-62, 64.

${ }^{213} 30$ novembre. 
Trecis $^{214}$. Quod si in altero dictorum locorum ut predictum est, dicto termino, supradicta pecunie summa eisdem mercatoribus aut uni eorum in solidum ut dictum est soluta et restituta integre non fuerit, convenit et promisit idem dominus episcopus, procuratorio sive gestorio nomine quo supra, dicto Bonaventure nomine quo supra legitime stipulante, se ipsum procuratorio seu gestorio nomine quo supra dictumque dominum Guidonem comitem et marchionem, reddituros refecturos et soluturos ex tunc in antea eisdem mercatoribus aut uni cuicumque eorum in solidum simul cum dicta integra solvenda et restituenda sorte tam in utroque dictorum locorum quod alibi ubicumque ab eodem domino Guidone comite et marchione vel eis heredibus aut successoribus petitum fuerit omnia et singula dampna, expensas et interesse que iidem mercatores aut unus quicumque eorum se vel socios dicte societatis ob defectum dicte solutionis aut eius occasione fecisse vel incurrisse dixerint vel dixerit, nudo verbo, sine cause cognitione, sine judicis taxatione et sine ulla alia probatione, et insuper expensas uni mercatoris cum uno equo et uno serviente ubicumque fuerit quousque eisdem mercatoribus aut uni cuicumque eorum in solidum ut dictum est fuerit integre de dicto debito satisfactum. Pro quibus omnibus et singulis sic solvendis et observandis ad plenum, dictus dominus episcopus, procuratorio seu gestorio nomine quo supra auctoritate litterarum dictarum, obligavit eidem Bonaventure nomine quo supra legitime stipulanti et cuilibet dictorum mercatorum in solidum, se ipsum, procuratorio seu gestorio nomine quo supra, et predictum dominum Guidonem comitem et marchionem suosque heredes et successores omnes et universam terram suam cum omnibus et singulis eiusdem domini comitis et marchionis bonis mobilibus et immobilibus, presentibus et futuris, ubicumque sunt vel poterunt inveniri. Hoc etiam acto expresse inter contrahentes predictos quod quilibet dictorum mercatorum in solidum possit sine ullo procuratorio aliorum petere et exigere atque recipere totum dictum debitum et omnia in presenti contractu contenta, uni tamen cuicumque eorum facta integra solutione, dictus debitor liber et quitus existat de debito memorato. Et in hiis omnibus predictis et infrascritpis renuntiavit idem dominus episcopus, procuratorio seu gestorio nomine pro dicto domino comite ac marchione auctoritate dictarum litterarum, exceptioni doli et infactum actioni, conditioni indebiti sine causa et ex iniusta causa omni tempori feriato, omni appellationis remedio, privilegio crucis et fori omni privilegio et indulto crucesignatis et crucesignandis concesso et concedendo, quadrimestri tempori quod condempnatis indulgetur ad solvendum, beneficio restitutionis in integrum, constitutioni De duabus dictis edite in concilio generali, conventioni locorum et judicum, juri revocandi domum, omnibus apostolicis litteris et privilegiis et gratiis concessis et concedendis sub quacumque forma verborum impetratis et impetrandis, et specialiter indulgentie apostolice, siquam dictus dominus comes et marchio habet, seu ipsum vel successores suos habere contigerit in futurum quod excommunicari suspendi vel interdici, nequeat aut non

214 Troyes (France, Aube). 
nisi in certo loco et coram certo judice, neque extra certam diecesim vel patriam ad judicum trahi vel evocari valeat, occasione debitorum in quibus obligatus exsteret, neque compelli, sine speciali mandato sedis apostolice faciente plenam et expressam aut de verbo ad verbum de indulto huiusmodi mentionem, omni consuetudini et statuto, omni inhibitioni tam regie quam cuiuscumque principis omnique alii exceptioni et juri canonico et civili generali et speciali, quod contra presens instrumentum vel factum posset ullatenus obici vel opponi et specialiter juri dicenti generalem renuntiationem non valere. In quorum omnium evidentium testimonium dictus dominus episcopus et etiam venerabilis vir dominus Gerardus ${ }^{215}$, prepositus Casletensis ${ }^{216}$, Morinensis ${ }^{217}$ diocesis, mandato eiusdem domini episcopi, sigilla sua presenti publico instrumento mandaverunt apponi. Acta sunt hec omnia apud Urbemveterem ${ }^{218}$, presentibus vocatis et rogatis testibus domino Gerardo preposito predicto, domino Jacobo de Haspra ${ }^{219}$ et Henrico de Cundato ${ }^{220}$, Cameracensis diocesis, et Jacobo de Sancto Eadmundo, Tornacensis ${ }^{21}$ diocesis clericis.

(S.M.) Et ego Raynerius Tholomei de Florentia, apostolica et imperiali auctoritate notarius, predicta omnia coram me acta rogatus publice scripsi manu propria.

Thomassin, notaire impérial, notifie que Jean, désormais évêque de Liège, a emprunté, à la requête de son père Guy, comte de Flandre et marquis de Namur, la somme de 500 livres de petits tournois, somme $q u$ 'ils s'engagent à rembourser aux prochaines foires de Lagny, renonçant à toute exception leur permettant de se soustraire à leurs obligations.

${ }^{215}$ En 1279, Guy de Dampierre se reconnaît débiteur d'une somme d'argent versée en cour de Rome par des marchands siennois à Gérard, prévôt de Cassel. En outre, en 1283, ce même prévôt est arbitre, désigné par Jean de Flandre dans un différend opposant ce dernier au chapitre de Saint-Lambert (BIGwood, Commerce de l'argent, t. 1, p. 66.- C.S.L., t. 2, p. 355).

${ }^{216}$ Cassel (France, Nord).

${ }^{217}$ Thérouanne (France, Pas-de-Calais)

${ }^{218}$ Orvieto (Italie, Ombrie, pr. Terni).

${ }^{219}$ Un Jean de Haspre est mentionné le 9 décembre 1269 à Cambrai. Cfr C. WYFFELS, Analyses de reconnaissances de dettes passées devant les échevins d'Ypres (1249-1291), éditées selon le manuscrit de ( $\dagger$ ) Guillmaume des Marez, Bruxelles, 1991, p. $16-17, n^{\circ} 145$.

${ }^{220}$ Henri de Condé, clerc de Guy de Dampierre, mentionné en 1286 (pensionné), 1288 (id.) et 1290. Cfr GAILLARD, Inventaire, p. 34, 39, 40, 41, n²50, 296, 313, 320.

${ }^{221}$ Cfr n. 11. 
Orvieto, 17 juin 1282

A. ORIGINAL sur parchemin (hauteur, à gauche : $295 \mathrm{~mm}$, à droite : $295 \mathrm{~mm}$, dont un repli, à gauche, de $14 \mathrm{~mm}$, à droite, de $8 \mathrm{~mm}$; largeur, en haut : $435 \mathrm{~mm}$, en bas : $437 \mathrm{~mm}$ ), muni de 2 sceaux, pendant sur double queue de parchemin : 1) sceau de Jean de Flandre, évêque de Metz, de type 3, avec contre-sceau de type $2 ; 2$ ) sceau en navette (hauteur : $46 \mathrm{~mm}$ ), en cire rouge, de Gérard, prévôt de Cassel, représentant, au-dessus d'une arcade gothique, saint Pierre à mi-corps, nimbé, tenant ses clés, accosté des lettres S · P - (Sanctus Petrus); au-dessous, un officiant à genoux devant un autel, consacrant (cfr G. DEMAY, Inventaire des sceaux de la Flandre recueillis dans les dépôts d'archives, musées et collections particulières du département du Nord, t. 2, Paris, 1873, p. 169, ${ }^{\circ} 6264$ ); de la légende, on peut lire [ ]ERARDI [ ]OSI[ ] PETRI CASLET[ ]; contre-sceas circulaire (diamètre : $12 \mathrm{~mm}$ ), de type héraldique; de la légende, on peut lire : + SIGNUM GERARDI. Acte conservé à LILLE, ARChIVES dU NORD ( $=$ A.D.N.), Chambre des comptes, B 4038-2375.

$\mathrm{Au}$ dos, en italien : Letarra di $\mathrm{V}^{\mathrm{c}}$ libre tornois che domino conte di Fiandolla ne die dare nela fiera di Lagnino anno otantedue.

Mentions : De Saint-Genors, Monuments, t. 1,2, p. 700.- Dehaisnes-Finot, Inventaire, t. 9, p. $82, \mathrm{n}^{\circ} \mathrm{B}$ 4038.- Bigwoon, Commerce de l'argent, t. 1 , p. 66 n. 5 .

Le document comporte, dans le coin inférieur gauche, le seing manuel du notaire impérial.

In nomine Domini amen. Anno a Nativitate Eius, millesimo ducentesimo octuagesimo secundo, indictione decima, die decimo septimo mensis junii, pontificatus domini Martini pape quarti anno secundo, in presentia mei, notarii, et testium subscriptorum, venerabilis pater dominus Johannes, Dei gratia olim Metensis episcopus nunc translatus in episcopatum Leodiensis, habens a nobili viro domino Guidone, comite Flandrie et marchione Namurcensis, patre suo, potestatem et mandatum speciale contrahendi mutuum cum quibuscumque personis, voluerit usque ad summam quingentarum librarum turonensium pro eiusdem domini comitis negociis in domini pape curia et alibi procurandis ipsumque dominum comitem, heredes et successores suos obligandi et etiam renuntiandi pro ut in patentibus litteris eiusdem domini comitis sigillo pendenti munitis plenius continetur. Auctoritate dictarum litterarum, nomine et vice ipsius domini comitis et pro negotiis eiusdem apud sedem apostolicam prosequendis et promovendis, constitutus apud sedem eandem fuit confessus ac recognovit se ex causa mutui de pura sorte, integre, non spe future numerationis, habuisse et recepisse ab Hugone Gigonis et Bonaventura Johannis, civibus et mercatoribus Senensis, de societate filiorum Salimbene, mutuantibus pro se et nomine Johannis Johannis Salimbenis, Raynerii Alberti, Cionis Baroncelli et aliorum socionum suorum et cuiuslibet eorum in solidum quingentas libras turonensium parvonum bonorum et legalium de Turonis, de quibus se bene contentum vocavit et tenuit, confitens et asserens eandem pecunie summam 
iam in dicti patris sui utilitatem esse conversam. Quas quingentas libras turonenses memoratas dominus episcopus, nomine et vice dicti domini comitis et etiam suo proprio et privato nomine, se principalem constituens, obligando eundem dominum comitem et se ipsum ac successores et heredes eorum et utrumque ipsorum in solidum, promisit solempniter dictis Hugoni et Bonaventure et utrique ipsorum in solidum, stipulantibus in solidum pro se et nomine dictorum sociorum suorum et cuiuslibet eorum in solidum, ita tamen quod quilibet eorum in solidum sine alia procuratione vel mandato sociorum suorum possit hoc debitum petere, exigere et recipere cum effectu uni tamen eorum solutione facta ab aliis liberentur, solvere, dare ac restituere eisdem Hugoni et Bonaventure aut alteri eorum aut alicui sociorum suorum sive ipsorum vel alicuius eorum certo nuntio, in nundinis Latiniaci proximis apud Latiniacum ${ }^{222}$, infra rectum pacamentum, aut ibidem dictarum nundinarum tempore si eas tunc ibi fieri non contingat. Quod si dictis loco et termino non solverit et omnia et singula in hoc contractu contenta non observaverit, promisit suo et dicti patris sui nomine dictis Hugoni et Bonaventure stipulantibus, ut dictum est, reficere et restituere eis omnia et singula dampna, expensas, interesse et constamenta que vel quas iidem creditores aut eorum socii fecerint vel substinuerint ob defectum dicte solutionis aut pro ipsa pecunia exigenda, et de hiis credere ipsorum et cuiuslibet sociorum suorum simplici verbo sine sacramento vel alia probatione. Dicta tamen refectione soluta et facta vel non rata maneant omnia et singula suprascripta et infrascripta et nichilominus sortem et predicta omnia ubicumque locorum terrarum et fori petitum fuerit ab eodem aut a dicto domino comite se et integre soluturos. Pro quibus omnibus et singulis firmiter observandis et ipsum integre adimplendis obligavit dictus dominus episcopus, suo et dicti patris sui nomine, dictis Hugoni et Bonaventure ut dictum est stipulantibus, se ipsum, dictum patrem suum, heredes et successores eorum et omnia sua et eorum bona mobilia et immobilia, redditus et proventus ecclesiasticos et ecclesiastica et mundana presentia et futura, quod precario iure se dictorum creditorum et sociorum suonum nomine possidere constituit usque ad integrem solutionem dicti debiti et satisfactionem omnium predictorum, dans eisdem creditoribus et eorum sociis et cuilibet eorum in solidum plenam et liberam potestatem, licentiam et auctoritatem quod a termino in antea si solutio facta non fuerit possit per pactum, propria auctoritate, absque aliqua curie proclamatione, aliqua denuntiatione aut aliquo preiudicio dictorum bonorum reddituum et proventuum et quorum ex eis voluerit ingredi possessionem et eos et ea accipere, vendere, alienare, alii obligare et apud se pro iusto precio retinere et se indempnem servare sine aliqua occasione legum iuris et usus, et renuntians in hiis omnibus, suo et dicti patris sui nomine, constitutioni De duabus dictis edite in concilio generali, beneficio restitutionis in integrum, conventioni locorum et judicum, juri revocandi domum, contradictioni litterarum, cuiuslibet appelationis remedio, omni tempori feriato, tempori quadrimestri,

22 Lagny (France, Seine-et-Marne). 
indulto crucesignatis et signandis concesso et concedendo, omnibus apostolicis privilegiis, indulgentiis et litteris impetratis et impetrandis, fori privilegio novarum constitutionum et epistule divi Adriani beneficio, exceptioni doli, condictioni sine causa et ob iniustam causam, infactum actioni, exceptioni sibi non date, solute, numerate mutuoque accepte et habite ob dictam causam dicte quantitatis pecunie, legi dicenti generalem renuntiationem non valere, omnique alii actioni, exceptioni, defensioni rei et iuris auxilio tam canonici quam civilis. Et in horum omnium evidens testimonium prefatus dominus episcopus presens instrumentum mandavit una cum sigillo domini Gerardi, prepositi Carlotensi, sigilli sui appensione muniri. Actum apud Urbemveterem ad hospicium quod idem dominus episcopus habitat, presentibus domino Guillelmo, preposito Cameracensi, domino Gerardo predicto preposito Carlotensi, Morinensis diocesis, et magistro Helino de Helines ${ }^{223}$, Tornacensis diocesis, testibus vocatibus et rogatibus.

(S.M.) Ego Thomaxinus, quondam Petricoli Armaninus de Bononis ${ }^{224}$, imperiali auctoritate notarius interfui et rogatus publice scripsi manu propria.

Le chapitre de la cathédrale Saint-Lambert de Liège notifie que, pour couvrir d'importantes dépenses, il a autorisé Jean, évêque de Liège, à contracter un emprunt de 2000 marcs liégeois et à gager son remboursement sur les revenus de l'évêché, les biens propres du chapitre étant cependant exclus de la transaction.

\section{4 janvier 1283}

A. ORIGINAL sur parchemin (hauteur, à gauche : $156 \mathrm{~mm}$, à droite : $158 \mathrm{~mm}$, dont un repli, à gauche, de $21 \mathrm{~mm}$, à droite, de $19 \mathrm{~mm}$; largeur, en haut : $262 \mathrm{~mm}$, en bas : $258 \mathrm{~mm}$ ), muni, pendant sur double queue de parchemin, du sceau circulaire (diamètre : $55 \mathrm{~mm}$ ), en cire verte, du chapitre de SaintLambert, représentant saint Lambert à mi-corps, mitré, crossé et bénissant; de la légende, on peut lire : $\uparrow$ SCS LA[ ]S LEODIENSIS (Saint-Lambert. Culte et iconographie, Liège, 1980 , p. 67-68, n5.- M. BRIBOSIA, L'iconographie de saint Lambert, BULLETIN DE LA COMMISSION ROYALE DES Monuments ET DES Sites, t. 6, 1955, p. 155-156, 163.- É. PONCELET, Le martyre de saint Lambert et les sceaux, BULLETIN DES BIBLIOPHILES LIÉGEOIS, t. 5, 1892-1895, p. 170); contre-sceau circulaire (diamètre : $37 \mathrm{~mm}$ ), de type indéterminé (en 1277, le contre-sceau de la cathédrale de Liège a pour sujet le martyre de saint Lambert.- Ibid.); de la légende, on peut lire : [ ]CRE[ ]VM : SIG[ ]. Acte conservé aux A.É.G., Chartes des comtes de Flandre, Fonds de Saint-Genois, $n^{\circ} 323$.

${ }^{223}$ Cfr n. 148.

${ }^{224}$ Cfr n. 9. 
Mentions : De SAINT-Genols, Inventaire Rupelmonde, p. 100, n⿳323.- É. PonCElet, Cartulaire de l'église Saint-Lambert de Liège (= C.S.L.), t. 6, Bruxelles, 1933, p. 29, n ${ }^{\circ}$ 163.- J. LeJeune, Liège et son Pays. Naissance d'une patrie (XIIT-XIV siècles) (= LEJEUNE, Liège et son Pays), Liège, 1948 , p. 169 n. 89,403 n. 115.

Universis presentes litteras inspecturis, decanus, archidiaconi totumque maioris ecclesie Sancti Lamberti Leodiensis capitulum salutem in Domino sempiternam. Noveritis quod reverendus pater et dominus noster Johannes, Dei gratia Leodiensis episcopus, expensas et sumptus magnos fecit pro negotiis episcopatus Leodiensis et in eo precipue quod ipse magnam summam pecunie solvit pro expensis factis a uno nobili domino Henrico de Lovanio $^{225}$ et aliis in mamburnia seu custodia bonorum et iurium episcopatus Leodiensis, sede episcopali vacante, et magnam summam pecunie dedit et solvit eidem domino Henrico pro eo quod idem dominus Henricus quedam franca allodia recepit in feodùm a domino episcopo supradicto et fecit homagium dicto domino episcopo pro eisdem, nomine episcopatus predicti, cum idem dominus Henricus predictus non esset homo feodalis episcopi vel episcopatus predicti. Quasdam etiam alias expensas fecit dictus dominus episcopus pro negotiis ecclesie et episcopatus antedicti, quas de fructibus perceptis de bonis episcopatus predicti solvere non valebat, scilicet necesse habuit mutuo recipere summas pecuniarum antedictas. Et ideo placet nobis et consentimus quod dictus dominus episcopus contrahat debitum seu debita pro causis predictis usque ad summam duorum milium marcharum leodiensis et se et omnes proventus, fructus et obventiones quascumque episcopatus predicti in quibuscumque consistentes vel percipiendos in anno presenti et futuro obliget uni vel pluribus creditoribus, pro causis predictis, prout ipsi videbatur expedire et quod ille vel illi a quo vel a quibus dictus dominus episcopus mutuum receperit usque ad summam predictam et cui vel quibus se et fructus, proventus et obventiones predictas obligaverit, habeat vel habeant fructus, proventus et obventiones predictas obligatas usque ad summam pecunie antedictam dum tamen per hoc bona ad capitulum predictum Leodiensis pertinentia non sint obligata per aliquam obligationem episcopi supradicti. In cuius rei testimonium presentes litteras sigillo ecciesie nostre fecimus sigillari. Datum anno Domini $\mathrm{M}^{\circ} \mathrm{CC}^{\circ} \mathrm{LXXX}$ secundo die Jovis post octavas Epyphanie Domini.

Jean, évêque de Liège, déclare qu'il doit à Nicolas de Condé, seigneur de Bailleul et de Morialmé, 2000 marcs de Liège, somme d'ar-

${ }^{225}$ Cfr n. 56. 
gent employée notamment pour certains remboursements à Henri de Louvain, seigneur de Herstal, et dont l'êvêque garantit le payement par divers biens de l'évêché.

\author{
Liège, 5 mai 1283
}

A. ORIGINAL sur parchemin (hauteur, à gauche : $173 \mathrm{~mm}$, à droite : $167 \mathrm{~mm}$, dont un repli, à gauche, de $22 \mathrm{~mm}$, à droite, de $24 \mathrm{~mm}$; largeur, en haut : $270 \mathrm{~mm}$, en bas : $272 \mathrm{~mm}$ ), muni, pendant sur double queue de parchemin, du sceau de Jean de Flandre, évêque de Liège, de type 3, avec contre-sceau de type 2. Acte conservé aux A.É.G., Chartes des comtes de Flandre, Fonds de Saint-Genois, $\mathrm{n}^{\circ} 332$.

MENTIONS : DE SAINT-GENOIS, Irventaire Rupelmonde, p. 103, n³32.- C.S.L, t. 6, p. 29-30, $n^{\circ} 164$.- D.D. BROUWERS, L'administration des finances du comté de Namur, du XIII au XIV's., Sources, t. 4, Chartes et réglements (= Brouwers, Chartes et réglements), t. 1, Namur, 1913, p. 232 n. 1.- LeJEUNE, Liège et son Pays, p. 169 n. 89, 403 n. 115.- KUPPER, Raoul de Zähringen, p. 73 n. 38.M. DusSART, Jean de Flandre, évêque de Liège. 1282-1291 (= DusSART, Jean de Flandre), Mem. de Lic. en Histoire dactyl., Liège, Université de Liège, 1977-1978, p. 121 n. 100.

Nous, Jehans, par la grace de Dieu, eveskes de Liege, faisons savoir a tous ke nous, a noble homme nostre chier cousin Nicolon de Condeit ${ }^{226}$, chevalier, signeur de Bailluel ${ }^{227}$ et de Moreaumeis ${ }^{228}$, devons deuz mil mars de liegois, dis saus de deniers de Braibant contés pour chascun marc, les queils deniers il nous a delivrés et les avons fait rechevoir par nos certains messagés et convertis les avons ens es propres usages del eveschiet de Liege necessaires et evidens k'on devoit a noble homme nostre chier foiable Henri de Louvaing, signeur de $\mathrm{Hastal}^{229}$, chevalier, de despens k'il avoit fais en tans dou siege vage, pour le mambornie de le terre et dou pays del eveschiet de Liege devantdite, dont li dis Henris fut wardains et mambours depar l'Eglise de Liege ens el dit tans de vacation, et pour l'aluiet ke li dis Henris a repris ou doit reprendre de nous et del eglise desindite et en doit estre hom del eveschiet hyretablement, et pour autres pluseurs besoignes de le dite terre et dou pays cuidens et necessaires k'il nous convint paiier et aquiter. Les queils deniers nous assenons a prendre a nostre chier cousin devantdit as fruis et as proufis ke nous avons et devons avoir a Thihange ${ }^{230}$, a Amaing ${ }^{231}$, a Wanze ${ }^{232}$, a Vinamont ${ }^{233}$, a Pytey ${ }^{234}$, a

${ }^{226}$ Cfr n. 132.

227 Bailleul (France, Nord).

${ }^{228}$ Morialmé (Belgique, pr. Namur, arr. Philippeville, comm. Florennes).

${ }^{229}$ Herstal (Belgique, pr. Liège, arr. Liège, comm. Herstal).

230 Tihange (Belgique, pr. Liège, arr. Huy, comm. Huy).

${ }^{231}$ Amay (Belgique, pr. Liège, arr. Huy, comm. Amay).

${ }^{232}$ Wanze (Belgique, pr. Liège, arr. Huy, comm. Wanze).

233 Vinalmont (Belgique, pr. Liège, arr. Huy, comm. Wanze).

${ }^{234}$ Pitet (Fallais)(Belgique, pr. Liège, arr. Waremme, comm. Braives). 
Ohaise $^{235}$, a Lestate ${ }^{236}$, a Meffe $^{237}$, a Waresch ${ }^{238}$, a Vaus-deles-Boursut ${ }^{239}$, a Bavenchien $^{200}$ et Huardes ${ }^{241}$, a Saintron ${ }^{242}$, a Waremme ${ }^{243}$, a Nandren ${ }^{244}$, a Uffey $^{245}$, a Fronvile ${ }^{246}$ et Noiseur ${ }^{247}$, a Opaigne ${ }^{248}$, a Halois ${ }^{249}$, a Brebant ${ }^{250}$, a Cyeney $^{251}$, a Burs ${ }^{252}$, a Revongne ${ }^{253}$, a Havelangne ${ }^{254}$, a Dynant ${ }^{255}$, a Couvin ${ }^{256}$, a Marchineles $^{257}$, a Fosses ${ }^{258}$ et a Mettin ${ }^{259}$ avoec le vivier de Fosses, a Spiers ${ }^{260}$, a Malone ${ }^{261}$ et a Franchimont ${ }^{262}$ et as appendances des villes devantdites, del mois d'aust ki sera en l'an del Incarnation nostre Signeur mil deuz cenz quatre vins et trois, de ci a deuz ans ensuiwans continuelment apres. Si volons et commandons a tous nos recheveurs sanz a warder autre commandement $k$ 'il tous les frais et proufis ki appartienent a nous dedens les dites viles et ens apendances delivrent et faicent delivrer a nostre chier cousin devantdit ou a sen commandement, et de tant k'il i prendra ou fera prendre depar lui et k'on li delivrera ens es lius devantdis, nous nous tenons a sout et a bien paiiet et enquitons ciaus ki li delivreront entirement de ci endroit de tant k'il prendera et k'on li delivrera, et commandons aussi nos recheveurs, $k$ 'il tous les fruis et les proufis des viles devantdites lievent et prendent el nom nostre chier cousin devantdit pour la quitance de le dette devantnoumee. Et pour ce k'il ensoit plus seurs, li avons

${ }^{235}$ Oha (Bas-Oha)(Belgique, pr. Liège, arr. Huy, comm. Wanze).

${ }^{236}$ Statte (Belgique, pr. Liège, arr. Huy, comm. Huy).

${ }^{237}$ Meeffe (Belgique, pr. Liège, arr. Waremme, comm. Wasseiges).

${ }^{238}$ Waret-l'Évêque (Belgique, pr. Liège, arr. Huy, comm. Héron).

${ }^{279}$ Vaux-et-Borset (Belgique, pr. Liège, arr. Huy, comm. Villers-le-Bouillet).

${ }^{200}$ Beauvechain, cfr n. 79.

241 Hoegaarden, cfr n. 79.

${ }^{2 * 2}$ Saint-Trond (Belgique, pr. Limbourg, arr. Hasselt, comm. Saint-Trond).

243 Waremme (Belgique, pr. Liège, arr. Waremme, comm. Waremme).

244 Nandrin (Belgique, pr. Liège, arr. Huy, comm. Nandrin).

${ }^{245}$ Ouffet (Belgique, pr. Liège, arr. Huy, comm. Ouffet).

${ }^{246}$ Fronville (Belgique, pr. Luxembourg, arr. Marche-en-Famenne, comm. Hotton).

${ }^{247}$ Noiseux (Belgique, pr. Namur, arr. Dinant, comm. Somme-Leuze).

240 Oppagne (Wéris)(Belgique, pr. Luxembourg, arr. Marche-en-Famenne, comm. Durbuy).

${ }^{249}$ Halloy (Braibant)(Belgique, pr. Namur, arr. Dinant, comm. Ciney).

${ }^{250}$ Braibant (Belgique, pr. Namur, arr. Dinant, comm. Ciney).

${ }^{251}$ Ciney (Belgique, pr. Namur, arr. Dinant, comm. Ciney).

${ }^{252}$ Boirs (Belgique, pr. Liège, arr. Liège, comm. Bassenge).

${ }^{253}$ Revogne (Honnay)(Belgique, pr. Namur, arr. Dinant, comm. Beauraing).

${ }^{254}$ Havelange (Belgique, pr. Namur, arr. Dinant, comm. Havelange).

${ }^{255}$ Dinant (Belgique, pr. Namur, arr. Dinant, comm. Dinant).

${ }^{256}$ Couvin (Belgique, pr. Namur, arr. Philippeville, comm. Couvin).

${ }^{257}$ Marcinelle (Belgique, pr. Hainaut, arr. Charleroi, comm. Marcinelle).

${ }^{258}$ Fosses-la-Ville (Belgique, pr. Namur, arr. Namur, comm. Fosses-la-Ville).

${ }^{259}$ Mettet (Belgique, pr. Namur, arr. Namur, comm. Mettet).

${ }^{200}$ Spy (Belgique, pr. Namur, arr. Namur, comm. Jemeppe-sur-Sambre).

${ }^{261}$ Malonne (Belgique, pr. Namur, arr. Namur, comm. Namur).

${ }^{202}$ Cfr n. 88. 
nous ces nostres presentes letres donnees, saielees de nostre saiel, ki furent faites a Liege l'an de grace mil deuz cenz quatre vins et trois, le cuincquime iour dou mois de may.

Baudouin d'Avesnes, seigneur de Beaumont, déclare que Nicolas de Condé, seigneur de Morialmé, a prêté 4000 livres, monnaie de Flandre, à Jean, évêque de Liège, prêt dont la restitution est cautionnée par Guy, comte de Flandre et marquis de Namur, avec, pour garantie, le château épiscopal de Bouillon, confié par le comte de Flandre à la garde de Baudouin, son demi-frère.

26 juin 1283

A. ORIGINAL sur parchemin (hauteur, à gauche : $205 \mathrm{~mm}$, à droite : $204 \mathrm{~mm}$, dont un repli, à gauche, de $24 \mathrm{~mm}$, à droite, de $25 \mathrm{~mm}$; largeur, en haut : $280 \mathrm{~mm}$, en bas : $273 \mathrm{~mm}$ ), muni, pendant sur double queue de parchemin, du sceau circulaire (diamètre : $76 \mathrm{~mm}$ ), en cire blanche et de type équestre à l'épée, de Baudouin d'Avesnes, seigneur de Beaumont; de la légende, quasi illisible (sceau très abimé), on peut lire [ ] BAL [ ]; contre-sceau circulaire (diamètre : $26 / 7 \mathrm{~mm}$ ) de type indéterminé (cfr infra); de la légende, on peut lire : + CLAVIS SIGILLI [identique à $R$. LAURENT, Sigillographie, Bruxelles, 1985, p. $140, \mathrm{n}^{\circ} 413$ (1271); le type de ce dernier sceau - éducation de Bacchus, la divinité assise étend les bras vers Silène et de celui de 1283 sont peut-être identiques]. Acte conservé aux A.É.G., Chartes des comtes de Flandre, Fonds de Saint-Genois, $n^{\circ} 338$.

Mentions : DE SAINT-GENOIS, Inventaire Rupelmonde, p. 104-105, n³38.C.S.L., t. 6, p. 29-30, n'165.- BrouwERS, Chartes et réglements, t. 1 , p. 232 n. 1.- E. PONCELET, Les droits souverains de la principauté de Liège sur le duché de Bouillon (= PONCELET, Droits de Liège sur Bouillon), B.C.R.H., t. 108, 1943, p. 133.- LeJeune, Liège et son Pays, p. 169 n. 89, 403 n. 115.- DuSSART, Jean de Flandre, p. 121 n. 100.

Nous, Bauduins d'Avesnes ${ }^{263}$, sires de Biaumont ${ }^{264}$, faisons savoir a tous ke coume il soit einsi ke reverens peres en nostre Seigneur J., par le grace de

${ }^{263}$ Fils de Marguerite de Constantinople (cfr n. 13) et de son premier époux,

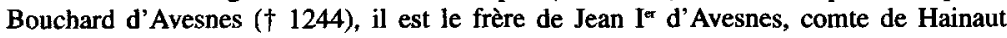
$(\dagger 1257)$ et l'auteur de la chronique qui porte son nom. Cfr Von IsENBURG, Stammtafeln, t. 2, tabl. 10.- D. BRISEMEISTER, Art. B., L.D.M., t. 1, Munich-Zurich, 1980, col. 1562-1563.

${ }^{264}$ Beaumont (Belgique, pr. Hainaut, arr. Thuin, comm. Beaumont). 
Dieu, eveskes de Liege, doive et soit tenus envers noble houme mon seigneur Nicolon de Condeit, seigneur de Moriaumeis, de quatre mil livres de le mounoie de Flandres, k'il li a presteis et delivreis avoec tous couls, frais et damages $k$ 'il $i$ averoit $u$ feroit par defaute de paiement, et a le priiere et a le requeste dou devant dit eveske, nos chiers sires et freres Guis, cuens de Flandres et marchis de Nameur, se soit establis pleges de teres et renderes de quatre mil livres devant dites envers le devant dit Nicolon, pour reverent pere le eveske desus dit, sen fil, et li devant dis eveskes, ses fils, l'en ait encouvent a aquiteir tout quite et wardeir sans domage, et avoec ce, pour plus grant seurte, il ait mis en le main de notre chier seigneur et frere desus noumei le castel de Boullon ${ }^{265}$ et toutes les apartenances ki i affierent pour tenir et wardeir jusques adont ke reverens peres li eveskes, ses fils, l'ara plainnement aquitei des dites quatre mil livres. Et nos chiers sires et freres Guis, cuens de Flandres et marchis de Nameur, ait mis le castiel de Bullon en nostre main pour tenir et wardeir de par lui et en non de lui iusques a se volentei et sen rapel. Nous, Baudouins d'Avesnes, sire de Biaumont, desus noumeis, le castel de Bullon et toutes les apiertenances proumetons et avons encouvent a rendre et a delivreir a nostre chier seigneur et frere Guion, conte de Flandres et marchis de Nameur desus noumei, a se volente et a se requeste k'il fera a nous par bouche $u$ par lettres pendans u de sen hoir conte de Flandres, se de lui estoit defailli, ke ja n'aviegne, et a ce bien et fermement tenir a nostre frere devant noumei $u$ a son hoir, nous metons en se main tout ce ke nous tenons de lui en le conté de Flandres, par le tesmoing de ces lettres, saielees de nostre saiel, faites en l'an de grace mil deus cens quatre vins et trois, le samedi apres le jour Saint Jehan.

Jean, évêque de Liège, enjoint ses sujets de Bouillon, terre qu'il a engagée à Guy, comte de Flandre et marquis de Namur, son père, d'obéir au représentant de ce dernier et souhaite que le château et ses dépendances lui soient remis par le châtelain de la localité.

10 août 1283

A. ORIGINAL sur parchemin (hauteur, à gauche : $99 \mathrm{~mm}$, à droite : $98 \mathrm{~mm}$; largeur, en haut : $213 \mathrm{~mm}$, en bas : $216 \mathrm{~mm}$ ), muni, pendant sur simple queue de parchemin, du sceau de Jean de Flandre, évêque de Liège, de type 3, avec contre-sceau de type 2. Acte conservé à LILLE, A.D.N., Chambre des comptes, B 830-2500. 
ÉDITION : C.S.L., t. 6, p. 266, d’après A.

Mentions : De Saint-Genois, Monuments, t. 1,2, p. 713.- Abbé Dehaisnes, J. FINOT, Inventaire sommaire des archives départementales antérieures à 1790. Nord. Archives civiles. Série B. Chambre des Comptes de Lille, Art. 653 à 1560 (= DehaISNES-Finor, Inventaire), t. 1,2, Lille, 1906, p. 54, n ${ }^{\circ} B$ 830.- C.S.L., t. 6, p. 30-31, $\mathrm{n}^{\circ} 166$-- PONCELET, Droits de Liege sur Bouillon, p. 133.- LeJEUNE, Liège et son Pays, p. 403 n. 115.- DuSSART, Jean de Flandre, p. 121 n. 100.

Jehans, par la grace de Dieu, eveskes de Liege, a ses foiiables tous, chevaliers, escuyers, prevost, eschevins, conseilliers, communs, chastelain et a tous ses sougis de Bullon et des appendances, salus et amour. Comme nous aiiemes mis nostre chastiel et nostre terre de Bullon en la warde de nostre tres chier signeur et pere Guy, conte de Flandres et marchis de Namur, nous vous mandons et commandons ke vous a celui qui nostres sires et peres devantdis envoyera a vous et au liu par ses lettres ouvertes, obeissies en toutes choses aussi comme a nous sauf le hiretage sainte Marie et saint Lambiert, et vous, chastelains, li delivreis le chastiel de Bullon, les cleis, et tout ce k'il i affiert. Ce fu dounei l'an de grace M CC LXXX et troiz, le iour Saint Leurench.

Étienne de Harchicourt, chapelain de Jean, évêque de Liège, s'engage à mettre tout en cuvre pour que le prélat rembourse la somme de 600 livres de noirs petits tournois à ses créanciers siennois, et ce à la prochaine foire de Provins, en mai 1284.

Lille, 21 septembre 1283

A. ORIGINAl sur parchemin (hauteur, à gauche : $95 \mathrm{~mm}$, à droite : $93 \mathrm{~mm}$; largeur, en haut : $195 \mathrm{~mm}$, en bas : $192 \mathrm{~mm}$ ), muni, pendant sur simple queue de parchemin, du sceau (très endommagé) en navette (hauteur : $40 \mathrm{~mm}$; largeur : $26 \mathrm{~mm}$ ) et en cire verte, de type symbolique (?, oiseau, colombe essorante, serpent, fleurs ?), d'Étienne de Harchicourt, chapelain épiscopal; de la légende, on peut lire : [ ] : STEPHANVS CAP [ ]. Acte conservé aux A.E.G., Chartes des comtes de Flandre, Fonds de Saint-Genois, $n^{\circ} 340$.

ÉDITION : DES MAREZ, Lettre de Foire, p. 195, $\mathrm{n}^{\circ} 103$, d'après A.

Mentions : De SAINT-Genois, Imventaire Rupelmonde, p. 105, $\mathrm{n}^{\circ} 340 .-$ C.S.L., t. 6, p. $30 \mathrm{n}$. 1.- VON ROON-BASSERMANN, Sienische Handelsgesellschaften, p. 60.- BIGWoOD, Documents, p. 209 n. 2.- ID., Commerce de l'argent, t. 1, p. 67.- ID., Les livres des comptes des Gallerani (= BIGWoOD, Gallerani), éd. A. Grunzweig, t. 2, Introduction et tables, Bruxelles, 1962, p. 60 n. 4. 
Je, Estevenes de Hareccourt ${ }^{266}$, capelains mon signeur le eveske de Liege, fait savoir a tous ke conme mes tres chiers sire li eveskes de Liege devant dis soit tenus a saiges honmes Renier Albert, Jehan Salembien et leur compaignons, marcheans de Saine, en sis cens livres de noirs petis tournois, a rendre et a paiier en le feste de Prouvins en may le premiere ke nous atendons, je ai enconvenent as dit marcheans loiaument en boine foi, ensi ke preudom doit et puet avoir enconvent, ke je meterai paine et travail et ramentenanche soigneusement envers men chier signeur le eveske devant dit et sen consel a che ke li denier devant dit soient rendu et paiiet as dis marcheans au terme dessus noumé. En tesmoignage de queles choses je ai scelees ces presentes lettres de men scel, ki furent faites et donnees a Lille l'an de grace M CC quatre vins et trois le jour Saint Mathieu l'Apostle.

Jean, évêque de Liège, déclare avoir obtenu un prêt de 600 livres de petits tournois de plusieurs marchands siennois, somme qu'il s'engage à restituer lors de la prochaine foire de Provins et dont il gage le remboursement sur les biens de l'évêché.

\section{7 février 1284}

A. ORIGinal sur parchemin (hauteur, à gauche : $149 \mathrm{~mm}$, à droite : $147 \mathrm{~mm}$, dont un repli, à gauche, de $23 \mathrm{~mm}$, à droite, de $22 \mathrm{~mm}$; largeur, en haut : $211 \mathrm{~mm}$, en bas : $218 \mathrm{~mm}$ ), muni, pendant sur double queue de parchemin, du sceau de Jean de Flandre, évêque de Liège, de type 3, avec contre-sceau de type 2. Acte conservé aux A.É.G., Chartes des comtes de Flandre, Fonds de Saint-Genois, $\mathrm{n}^{\circ} 1826$.

Au dos, en italien (sous réserves) : Letara de domino vescovo di Legi di $\mathrm{VI}^{\mathrm{c}}$ libre tournois a paghare a Provinno di magio anno otantequatro. Diesi redare a domino chonte di Fiandola [chol atre] isieme e denari [se s'avesero]

MentTónS : De SAINT-Genots, Inventaire Rupelmonde, p. 518, $\mathrm{n}^{\circ} 1826 .-$ C.S.L., t. 6, p. 30 n. 1.- Bigwood, Documents, p. 209 et n. 2.- ID., Commerce de l'argent, t. 1, p. 66.- ID., Gallerani, t. 2, p. 60 n. 4.

Nous, Jehans, par le grace de Dieu, eveskes de Liege, faisons savoir a tous ke nous, de nos chiers amis, Renier Albert, Jehan Salembien et leur compaignons, marcheans de Saine, avons rechut sis cens livres de noirs petis tournois, les ques il nous ont presté sans cous, sans usure et sans vilain marchiet et deli- 
vrés en boine monnoie, bien contee et bien nonmbree et les avons converti en l'utilite et le prufit de nostre eveskie de Liege, les ques dis deniers nous pronmetons en boine foi a rendre et a paiier a aus et a leur certain covinant ki ces presentes lettres nous rendera dedens le prochaine feste de Prouvins en may avoec tous cous, tous damaiges k'il aroient et feroient pour le defaute de no paiement, qui ja n'aviegne, sour leur plain dit raisnable, sans autre prouvanche faire. Et pour chou fermement atenir oblegon nous, nos biens et les biens de nos successeurs, moebles et non moebles, presens et a venir, et renonchons a toutes cauteles, toutes cavillations, toutes constitutions generans et esperans et a toutes autres coses ki nous poroient aider et les devans dis marcheans nuisir, a che ke li paiemens ne fust fais de nous u de par nous, ensi ke deseure est dit et devisé. Et est asavoir ke le dit paiement fait des sis cens livres dessus dites, avoec ces lettres il nous doivent quitement delivrer unes autres lettres scelees dou scel nostre chier signeur et pere Guy, conte de Flandres et marchis de Namur, les queles parolent de chienc cens livres de petis tournois ke il nous presterent en le court de Bovine ${ }^{26}$. En seurte et en tesmoignoige de toutes les coses dessus dites nous avons fait sceler ces presentes lettres de no scel, ki furent faites et donnees l'an del Incarnation notre Signeur mil CC quatre vins et trois, le joedi devant la feste Saint Piere en Chaiiere ${ }^{268}$.

\section{1}

Jean, évêque de Liège, déclare que son père Guy, comte de Flandre et marquis de Namur, a donné son aval au paiement de 12500 , parmi les 23000 livres de noirs petits tournois empruntées à divers marchands lucquois par le prélat liégeois; ce dernier s'engage à acquitter sa dette et offre en garantie divers biens de la principauté.

22 septembre 1284

A. ORIGINAl sur parchemin (hauteur, à gauche : $191 \mathrm{~mm}$, à droite : $197 \mathrm{~mm}$, dont un repli, à gauche, de $17 \mathrm{~mm}$, à droite, de $23 \mathrm{~mm}$; largeur, en haut : $235 \mathrm{~mm}$, en bas : $229 \mathrm{~mm}$ ), muni, pendant sur double queue de parchemin, du sceau de Jean de Flandre, évêque de Liège, de type 3, avec contre-sceau de type 2. Acte conservé aux A.É.G., Chartes des comtes de Flandre, Fonds de Saint-Genois, $\mathrm{n}^{\circ} 357$.

Mentions : De SAINT-GenoIs, Inventaire Rupelmonde, p. $110, \mathrm{n}^{\circ} 357 .-$ C.S.L., t. 6, p. 30 n. 1.- Brouwers, Chartes et réglements, t. 1, p. 232 n. 1.BIGwood, Commence de l'argent, t. 1, p. 67.- LeJeUne, Liège et son Pays, p. 169 n. 89,403 n. 115

${ }^{267}$ Bouvignes-sur-Meuse (Belgique, pr. Namur, arr. Dinant, comm. Dinant).

26822 février. 
Nous, Jehans, par le grace de Dieu, eveskes de Liege, faisons savoir a tous ke comme nos tres chiers sires et peres Guys, cuens de Flandres et marchis de Namur, se soit fais et establis pleges et renderes pour nous et a no requeste enviers nos chiers amis Ghet et digne hounieste Barthremiu et lor compaignons marcheans de Luke ${ }^{269}$ de douze mil et chiunc cens livres de noirs tournois petis, des vint et troiz mil livres de tournois ke nous devons as dis marcheans et a leur compaignie, li queil denier sunt tourneit et mis el proufit et en le utilitei de nostre eveschiet et de l'Eglise de Liege. Si comme de siz mil livres tournois ke nous soumes tenu de payer par le commant de l'Eglise de Roume pour no devantier ki les devoit au dizime. Encore de mil mars de liegois ke nos dis devantiers devoit a noble houme le duc de Braibant ${ }^{270}$ pour une convenance ki fu entre aus le quile summe nous avons paiiee. Encore de noef cens mars de liegois k'il devoit au signeur de Durbuy ${ }^{271}$ pour l'achat de paille dont nous avons finei. Encore de quatorze cens mars de liegois k'il nous a convenu payer et faire fin pour ses despens k'il fist quant il fu warde de l'eveschiet el tans de siege vaghe et pour sen houmage. Nous de cele plegerie devantdite de ces douze mil et chiunc cens livres de tournois avons encouvent et proumetons no tres chier signeur et pere devandit, ses hoirs et ses successeurs a aquiteir et wardeir sans damage avoec tous cous, frais et damages $k^{\prime}$ il en aroit pour defaute de no aquit, et volons k'il et si hoir fussent $\mathrm{creu}^{a}$ de ses frais, cous et damages a lor plain dit sans autre prouvance et sans le dete principal amenrir. Et pour plus grant seurtei, nous en avons a lui et a ses hoirs obligiet et encore obligons nos viles et les apendances ki ci apres sunt noumees, s'est a savoir Fosses, Methyn, Marbais ${ }^{272}$, Ghosees ${ }^{273}$, Marchenieles, Espiers ${ }^{274}$, Jambes ${ }^{275}$ et quoiques nous ${ }^{b}$ avons, en tous proufis et en toutes values a tenir paisuilement tant ke il et si hoir seroiient aquitei et wardei sans damage si ke dit est. Et en tesmoingnage de toutes ces choses nous avons fait metre nostre saiiel a ces presentes lettres dounees l'an de grace mil CC LXXX et quatre, lendemain de le Saint Mahiu 1'Apostle ${ }^{276}$.

$a_{\text {A. porte oreu mais creu semble plus judicieux.- }}{ }^{b}$ Rature.

${ }^{209}$ Lucques (Italie, Toscane, pr. Lucques).

${ }^{270}$ Cfr n. 25.

${ }^{271}$ Cfr n. 82.

${ }^{272}$ Marbaix (Belgique, pr. Hainaut, arr. Thuin, comm. Ham-sur-Heure-Nalinnes).

${ }^{273}$ Gosée (Belgique, pr. Hainaut, arr. Thuin, comm. Thuin).

${ }^{274}$ Espierres (Spiere-Helkijn)(Belgique, pr. Flandre occidentale, arr. Courtrai, comm. Spiere-Helkijn).

${ }^{275}$ Jambes (Belgique, pr. Namur, arr. Namur, comm. Namur).

27621 septembre. 
Jean, évêque de Liège, déclare que son père Guy, comte de Flandre et marquis de Namur, s'est porté caution en sa faveur pour le paiement de 3168 livres, monnaie de Flandre, somme prêtée par Simon Malet, bourgeois de Douai, au prélat; ce dernier s'engage à libérer son père de cet engagement et lui concède en garantie le château de Bouillon.

\section{2 novembre 1284}

A. ORIGINAL sur parchemin (hauteur, à gauche : $157 \mathrm{~mm}$, à droite : $154 \mathrm{~mm}$, dont un repli de $21 \mathrm{~mm}$; largeur, en haut : $252 \mathrm{~mm}$, en bas : $253 \mathrm{~mm}$ ), muni, pendant sur double queue de parchemin, du sceau de Jean de Flandre, évêque de Liège, de type 3 , avec contre-sceau de type 2 . Acte conservé aux A.É.G., Chartes des comtes de Flandre, Fonds de SaintGenois, $\mathrm{n}^{\circ} 360$.

ÉdTION : Espinas, Vie urbaine de Douai, t. 3, p. 530-531, d'après $A$.

Mentions : De SAINT-GenoIs, Inventaire Rupelmonde, p. 111, $\mathrm{n}^{\circ} 360$-- C.S.L., t. 6, p. 30 n. 1.- PONCELET, Droits de Liège sur Bouillon, p. 134.- LeJEUNE, Liège et son Pays, p. 169 n. 89, 403 n. 115.- DussART, Jean de Flandre, p. 121 et n. 100.

Nous, Jehans, par le grace de Dieu, eveskes de Liege, faisons savoir a tous ke coume nostres tres chiers sire et pere Guis, cuens de Flandres et marchis de Namur, se soit establis pour nous pleges, respondans et dette principaus envers Symon Milet, nostre bourgois de Douay, de trois mil cent et sissante et wiit livres de le mounoie de Flandres, les queils il nous a delivreis a nostre grant besoing et a nostre requeste et lesqueils nous avons mis et convertis el pourfit et en le utiliteit de nostre eveschiet de Liege. Et de tous cous, tous frais et tous damages ke li dis Symons encourroit pour defaute de nostre paiement, sour son plain dit et resnable, sans autre prouvance faire et sans le dette principal amenrir einsi k'il est convenu es lettres de ce faites, nous nostres chier seigneur et pere devant dit avons enconvent a aquiter et a wardeit sans damage de toutes ces choses lui, ses hoirs et ses successeurs avoec tous cous, tous frais et tous damages k'il en aroit $u$ feroit pour nostre defaute, ke ia n'aviegne. Et en plus grant seurte, nous metons et avons mis en se main et en se warde nostre castiel de Buillon et toutes les apiertenances a tenir iusques adont $k$ 'il soit de par nous aquiteis plainnement de le dite soume et des devant dis cous, frais et damages, si ke dit est, sans le hiretage de nostre eglise amenrir. En tiesmoignage et en seurte de laqueille chose nous avons fait mettre nostre saiel a ces presentes lettres faites et donnees en l'an de grace mil deus cens quatre vins et quatre, le juesdi apres le jour de tous sains ou jour des ames. 
Jean, évêque de Liège, déclare que son père Guy, comte de Flandre et marquis de Namur, s'est porté caution en sa faveur pour le paiement de 5000 livres, monnaie de Flandre, somme prêtée par Nicolas de Condé, seigneur de Morialmé, au prélat; ce dernier s'engage à libérer son père de cet engagement et lui concède en garantie le château de Bouillon.

2 novembre 1284

A. ORIGINAL sur parchemin (hauteur, à gauche : $146 \mathrm{~mm}$, à droite : $153 \mathrm{~mm}$, dont un repli, à gauche, de $20 \mathrm{~mm}$, à droite, de $22 \mathrm{~mm}$; largeur, en haut : $247 \mathrm{~mm}$, en bas : $252 \mathrm{~mm}$ ), muni, pendant sur double queue de parchemin, du sceau de Jean de Flandre, évêque de Liège, de type 3 , avec contre-sceau de type 2 . Acte conservé aux A.É.G., Chartes des comtes de Flandre, Fonds de Saint-Genois, $\mathrm{n}^{\circ} 361$.

MENTIONS : De SAINT-GeNOIS, Inventaire Rupelmonde, p. 111, $\mathrm{n}^{\circ} 361 .-$ C.S.L., t. 6, p. 30 n. 1.- PONCELET, Droits de Liège sur Bouillon, p. 134.- LeJeune, Liège et son Pays, p. 169 n. 89, 403 n. 115.- DuSSART, Jean de Flandre, p. 121 et n. 101.

Nous, Jehans, par le grace de Dieu, eveskes de Liege, faisons savoir a tous ke conme nostre chier sire et peres Guis, cuens de Flandres et marchis de Namur, se soit establis pour nous pleges, respondans et dette principaus envers noble houme nostre tres chier cousin Nicholon de Condet, seigneur de Moriaumeis, de cuinc mil livres de le mounoie de Flandres, les queils il nous a delivreis a nostre grant besoing et a nostre requeste et les queils nous avons mis et convertis el pourfit et en le utiliteit de nostre eveschiet de Liege. Et de tous cous, tous frais et tous damages ke nos dis cousins encourroit pour defaute de nostre paiement, sour son plain dit et raisnauble, sans autre provance faire et sans le dette principal amenrir einsi k'il est contenu es lettres de ce faites, nous nostre chier seigneur et pere devant dit avons encouvent a aquiter et a wardeir sans damage de toutes ces choses lui, ses hoirs et ses successeurs, avoec tous cous, tous frais et tous damages $k$ 'il en aroit $u$ feroit pour nostre defaute, ke ia n'aviegne, et en plus grant seurte, nous metons et avons mis en se main et en

se warde nostre castiel de Buillon et toutes les apiertenances, a tenir iusques adont k'il soit de par nous aquiteis plainnement dele dite soume et des devant dis cous, frais et damages si ke dit est, sans le hiretage de nostre eglise amenrir. En tiesmoignage et seurtei de laqueille chose nous avons fait mettre nostre saiel a ces presentes lettres donnees l'an del Incarnation nostre Seigneur mil deus cens quatre vins et quatre, le jour des ames. 
Jean, évêque de Liège, reconnaît devoir la somme de 5000 livres parisis à Nicolas de Condé, seigneur de Bailleul et de Morialmé, somme qu'il promet de restituer le 19 mars 1285 et qu'il gage sur ses biens propres.

\section{7 décembre 1284}

A. ORIGINAL sur parchemin, muni, pendant sur double queue de parchemin, du sceau de Jean de Flandre, évêque de Liège, de type 3, avec contre-sceau de type 2. Acte conservé à LILLE, A.D.N., Chambre des comptes, B 4041, $\mathrm{n}^{\circ} 2605$.

Mentions : De SaINT-Genois, Monuments, t. 1,2, p. 724.- Dehaisnes-Finot, Inventaire, t. 9, p. 85, ${ }^{\circ} \mathrm{B}$ 4041-2605.

Nous, Jehans, par la grace de Dieu, eveskes de Liege, faisons savoir a tous ke nous, a noble homme nostre tres chier cousin et foiable Nicolon de Condeit, chevalier, signeur de Bailluel et de Moreaumeis, devons de boine dete loial cuinc mile livres de paresis k'il nous a presteis en deniers contans a nostre tres grant besoing et tres necessaire, et delivreis et fait delivrer a nous et a nostre certain commant, les queils deniers nous avons mis et convertis el proufit et en l'apparant utilitei de nostre eglise et de nostre eveschiet de Liege. Et les queils nous li proumetons et avons en convent loialment en boine foi a rendre et a paiier a lui $u$ a son certain commant porteur de ces lettres $u$ a ses hoirs se de lui defalloit, au mi quaresme prochain ke nous atendons, avoec tous cous, tous frais et tous damages k'il $\mathbf{u}$ si hoir $\mathbf{i}$ aroient $u$ feroient pour le defaute de nostre paiement au terme devantnoumei, ke ia n'aviegne, a son plain dit rainsnable, $u$ de ses hoirs se de lui defalloit si ke dit est, sanz autre prouvance faire. Et a ce fermement tenir et acomplir entirement sanz faiblir obligons nous et tous nos biens meubles et non meubles presens et avenir, $\mathbf{u}$ k'il soient et k'on les puist trouver. Et renonchons en tout et en partie a toutes choses et toutes exceptions ki nous porroient aidier et nostre devant dit cousin u ses hoirs nuire, a ce ke li devantdis paiemens des deniers devantnoumeis ne fuist fais et acomplis entirement, ensi ke deseure est dit et deviseit. En tesmoing de la queile chose nous avons ces presentes lettres fait saieler de nostre saiel, ki furent faites et dounees a Tournay l'an de grace M CC LXXX et quatre, le dimence devant le feste saint Thumas l'Apostle. 
Jean, évêque de Liège, notifie qu'il a reçu 880 livres, monnaie de Flandre, de Siger de Bailleul, maréchal et receveur de Flandre, par l'intermédiaire de son clerc, maître Hellin de Helemmes, chanoine de Notre-Dame de Huy.

18 novembre 1286

A. ORIGINAL sur parchemin (hauteur, à gauche : $89 \mathrm{~mm}$, à droite : $87 \mathrm{~mm}$; largeur, en haut : $220 \mathrm{~mm}$, en bas : $225 \mathrm{~mm}$ ), muni, pendant sur simple queue de parchemin, du sceau de Jean de Flandre, évêque de Liège, de type 3, avec contre-sceau de type 2. Acte conservé à LILLE, A.D.N., Chambre des comptes, B 4043-2765.

Mentions : De Saint-Genols, Monuments, t. 1,2, p. 739.- Dehaisnes-Finot, Inventaire, t. 9, p. $88, \mathrm{n}^{\circ}$ B 4043.- C.S.L., t. 6, p. 33, $\mathrm{n}^{\circ} 177$.- DuSSART, Jean de Flandre, p. 121 et n. 102.- Lejeune, Liège et son Pays, p. 403 n. 115.

Nous, Jehans, par la grace de Dieu, eveskes de Liege, faisons savoir a tous ke nous de sage honme nostre boin ami mon signeur Soyier de Bailluel, chevalier, mareschal et recheveur de la terre de Flandre ${ }^{27}$, avons rechuit en deniers contans wit cens quatre vins livres de le mounoie de Flandre par le main maistre Hellin de Helemes, chanoine de Huy, notre chier et foiable clerc, par le tesmoing de ces presentes lettres saielees de nostre saiel. Faites et dounees l'an de grace M CC LXXX et sis, le lundi apres le feste Saint Martin ${ }^{278}$.

Jean, évêque de Liège, notifie qu'il est redevable d'une somme de 2000 livres parisis à Nicolas de Condé, seigneur de Morialmé.

${ }^{277}$ Cfr n. 147.

${ }^{278} 11$ novembre. 
18 juin 1287

A. ORIGINAL sur parchemin (hauteur, à gauche : $91 \mathrm{~mm}$, à droite : $80 \mathrm{~mm}$, dont un repli, à gauche, de $14 \mathrm{~mm}$, à droite, de $8 \mathrm{~mm}$; largeur, en haut : 278 $\mathrm{mm}$, en bas : $280 \mathrm{~mm}$ ), muni, pendant sur double queue de parchemin, du sceau de Jean de Flandre, évêque de Liège, de type 3, avec contre-sceau de type 2. Acte conservé à LILlE, A.D.N., Chambre des comptes, B 40442831.

MENTION : Dehaisnes-FinOt, Inventaire, t. 9, p. 88, nº 4044.- BigwOOD, Commerce de l'argent, t. 1, p. 12.

Nous, Jehans, par le grasce de Dieu, evesques de Liege, faisons savoir a tous ke nous devons a no chier cousin et feauble Nicholon de Condet, signeur de Moriaumes, deus mil livres de parisis, qu'il nos a prestés en bone mounoie a no besoing et a no pourfit apparant et au pourfit de nostre eglise, dont nous nos tenons bien a sous et a paiet, les ques deniers devandis nous li avons encovent a rendre et a paier puis le $\mathrm{Sa}\left[\right.$ int I] ehan $^{a}$ prochainement venant a se volente. Et sensi avenoit ke nous ne li rendissiens u paiissiens ces deniers devandis et il i euist cous ne damages pour l'oquison de no paiement, nous li renderiemes et seriens tenut do rendre tous cous, tous despens et tous damages qu'il i aroit $\mathbf{u}$ feroit par le defaute de no paiement en quelconques maniere ke ce fust iusques a sen dit et iusques au dit de sen hoir, se de lui estoit defalit u de celui qui cestie letre aporteroit sans autre provance faire, avoec le dete devandite. Et avoec chou nous volons et otrions ke Nicholes de Condet devantnomés u cil qui ceste letre aporteroit puist doner del no aques signeurs u aquele iustice qu'il vorra pour cascunes cent livre de le devantdite dete requerre et faire avoir iusques a vint livres de parisis sans se covenance et le dete devantdite ramenrir. Et pour tout chou faire et tenir nous metons et avons mis en droit, en loi et en abandon envers tous signeurs et toutes iustices tous nos biens et tout le no partout $u$ ke nous l'aiens, en tel maniere qu'il u cil qui ceste letre aporteroit le puist prendre et faire prendre a tout le no partout u que nous l'aiens et par quele iustice qu'il vorra et vendre et despendre comme le sien iusques a cele covenance qui chi deseure est dite. Et en toutes ces couses nous renoncons et avons renonchiet a tous privileges de crois prises et a prendre, a tous autres privileges, a toutes baves, a toutes exeptions, a toutes aiwes de crestientet et de loi mondaine, et a toutes les autres chouses qui dendroit ces covenances nos poroient aidier et valoir et le dit Nicholon u celui qui ceste letre aporteroit grever u nuire. Et tout chou li avons nous encovent bien et loiaument a tenir et $i$ obligons nous et nos successeurs a toutes ces covenances deseuredites tenir bien et loiaument par le teneur de ces letres saielees de nostre saiel qui furent donees en l'an del Incharnation nostre Signeur mil deus cens quatre vins et siet, le mercredi devant le iour dele Nativitet saint Iehan Baptiste.

\footnotetext{
$a^{\text {Encre ternie. }}$
} 
Jean, duc de Brabant, se constitue caution à l'égard de Nicolas de Condé, seigneur de Morialmé, pour assurer le remboursement de 2000 livres prêtées par ce dernier à Jean, évêque de Liège.

18 juin 1287

A. ORIGINAL sur parchemin (hauteur, à gauche : $179 \mathrm{~mm}$, à droite : $176 \mathrm{~mm}$, dont un repli, à gauche, de $25 \mathrm{~mm}$, à droite, de $24 \mathrm{~mm}$; largeur, en haut : $234 \mathrm{~mm}$, en bas : $217 \mathrm{~mm}$ ), muni, pendant sur double queue de parchemin, du sceau circulaire (diamètre : $90 \mathrm{~mm}$ ), en cire brune et de type équestre à la lance, de Jean $\mathrm{I}^{\alpha}$, duc de Brabant (grand sceau équestre à la lance I); de la légende (SIGI/LLVM : IO/hANNIS : DVCIS : LOT/hARINGIE : BRABANTIE, cfr LAURENT, Sceaux princes belges, t. 1,1, p. 267-268; t. 2, pl. 115-116), on peut lire : S[ ] hANNIS : DVCIS : LOT/[ ]RIN [ ]IE : BRABANTIE; contre-sceau circulaire (diamètre : $50 \mathrm{~mm}$ ), de type équestre à l'épée (contre-sceau équestre à l'épée I); de la légende, on peut lire $Z$ (rose à cinq lobes) MA/RChI/ONIS (rose) I/M/PERII (rose) (LAURENT, Sceaux princes belges, t. 1,1, p. 268; t. 2, pl. 115-116). Acte conservé aux ARCHIVEs DE L'ÉTAT À LIÈGE (= A.É.L.), Cathédrale, Chartrier, $\mathrm{n}^{\circ} 394$ (cote Bormans-Schoolmeesters, -), 409.

ÉDITION : C.S.L., t. 2, p. 407-408, d'après $A$.

MENTION : J.G. SCHOONBROODT, Inventaire analytique et chronologique des chartes du chapitre de Saint-Lambert, à Liège (= ScHOONBROODT, Inventaire Saint-Lambert), Liège, 1863, p. 104, n³94.

Nous, Jehans, par le grasce de Dieu, dus de Lotheringe et de Braibant, faisons savoir a tous ke nous devons et avons encovent a no chier feauble Nicholon de Condet, signeur de Moriaumes, pour reverent pere no chier signeur et nostre chier frere Jehan, par le grasce de Dieu, evesque de Liege, deus mille livres de parisis lesques il li a prestés a sen propre besoing apparant, les ques deniers devandis nous avons encovent a rendre et a paier audit Nicholon $u$ a sen hoir se de lui estoit defalit, u a celui qui ceste letre aporteroit, puis le Saint Iehan prochainement venant a se volente; et sensi avenoit ke nous ne li rendissiens u paiissiens ces deniers devandis, et il i euist cous ne damages pour l'oquison de no paiement, nous li renderiemes et seriens tenut dou rendre tous cous, tous despens et tous damages qu'il $\mathrm{i}$ aroit $\mathrm{u}$ feroit par le defaute de no paiement, en quelconques maniere ke ce fust, iusques a sen dit $u$ iusques au dit de celui qui ceste letre aporteroit, sans autre provance faire, avoec le dete devandite. Et avoec tout chou nous volons et otrions ke Nicholes devandis u cil qui ceste letre aporteroit, 
puist doner del no a ques signeurs $\mathbf{u}$ a quele iustice qu'il vorra, pour cascunes cent livres dele devandite dete requerre et faire avoir iusques a vint livres de parisis, sans se covenance et se dete devandite ramenrir. Et pour tout chou faire et tenir nous metons et avons mis en droit, en loi et en abandon envers tous signeurs et envers toutes iustices tous nos biens et tout le no $u$ que nous l'aiens, en tel maniere qu'il u cil qui ceste letre aportera le puist prendre et faire prendre a tout le no partout u ke nous l'aiens et par quele iustice qu'il vorra, et vendre et despendre comme le sien iusques a tele covenance qui chi deseure est dite. Et en toutes ches couses nous renonçons et avons renonchiet a tous privileges de crois prises et a prendre, a tous autres privileges, a toutes bares, a toutes exceptions, a toutes aiwes de crescience et de loi mondaine, et a toutes les autres chouses qui dendroit ces covenances nos poroient aidier et valoir, et le dit Nicholon u sen hoir $u$ celui qui ceste letre aporteroit grever $u$ nuire. Et tout chou li avons nous encovent bien et loiaument a tenir et $\mathrm{i}$ obligons nous et nos hoirs a toutes ches covenances deseuredites a tenir bien et loiaument par le teneur de ches lettres saielees de nostre saiel, qui furent faites et donees en l'an del Incharnation nostre Signeur mil deus cens quatre vins et siet, le mercredi devant le Nativitet saint Jehan Baptiste.

Le chapitre de la cathédrale Saint-Lambert de Liège autorise Jean, évêque de Liège, à emprunter la somme de 4000 marcs liégeois en vue d'éteindre les dettes contractées pour la défense du pays.

15 octobre 1289

A. Original sur parchemin (hauteur, à gauche : $130 \mathrm{~mm}$, à droite : $124 \mathrm{~mm}$, dont un repli, à gauche, de $9 \mathrm{~mm}$, à droite, de $7 \mathrm{~mm}$; largeur, en haut : $214 \mathrm{~mm}$, en bas : $218 \mathrm{~mm}$ ), muni, pendant sur double queue de parchemin, de deux fragments du sceau, en cire verte, du chapitre de Saint-Lambert (cfr acte 5); de la légende, on peut lire [ ]BERT] ] LEODI] ]. De celle du contre-sceau, on peut lire [ ]UM SI[ ]. Acte conservé aux A.É.L., Cathédrale Saint-Lambert, Chartrier, ${ }^{\circ} 404$ (numérotation BormansSchoolmeesters, 796), 420.

ÉDITION : C.S.L., t. 2, p. 456, d'après $A$.

MENTIONS: SCHOONBROODT, Inventaire Saint-Lambert, p. 106, $\mathrm{n}^{\circ} 404 .-$ Bigwoon, Commerce de l'argent, t. 1, p. 94. 
A. ${ }^{279}$, Dei gratia prepositus, magister $\mathrm{J}^{280}$, decanus, archidiaconi totumque maioris ecclesie Leodiensis capitulum, universis presentes litteras visuris, salutem in Domino sempiternam. Cum reverendus pater et dominus noster J., Dei gratia Leodiensis episcopus, pro defentione et tuitione episcopatus sui Leodiensis et iurium eiusdem, plures labores sustinuerit et expensas diversas fecerit in tantum quod in diversis est debitis propter hoc obligatus; nos de comuni consensu et deliberatione prehabita diligenti, capitulo ad hoc assignato, ne debita huiusmodi per usuras vel alias augmententur, consentimus, volumus et concedimus quod idem dominus episcopus ad solutionem debitorum suorum, mutuum recipere et contrahere possit ad summam quatuor milium marcharum Leodiensium, triginta solidis turonensibus pro marcha computandis, solvendarum infra quatuor annos proximos a festo beati Petri ad vincula ${ }^{281}$ nuper preterito in antea continue computandos, videlicet quolibet anno mille marcharum predictarum, et assignare dictam solutionem faciendam ad certa bona dumtaxat ad episcopum Leodiensem predictum pertinentia per ipsum episcopum declaranda, ita ut bona nostra et aliarum ecclesiarum civitatis et dyocesis Leodiensis obligare non possit, sua cum prout supra dictum est possit obligare et assignare; quam assignationem et obligationem ad dicta bona domini episcopi si facte fuerint, volumus et consentimus ratas esse debere, licet dictum dominum episcopum cedere vel decedere medio tempore contingat. In testimonium autem premissorum litteris presentibus sigillum ecclesie nostre Leodiensis duximus apponendum. Datum anno Domini millesimo ducentesimo octuagesimo nono, sabbato post festum beati Dyonisii ${ }^{282}$.

Jean, évêque de Liège, notifie que son père Guy, comte de Flandre et marquis de Namur, s'est porté garant en sa faveur du payement de l'amende de 2000 marcs de Liège que le prélat encourt s'il ne respecte pas les accords conclus avec le seigneur de Durbuy.

779 Ange ou Archio de Urbe, prévôt de Saint-Lambert et archidiacre de Liège de 1289 à 1291. Cfr RENARDY, Répertoire, p. 174.- S. CHOT-STASSART, Le chapitre cathédral de Saint-Lambert à Liège au moyen age: Nationalité, conditions juridique, sociale et intellectuelle des chanoines, Mém. de Lic. en Histoire dactyl., Liège, Université de Liège, 1954-1955, p. 109.

Jean des Canges, doyen de Saint-Lambert du 14 juillet 1279 à sa mort, le 12 décembre 1303, homme de confiance de Jean de Flandre et allié du comte Guy de Dampierre. Cfr RenaRDY, Répertoire, p. 333-334.- MARChANDISSE, Fonction épiscopale, p. 421.

281 1" aô̂t.

${ }^{282} 9$ octobre. 
25 janvier 1290

A. ORIGINAL sur parchemin (hauteur, à gauche : $98 \mathrm{~mm}$, à droite : $79 \mathrm{~mm}$; largeur, en haut : $258 \mathrm{~mm}$, en bas : $253 \mathrm{~mm}$ ), autrefois muni, pendant sur simple queue de parchemin, du sceau de Jean de Flandre, évêque de Liège (de type 3, avec contre-sceau de type 2, vraisemblablement). Acte conservé à LILLE, A.D.N., Chambre des comptes, B 4047-3115.

ÉDITION : É. PONCELET, Nouveaux documents relatifs à la guerre dite "de la Vache de Ciney », B.C.R.H., 5' sér., t. 7, 1897, p. 509-510, d'après $A$.

Mentions : De Saint-Genois, Monuments, t. 1,2, p. 777.- Dehaisnes-Finot, Inventaire, t. 9, p. $92, \mathrm{n}^{\circ} \mathrm{B}$ 4047.- C. WAMPACH, Urkunden- und Quellenbuch zur Geschichte der altluxemburgischen Territorien bis zur burgundischen Zeit, t. 5, Luxembourg, 1948, p. 343-344.

Nous, Iehans, par le grace de Diu, eveskes de Liege, faisons savoir a tous com einsi soit que nous soiemes mis en mise, nous, d'une part, et nobles hom li sires de Durbui, d'autre part, des debas qui estoient entre nous et luy selont che qu'il est contenut ou conpromis sour che fait entre nous et lui, saelé de nos seaus, et nous aions encouvent a tenir et a warder le dit de cheaus qui sunt sour che pris, sour painne de deus mil mars de ligois pour les quels nous avons mis en plege no chier segneur et pere le conte de Flandres et marchis de Namur. Nous par ces presentes lettres nous obleions et le nostre partout de lui aquiter de tous cous, de tous frais et de tous damages qu'il poreit avoir par le raison de le dite plegerie, en tiesmoingnage de ces presentes lettres saelees de nostre proppre saiel. Faites et donnees en l'an mil deus cens quatre vins et noef, le merkedi apres le mois de Noel qui fu iours de le convertion saint Pol.

Jean, évêque de Liège, notifie que son père Guy, comte de Flandre et marquis de Namur, lui a prêté la somme de 60 livres tournois.

20 septembre 1290

A. ORIGINAl sur parchemin (hauteur, à gauche : $75 \mathrm{~mm}$, à droite : $71 \mathrm{~mm}$; largeur, en haut : $227 \mathrm{~mm}$, en bas : $221 \mathrm{~mm}$ ), muni, pendant sur simple queue de parchemin, du sceau de Jean de Flandre, évêque de Liège, de type 3, avec contresceau de type 2. Acte conservé aux A.É.G., Chartes des comtes de Flandre, Fonds de Saint-Genois, ${ }^{\circ} 539$.

ÉDITION : BrouWERs, Chartes et réglements, t. 1, p. 231-232, d'après $A$.

Mentions : De SAINT-Genois, Inventaire Rupelmonde, p. 160, n539.- C.S.L., t. 6, p. 30 n. 1.- LeJeune, Liège et son Pays, p. 169 n. 89, 403 n. 115. 
Nous, Jehans, par le grace de Dieu, eveskes de Liege, faisons savoir a tous ke nous avons rechuit de nostre tres chier signeur et pere $\mathbf{G}$., conte de Flandre et marchis de Namur, par le main son maiieur de Namur ${ }^{283}$ ki les a deluivrés a nos gens, sissante livres de tournois par le tesmoing de ces presentes lettres saielees de nostre saiel. Donees l'an de grace mil CC LXXX et diz, le merkedi devant le Saint Mathieu I'Apostle.

Jean, évêque de Liège, reconnaît devoir à son père Guy, comte de Flandre et marquis de Namur, la somme de 17250 livres de petits tournois, somme empruntée par le comte à diverses parties, convertie au profit de l'évêché et que le prélat promet de rembourser dès qu'il lui en sera fait la demande.

17 janvier 1291

A. ORIGINAL sur parchemin (hauteur : $171 \mathrm{~mm}$, dont un repli de $29 \mathrm{~mm}$; largeur : $282 \mathrm{~mm}$ ), muni, pendant sur double queue de parchemin, du sceau de Jean de Flandre, évêque de Liège, de type 3, avec contre-sceau de type 2. Acte conservé aux A.É.G., Chartes des comtes de Flandre, Fonds de Saint-Genois, $\mathbf{n}^{\circ} 548$.

MENTIONS : De SAINT-GeNoIs, Inventaire Rupelmonde, p. 163, n548.- C.S.L., t. 6, p. 30 n. 1.- A. WAUTERS, Le duc Jean Ir et le Brabant sous le règne de ce prince (1267-1294) (= WaUTERs, Jean Ir), Bruxelles-Liège, 1862, p. 202 n. 5.- Bigwoon, Documents, p. 213 et n. 2.- ID., Commerce de l'argent, t. 1, p. 67.- LeJEUNE, Liège et son Pays, p. 169 n. 89, 403 n. 115.BIGWOOD, Gallerani, t. 2, p. 60-61.

Nous, Jehans, par le gracie de Dieu, eveskes de Liege, faisons savoir a tous ke nous devons a nostre tres chier segneur et pere Guyon, conte de Flandres et marquis de Namur, de prest k'il nos a fait et fineit pour nous en deniers contans, a nos besoins, pour pluseurs parties ki ci apres sunt escrites. Premierement au segneur de Bailluel, sis mil deus cens ciunquante livres tournois petis. Item pour les cous et les frais de ces deniers mil deus cens ciunquante livres. Item au segneur de Bailluel devant dit trois mil livres dont li sires de Bailluel a les lettres mon segneur le conte. Item pour un paiement fait a Aldebrant et ses compaignons deus mil livres. Item pour un paiement fait a 
Jake Seghier ${ }^{284}$ ciunc cens livres. Item de prest mil ciunc cens livres ke nous rechevimes en deniers contans a Lille. Item de prest fait a nous par mon segneur Sohier de Bailluel par le main maistre Hellin de Helemmes, nostre clerc, onze cens livres. Item de prest fait par mon segneur Willem de Mortaigne $^{285}$ ciunquante livres. Item de prest delivreit par ceaus de Bruges au coustre de Fosses ${ }^{286}$ ki de par nous les rechiut, trois cens sissante et quinze livres. Item sis cens livres ki de par nous furent paiiet et delivreit au segneur de Durbui. Item de prest fait par mon segneur Willem de Mortaigne se les rechiut pour nous maistres Gerars de Frelin ${ }^{287}$, sis cens vint et ciunc livres. Et est a savoir ke tout cil denier sunt tournois petit. Soume de toutes ces pieces dis et siet mil deus cens et ciunquante livres de tournois petits, le quele soume de deniers nous, Jehans, par le grace de Dieu, eveskes de Liege, deseure dis avons mise et convertie el pourfit et en l'esploit de nos besougnes et de nostre eveschiet de Liege puis le tans ke nous en sumes eveske et le prometons loiaument et avons enconvent a rendre et a paiier a nostre chier seigneur et pere devant dit a se volentei. Par le tiesmoing de ces lettres saielees de nostre saiel, faites et donnees en l'an de grace mil deus cens quatre vins et dis, le merkedi devant le jour Saint Vinchant ${ }^{288}$.

Jean, évêque de Liège, reconnaît devoir à son père Guy, comte de Flandre et marquis de Namur, les sommes de 1530 et 150 livres de petits tournois, sommes converties au profit de l'évêché et que le prélat promet de rembourser au comte dès qu'il le souhaitera.

Iacobo Sicherii, appartient à la célèbre famille marchande siennoise des Gallerani, dont il fut le représentant en France en 1260 et de 1274 a 1290, commerçant avec ce pays et avec les Pays-Bas. Il fut un créancier régulier des Dampierre (1275-1290), du duc de Brabant (1278), de Robert d'Artois (1282, 1283) et de Philippe III le Hardi, roi de France (1287), $\uparrow$ av. 25 avril 1303. Cfr BiGwood, Commence de l'argent, t. 1, p. 64, 66, 67, 76, 79, 120, 166.- ID., Gallerani, t. 2, p. 36-38, 41-43, 51-64, 70-73, 78-80, 86, 88, 92, 125, 232.ID., Documents, p. 213.- GAILLARD, Inventaire, p. 63, $\mathrm{n}^{\circ} 517$.- DEHAISNES-FinOT, Inventaire, t. 9, p. 81, n $^{\circ} \mathrm{B} 4037$.

${ }^{285}$ Guillaume de Mortagne (1268-1302), seigneur de Rumes (1268) et de Dossemer (1292) (fils d'Arnulf, bourgmestre de Tournai, seigneur de Mortagne, pair de Flandre), noble en 1289, chevalier en 1268, conseiller de Guy de Dampierre et l'un de ses diplomates, épousa en troisièmes noces, la fille de Gérard de Durbuy (cfr n. 82). Cfr WARLOP, Vlaamse adel, t. 1, p. 173, 358-360, 381, 409, 413; t. 2,1, p. 161, 168; t. 2,2, p. 435.QUELLER, Diplomatic personnel, p. 387-388, 396, 399, 402.

${ }^{235}$ Cfr n. 155.

${ }^{207}$ Cfr n. 151.

${ }^{288} 22$ janvier. 
4 février 1291

A. ORIGINAl sur parchemin (hauteur, à gauche : $95 \mathrm{~mm}$, à droite : $94 \mathrm{~mm}$, dont un repli, à gauche, de $12 \mathrm{~mm}$, à droite, de $15 \mathrm{~mm}$; largeur, en haut : $242 \mathrm{~mm}$, en bas : $241 \mathrm{~mm}$ ), muni, pendant sur double queue de parchemin, du sceau de Jean de Flandre, évêque de Lìzge, de type 3 , avec contre-sceau de type 2. Acte conservé à LLLLE, A.D.N., Chambre des comptes, B 4048-3217.

ÉDTTION : É. PONCELET, Les maréchaux d'armée de l'évêché de Liège, Liège, 1903, p. 202-203, d'après $A$.

Mentions : Dehaisnes-Finot, Inventaire, t. 9, p. 94, nº ${ }^{\circ}$ 4048.- A. WaUTERS, Table chronologique des chartes et diplômes imprimés concernant l'histoire de la Belgique (= WAUTERS, Table), t. 11,2, Bruxelles, 1912, p. 416.-

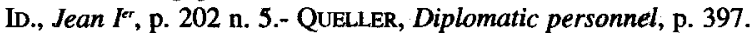

Nous, Jehans, par la grace de Dieu, eveskes de Liege, faisons savoir a tous ke nous devons et sommes tenut a nostre tres chier signeur et pere G., conte de Flandre et marchis de Namur, en mil cuinc cens en trente livres de petis tournois k'il a paiiet et delivreit pour nous et en nostre nom a Jehan, chastelain de Hosemont ${ }^{289}$, iadis nostre mareschal del eveschiet de Liege; item, cent et cuinquante livres de le dite monnoie ke nous avons de lui rechuit par le main Lothin de Bruges ${ }^{200}$, son seriant, pour aucunes nos certaines besoignes, les queils deniers nous avons mis et convertis el proufit et en l'apparant utiliteit de nostre eglise et de nostre eveschiet de Liege, et les queils dites sommes d'argent nous pronmetons et avons enconvent bien et loialment a rendre et a paiier a nostre tres chier signour et pere devant dit $u$ a son certain commandement a sa volentei par le tesmoing de ces lettres saielees de nostre saiel, donnes l'an de grace M CC LXXX et dis, le dimence apres le Chandeler.

${ }^{289}$ Sénéchal du comté de Looz (1281-1284) et homme de fief du comte (12811285), Jean, châtelain de Hozémont, est maréchal de l'évêque de Liège en février 1290. Il ne l'est plus le 4 février 1291 mais l'est redevenu en mai de la même année. Cfr JACQUES DE HEMRICOURT, Le Miroir des Nobles de Hesbaye (= JACQUES DE Hemricourt, Mimir), éd. C. De Borman, A. Bayơt, dans Jacques de Hemricourt, Oeuvres, éd. C. De Borman, A. BaYot, É. Poncelet, t. 1, Bruxelles, 1910, p. 247 n. 3.A. VERKOOREN, Inventaire des chartes et cartulaires du Luxembourg (comté puis duché), t. 1, Bruxelles, 1914, p. 254-255, n³31.- C.S.L., t. 6, p. 279.- É. PonCELET, Les maréchaux d'armée de l'évêché de Liège, Liège, 1903, p. 75-76, 203-207 (extrait de B.I.A.L., t. 32, 1902)-- C. DE BoRMAN, É. PonCELET, Tableaux généalogiques des principales familles traitées dans le Miroir des Nobles de Hesbaye $(=$ DE BORMANPonCElet, Tableaux généalogiques), dans JAcQues DE HeMricourT, Oeuvres, éd. C. de Borman, A. Bayot, E. PonCelet, t. 2, Bruxelles, 1925, p. 212.

${ }_{290}$ Principal officier financier de Guy de Dampierre (1271-1272), receveur de Namur (1279-1280), receveur général de Flandre (1280-1282), châtelain et souverain bailli de Namur (1283-1284), bailli de Gand (1286), il est souvent appelé sergent du comte. Cfr QuelLeR-KITTEL, Jakemon of Deinze, p. 291-292.- KITTELL, Medieval bureaucraty, p. 207, 209, 212.- QUELLER, Diplomatic personnel, p. 385-386. 
Gérard de Ferlin, clerc de Jean, évêque de Liège, et chanoine de la collégiale Saint-Paul de Liège, fait savoir que Gérard, receveur de Flandre, a concédé 676 livres parisis, 17 sous et 10 deniers pour financer divers besoins épiscopaux.

Bruges, 19 mai 1291

A. ORIGINAL sur parchemin (hauteur, à gauche : $82 \mathrm{~mm}$, à droite : $75 \mathrm{~mm}$; largeur, en haut : $242 \mathrm{~mm}$, en bas : $242 \mathrm{~mm}$ ), muni, pendant sur simple queue de parchemin, du sceau circulaire (diamètre : $26 / 7 \mathrm{~mm}$ ), en cire verte/brune et de type gravure antique (buste aux cheveux longs), de Gerard de Ferlin, chanoine de Saint-Paul de Liège et clerc épiscopal; de la légende, nous pensons

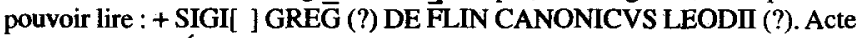
conservé aux A.É.G., Chartes des comtes de Flandre, Fonds de Saint-Genois, $\mathrm{n}^{\circ} 591$.

Mentions : De SAINT-Genols, Inventaire Rupelmonde, p. 172, $\mathrm{n}^{\circ} 591 .-$ C.S.L., t. 6, p. 30 n. 1.- WAUTERS, Jean Fr, p. 202 n. 5.- LeJEUNE, Liège et son Pays, p. 169 n. 89, 403 n. 115.

A tous chiaus ki ces presentes lettres veront et oront, jou, mestre Gerars de Ferlin, clers mon signeur de Liege, et cannones de Saint Pol de Liege, salus et cognissance de veriteit. Sayroit tout ke jou ay rechut de Gerard ${ }^{221}$, le recheveur de Flandres, pour mon signeur de Liege deus cens sesante seze livres, dis et siet sols, dis deniers paresis des queils il a fineit a Bruges pour dras, pour pennes, et pour cendaus, pour mon signeur et pour ses gens. Item j'ay rechut de li cent et dis livres paresis k'il a payiet pour mon signeur a Henri Bouwers, bourgoys de Bruges, et deux cens quatrevins dis livres paresis k'il m'a delivret en sec argent, c'est en summe de tout l'argent siz cens sensante seze livres dis siet sols et dis deniers paresis. En tesmognaige de laqueile chose jou ly ay donnees ces lettres sayelees de men siel, ki furent fetes a Bruges, l'an del Incarnation nostre Signeur mil CC quatrevins et onze, le samedi apres le mi may.

Jean, évêque de Liège, déclare devoir à son père Guy, comte de Flandre et marquis de Namur, la somme de 1356 livres, 2 sous,

${ }^{291}$ Cfr n. 146. 
3 deniers et maille de petits tournois, somme empruntée par le comte à diverses parties, convertie au profit de l'évêché et que le prélat promet de rembourser, dès qu'il lui en sera fait la requête.

\section{7 mai 1291}

A. ORIGINAL sur parchemin (hauteur, à gauche : $169 \mathrm{~mm}$, à droite : $177 \mathrm{~mm}$, dont un repli, à gauche, de $21 \mathrm{~mm}$, à droite, de $22 \mathrm{~mm}$; largeur, en haut : $277 \mathrm{~mm}$, en bas : $277 \mathrm{~mm}$ ), muni, pendant sur double queue de parchemin, du sceau de Jean de Flandre, évêque de Liège, de type 3, avec contre-sceau de type 2. Acte conservé aux A.É.G., Chartes des comtes de Flandre, Fonds de Saint-Genois, ${ }^{\circ} 592$.

Mentions : De SAINT-GenoIs, Inventaire Rupelmonde, p. 172, n592.- C.S.L., t. 6, p. 30 n. 1.- Wauters, Jean In, p. 202 n. 5.- Poncelet, Guy de Hainaut, élu de Liège (= PONCELET, Guy de Hainaut), B.C.R.H., 5' sér., t. 8, 1898, p. 503 et n. 3.- Brouwers, Chartes et réglements, t. 1, p. 232 n. 1.Bigwood, Commerce de l'argent, t. 1, p. 32, 38.- LeJEune, Liège et son Pays, p. 169 n. 89,403 n. 115.

Nous, Jehans, par le grace de Dieu, eveskes de Liege, faisons savoir a tous ke nous devons a nostre tres chier signeur et pere, mon signeur G., conte de Flandres et marchis de Namur, de prest k'il nous a fait et fineit pour nous en deniers contans a nos besoings par pluiseurs parties ki ci apres sont escrites. Premierement par le main maistre Gerart de Ferlin, nostre clerc, del recheveur de Namur ${ }^{292}$, cent et chiunquante livres tournois petis. Item par lui del maiieur de Namur sessante livres tournois. Item par lui del recheveur de Namur trois cens livres tournois. Item par lui de Gerart le Lombart, recheveur de Flandres, pour dras, cendaus et pennes deus cens sessante et sese livres, siet sols et diz deniers paresis, valent trois cens quarante et siz livres, deuz sols, trois deniers et maille tournois. Item par lui del devantdit Gerart, recheveur de Flandres, deuz cens quatre vins et diz livres paresis en ses deniers contans, valent trois cent sessante et deuz livres, diz sols tournois. Item par lui del devantdit Gerart, recheveur de Flandres, cent et diz livres paresis, paiiés a Henri le vairier de Huy, valent cent trente et siet livres, diz sols tournois petis. Summe de toutes ces preches : mil trois cens chiunquante et siz livres, deuz sols, trois deniers et maille tournois petis, le queile somme de deniers nous avons mis et convertis el pourfit et el esploit de nous de nos besoignes et de nostre eveschiet de Liege, le quele somme de deniers nous prometons loiiaument et avons encouvent a rendre et a paiier a nostre tres chier seigneur et pere devant dit, a se volenteit. Par le tesmoing de ces presentes lettres saiielees de nostre saiiel, faites et dounees l'an de grace mil deuz cens quatre vins et onze, le diemenche devant le Ascension notre Seigneur. 
Jean, évêque de Liège, déclare que son père Guy, comte de Flandre et marquis de Namur, lui a prêté la somme de 1010 livres parisis afin de couvrir les besoins de l'évêché et les siens propres, une somme qu'il s'engage à restituer selon le désir du comte.

28 juillet 1291

A. ORIGINAL sur parchemin (hauteur, à gauche : $141 \mathrm{~mm}$, à droite : $137 \mathrm{~mm}$, dont un repli, à gauche, de $21 \mathrm{~mm}$, à droite, de $25 \mathrm{~mm}$; largeur, en haut : $209 \mathrm{~mm}$, en bas : $213 \mathrm{~mm}$ ), muni, pendant sur double queue de parchemin, du sceau de Jean de Flandre, évêque de Liège, de type 3, avec contre-sceau de type 2. Acte conservé aux A.É.G., Chartes des comtes de Flandre, Fonds de SaintGenois, $\mathrm{n}^{\circ} 598$.

Mentions : De SAINT-Genois, Inventaire Rupelmonde, p. 175, $\mathrm{n}^{\circ} 598 .-$ C.S.L., t. 6, p. 30 n. 1.- Wauters, Jean $I^{r r}$, p. 202 n. 5.- PonCelet, Guy de Hainaut, p. 503 et n. 3.- Bigwood, Commerce de l'argent, t. 1, p. 13.LEJEUNE, Liège et son Pays, p. 169 n. 89, 403 n. 115.

Nous, Jehans, par le grace de Dieu, eveskes de Liege, faisons savoir a tous ke par les mains maistre Gerart de Ferlin, chanoine de Saint Pol de Liege, no chier clerc, nous avons rechiut de pur prest a no requeste et a no tres grand besoing, de no tres chier signeur et pere Guyon, conte de Flandres et marchis de Namur, mil et diz livres paresis en seche monnoye, loiial et bien contee, li quele summe toute est mise et convertie entierement el proufit, en le utilitei et es necessiteis apparans de nous et de nostre eveschiet de Liege, si comme a Stassart de Harstal pour ravoir le chastiel de Franchimont ${ }^{293}$ et aquiteir ce ke on li devoit dont quatorze plege gisoiient en mengailles et avoec ce conroit toute cele dette a usures sour nous. Et tous li remanans de le dite summe fu tourneis et convertis es propres despens de boinre et de mengier pour nous et pour no propre osteil. Et avons encouvent et proumetons loiiaument en boene foit a rendre et a paiier a no dit signeur et pere u a sen certain commant le dite summe de mil et diz livres paresis, a se volentei u autre souffisant et coursaule monnaiie au vaillant. Et se nous en estiemes en defaute, ke ia n'aviegne, nous avons encouvent et proumetons a no dit signeur et pere $\mathbf{u}$ a sen certain commant a rendre a sen plain dit sans autre prouvance tous cous, tous frais et tous damages $k$ 'ilh aroit $u$ encouroit pour la defaute de no dit paiiement, sans les dites mil et diz livres de paresis a amenrir. Et a tout ce ke dit est wardeir et acomplir entierement sans riens enfraindre, nous obligons nous et tous nos

${ }^{293}$ Cfr n. 88. 
biens meubles et non meubles et nos successeurs eveskes de Liege et tous leur biens meubles et non meubles enviers no dit signeur et pere et ses hoirs $u$ sen certain commant. En tiesmoignage et en seurtei de toutes les choses devantdites, nous avons fait metre no saiiel a ces presentes lettres, dounees l'an de grace mil deuz cens quatre vins et onze, le samedi apres le iour Saint Jakeme et Saint Cristofle ${ }^{294}$.

Jean, évêque de Liège, déclare avoir été remboursé par Nicolas de Condé, seigneur de Morialmé, des 500 livres de petits tournois prêtées par Guy, comte de Flandre et marquis de Namur, au nom de l'évêque.

28 septembre 1291

A. Original sur parchemin (hauteur : $80 \mathrm{~mm}$; largeur : $208 \mathrm{~mm}$ ), muni, pendant sur simple queue de parchemin, du sceau de Jean de Flandre, évêque de Liège, de type 3 , avec contre-sceau de type 2 . Acte conservé aux A.É.G., Chartes des comtes de Flandre, Fonds de Saint-Genois, $n^{\circ} 606$.

MENTION : DE SAINT-GENOIS, Inventaire Rupelmonde, p. 178, ${ }^{\circ} 606$.

Nous, Jehans, par la grace de Dieu, eveskes de Liege, faisons savoir a tous ke nous noble homme nostre chier cousin et foiable Nicolon de Condeit, chevalier, signeur de Moriaumeis, quitons et clamons quite des cuinc cens livres de tournois petis k'il nous devoit, dont nostres tres chiers sires et peres G., cuens de Flandres et marchis de Namur, fina a lui pour nous et en nostre nom par le tesmoing de ces presentes lettres saielees de nostre saiel, donnees l'an de grace M CC LXXX et onze, le venredi, nuit de la feste Saint Michel.

Jean, évêque de Liège, reconnaît que son père Guy, comte de Flandre et marquis de Namur, a acquitté les sommes dues à Wautoule de Jupille, châtelain de Cornillon, soit 1651 livres 18 sous 10 deniers, monnaie de Louvain, sommes dont il lui promet le remboursement, lequel est gagé sur les biens de son évêché.

29425 juillet. 
6 octobre 1291

A. ORIGINAL sur parchemin (hauteur, à gauche : $190 \mathrm{~mm}$, à droite, au-dessus du sceau : $158 \mathrm{~mm}$; largeur : $228 \mathrm{~mm}$ ), muni, pendant sur simple queue de parchemin, du sceau de Jean de Flandre, évêque de Liège, de type 3, avec contre-sceau de type 2. Acte conservé aux A.É.G., Chartes des comtes de Flandre, Fonds de Saint-Genois, $n^{\circ} 610$.

Mentions : De SAINT-Genois, Inventaire Rupelmonde, p. 179, n610.- C.S.L., t. 6, p. 30 n. 1.- PONCELET, Guy de Hainaut, p. 503.- LeJEUNE, Liège et son Pays, p. 169 n. 89, 403 n. 115.

Nous, Jehans, par le grace de Dieu, evesques de Liege, faisons savoir a tous ke nos tres chiers sires et peres Guis, cuens de Flandre et marchis de Namur, a paiet et finei pour nous a Wautoule de Jupiille ${ }^{29}$, qui fu castelains de Cornillon $^{206}$, pour les frais et pour les despens ke li dis Wautoule fist en wardant le castel et en tenant et governant le castellerie de Cornillon premierement en bons deniers appareilliés tous ses contans siis cens livres lovignoises, encore mil et chiuncquante et une livres diis et wiit sols et diis deniers lovignois, par une lettre que li devant dis Wautoule en a de mon chier seigneur et pere devantdit. Et tous ces deniers deseure dis, nous sommes tenu a rendre et promettons a rendre a nostre devant dit tres chier seigneur et pere ou a ses hoirs, se de lui defausist, ke Deus destort, ou au certain messagé dou quel ke fust qui ces lettres aroit $u$ moustreroit, et se faute $i$ avoit par nous $u$ par no partie dont il eust cous et frais $\mathbf{u}$ adamagiés en fust, par quelconques maniere ke li damages li envenist, nous li promettons ces cous, ces frais et ces damages a restorer, a paiier et a rendre entirement avoec le principal dette, tout a sa volentei et par son plain dit, sans point amenuisier le dette principal. Et recognissons par ces presentes lettres ke pour le honeur et pour le proffit de nostre evesquie de Liege, nos chiers sires et peres devant dit nos a presteis ces devantdis deniers qu'il a paiés et dont il a finei pour nous si com deseure dit est. Et pour ce nous otroions et volons ke ces soventdis deniers et tous les cous, les frais et les damages qu'il en ara ensi com dit est il reprengne entirement as biens de no evesquie devantdite, a tous les plus apparans et les plus appareilliés proffis, revenues et autres biens, sans nul empechement et sans nul contredit. Et a ces covenances et as choses desus dites bien et loiaument tenir et aemplir a nostre chier seingneur et pere devantdit $u$ as ses hoirs nous obligons, nous et nos successeurs et tous les biens de nostre dite evesquie. En tiesmoingnage de la quel chose nous avons ces presentes lettres donnees a nostre chier seingneur et pere desus nommei saelees de nostre saiel, faites l'an de grace mil deus cens quatre vins et onze, le semedi apres le Saint Remi ${ }^{297}$.

\footnotetext{
${ }^{295}$ Cfr n. 75.

296 Forteresse de Liège.

${ }^{297} 1^{\text {er }}$ octobre.
} 
Jean, évêque de Liège, fait état des sommes d'argent qu'il doit à certains membres de son entourage ainsi qu'à ses fournisseurs, et précise les diverses modalités de remboursement.

\section{1 octobre 1291}

A. ORIGINAL sur parchemin (hauteur, à gauche : $267 \mathrm{~mm}$, à droite : $271 \mathrm{~mm}$, dont un repli, à gauche, de $32 \mathrm{~mm}$, à droite, de $30 \mathrm{~mm}$; largeur, en haut : $350 \mathrm{~mm}$, en bas : $350 \mathrm{~mm}$ ), muni, pendant sur double queue de parchemin, du sceau de Jean de Flandre, évêque de Liège, de type 3, avec contre-sceau de type 2. Acte conservé aux A.É.G., Chartes des comtes de Flandre, Fonds de Saint-Genois, $\mathrm{n}^{\circ} 613$.

ÉDTron : C.S.L., t. 6, p. 280-282, d'après $A$.

MEnTins : De SAINT-GenoIs, Inventaire Rupelmonde, p. 180, n613.- C.S.L., t. 6, p. 37, ${ }^{\circ} 199$.- H. BALlIEN, De regesten der stad Tongeren, addenda 1291-1498, B.C.R.H., t. 133, 1967, p. 4, nº 1 .- WAUTERS, Jean $I^{\pi}$, p. 203 n. 2.- Poncelet, Guy de Hainaut, p. 503-504 et n. 1.- LeJeune, Liège et son Pays, p. 169 n. 89, 173, 403 n. 115, 451 n. 41.

Nous, Jehans, par le grace de Dieu, eveskes de Liege, faisons savoir a tous ke nous devons et sommes tenut envers nostre chier et foiiable maistre Willaume d'Arras ${ }^{297}$, archediakene de Liege, en chiunquante siz marcs treze sols quatre deniers liegois, conteis trois tournois petis pour deuz liegois, les queils a paiiés et fineis pour nous a nostre eglise de Saint Lambert pour arrierages et pour amendemens de monnoies. Item envers lui en quarante mars les queils il nous a presteis en ses deniers pour les despens de nostre hosteil. Item envers Jehan d'Arras, chanone de Saint Piere de Liege, en chiunquante et chiunc marcs, pour bleis et avaine delivreis en nostre hosteil. Item envers Gerart le Cuvelier en trente mars pour vins delivreis en nostre chastel a Huy. Item envers Servais Chabotel ${ }^{299}$ en trente mars pour vins delivreis en nostre chastel a Huy. Item envers Jakemon Chabotel ${ }^{300}$, nostre charrier de Liege, en chiunquante mars pour dras dont il a fineit a diverses gens et pris sour lui pour nous en le hale a Liege. Item envers lui pour

Cfrn. 153.

${ }^{299}$ Servais Chabot est encore mentionné ca 1298. Il est le frère de Jacques Chabot, mentionné n. suivante. Cfr De Borman-PonCELET, Tableaux généalogiques, p. 427.

${ }^{300}$ Fils de Gilles Chabot ( $\dagger$ 1279), Jacques ${ }^{\circ}{ }^{\circ}$ Chabot de Neuvice est échevin de Liège entre 1280 et 1303. Cfr JACQUES DE HEMRICOURT, Miroir, t. 1, p. 26, 31, 32, 86, 119, 142, 306-308, 310, 412.- De Borman-PonCelet, Tableaux généalogiques, p. 174, 314, 376, 427.- PONCELET, Introduction, p. LIII.- C. DE BORMAN, Les échevins de la souveraine justice de Liège, t. 1, Liège, 1892, p. 90-91. 
vins delivreis par lui et paiiés pour nous ki furent envoiet a Franchiermont et a Huy, en trente et un marc. Item a lui pour les ouvrages et despens de Cornillon paiiés et delivreis par lui puis le pentecouste nouvelement passee, en quatre vins diz mars siz sols et wit deniers. Item envers Quentin pour pennes en diz et siet mars. Les queils pretes font somme de quatre cens mars, pour les queils deniers a reprendre nous leur faisons assenement a le value des biens des villes de Liege et de le charrie de Freres ${ }^{301}$, de Vilers ${ }^{302}$, de Tongres ${ }^{303}$, de Le Wege ${ }^{304}$, de Reppes ${ }^{305}$, de Hourle ${ }^{306}$, de Saintron et de Wareme ki sera outre le assenement des siz cens mars ke nous avons fait as Lombars de nostre eveschiet. Item a le value de Alke ${ }^{307}$ et de Treit ${ }^{308}$, tant $k^{\prime}$ 'il soient entirement et plainement paiiet de le somme des quatre cens mars devantdis. Et encore, pour plus grant seurteit des choses devantdites, comment k'il peuist avenir de nous, comme li prevos, li doiiens, li archediakene et tous li chapitles de nostre eglise de Saint Lambert nous aient otriiet et fait grace de faire emprunt juskes a le summe de quatre mil mars a prendre sour nos rentes et nos values a quatre ans, chascun an mil mars, si comme il est plus plainement contenut en leur lettres saielees de leur saiiel ke nous avons d'eaus, dont li troi an sont passeit tres le feste Saint Jean Baptiste nouvelement passee, ke li quarte annee commencha, de le quele quarte annee li Lombart de nostre eveschiet sont asseneit sour le dite lettre de siz cens mars de liegois et quatre cens mars en demeurcent de le dite quarte annee a asseneir, nous reconnissons et volons ke li devantdis assenemens des biens devantdis fais as persones devantdites soit des quatre mil mars devant dis, les queils nous poons emprunter et rechevoir par emprunt par le consent del dit chapitle Saint Lambert si ke dit est. Et les biens et les values les queils nous avons asseneis as devant dis maistre Willaume, Jehan, Jakemon et les autres pour les dites quatre cens mars en certains lieus si ke deseure apeirt, nous leur obligons et volons k'il soient obligiet pour assenement par ces presentes lettres et volons encore ke li dite lettre dou dit chapitle soit obligié a eaus et l'obligons a eaus juskes adont k'il soient plainement paiiet des quatre cens mars devantdis. Et mandons et commandons a tous ceaus $\mathbf{k i}$ nos dites rentes rechoivent es lius devantdis ke il as devandites personnes baillent et rendent nos dites rentes et values par les mains nostres chiers et foiiables Grigoire, cousteur de Fosses, nostre chier clerc, et Jakemon Chabotel, nostre charrier devantdit, el nom des persones deseure escrites juskes a le somme des quatre cens mars devant-

301 Vreren (Belgique, pr. Limbourg, arr. Tongres, comm. Tongres).

${ }^{302}$ Villers, peut-être Villers-le-Bouillet (Belgique, pr. Liège, arr. Huy, comm. Villersle-Bouillet).

${ }^{309}$ Cfr n. 81.

${ }^{304}$ Lowaige (Lauw)(Belgique, pr. Limbourg, arr. Tongres, comm. Tongres).

${ }^{305}$ Neerrepen (Kolmont) ou Overepen (Belgique, pr. Limbourg, arr. Tongres, comm. Tongres).

${ }^{306}$ Non identifié.

30 Cfr n. 81

${ }^{308}$ Maastricht (Pays-Bas, Limbourg). 
dis. Et nous de tout ce k'il paieront et deliverront as dit Grigoire et Jakemon dont il aront leur reces $u$ de l'un d'eaus, nous tenrons et tenons a paiiet et les enquitons par le tesmoing de ces presentes lettres en le fourme et en le maniere deseure dite et devisee. En tesmoignage de la queil chose nous avons fait metre nostre saiiel a ces presentes lettres ki furent faites et donnees l'an de grace M CC LXXX et onze, le joedi au matin apres le iour de lè feste Saint Denis.

Jean, évêque de Liège, reconnaît devoir a son père Guy, comte de Flandre et marquis de Namur, la somme de 2000 livres de petits tournois.

13 octobre 1291

A. ORIGINAL sur parchemin (hauteur, à gauche : $93 \mathrm{~mm}$, à droite : $91 \mathrm{~mm}$, dont un repli, à gauche, de $22 \mathrm{~mm}$, à droite, de $23 \mathrm{~mm}$; largeur, en haut : $288 \mathrm{~mm}$, en bas : $290 \mathrm{~mm}$ ), muni, pendant sur double queue de parchemin, du sceau de Jean de Flandre, évêque de Liège, de type 3, avec contre-sceau de type 2. Acte conservé à LILLE, A.D.N., Chambre des comptes, B 3229-3280.

Mentions : Finot, Inventaire, t. 7, p. 2, n' ${ }^{\circ}$ 3229.- Wauters, Table, t. 6 , p. 357.- O. VREDIUs, Genealogiae comitum Flandriae Pars secunda continens probationes XII. posteriorum tabularum, quibus, praeter alia stemmata, elucidantur : Burgundicum et Austriacum, t. 2, Bruges, 1643, p. 24.Poncelet, Guy de Hainaut, p. 503 et n. 2.- Brouwers, Chartes et réglements, t. 1, p. 232 n. 1.- LeJEuNe, Liège et son Pays, p. 403 n. 115.DussarT, Jean de Flandre, p. 121 et n. 103, 165.

Nous, Jehans, par le grace de Dieu, eveskes de Liege, faisons savoir a tous ke nous devons et sommes tenut envers nostre tres chier signeur et pere Guy, conte de Flandres et marchis de Namur, en deuz mil livres tournois petis, les queils il a paiiés et fineit pour nous a divers poures creanciers a qui nous estiemes tenut pour les propres despens de nostre hosteil, si comme il apert plus plainement par les contes des dis despens de nostre hosteil. Pour les queils deniers reprendre et ravoir nous obligons envers nostre tres chier signeur et peire devantdit nous et nos successeurs, et tous nos biens et les biens de nos successeurs presens et a venir $\mathrm{u}$ ke il soient ne u ke on les puist trouver, par le tesmoing de ces presentes lettres saiellees de nostre saiiel, donnees l'an de grace M CC LXXX et onze, le samedi apres le Saint Denis. 
Extraits des comptes établis par Lotin de Bruges, receveur de Flandre, à propos notamment des dépenses occasionnées par le décès de Jean, évêque de Liège, ainsi que par les voyages et séjours à Liège des émissaires du comte de Flandre.

\section{Wijnendale, 16 janvier 1292}

A. ORIGINAL sur parchemin, rôle constitué de trois feuilles de parchemin (1) hauteur à gauche : $\mathbf{4 0 0} \mathrm{mm}$, à droite : $\mathbf{4 0 9} \mathrm{mm}$; largeur, en haut : $212 \mathrm{~mm}$, en bas : $218 \mathrm{~mm} ; 2$ ) hauteur à gauche : $200 \mathrm{~mm}$, à droite : 210 $\mathrm{mm}$; largeur, en haut : $214 \mathrm{~mm}$, en bas : $210 \mathrm{~mm} ; 3$ ) hauteur à gauche : $288 \mathrm{~mm}$, à droite : $300 \mathrm{~mm}$; largeur, en haut : $192 \mathrm{~mm}$, en bas : $195 \mathrm{~mm}$ ), cousues, au fil blanc, sur la largeur; non scellé. Rôle conservé aux A.E.G., Chartes des comtes de Flandre, Fonds de Saint-Genois, $\mathrm{n}^{\circ} 622$.

ÉDTION (partielle) : PONCELET, Guy de Hainaut, p. 528-530, d'après $A$.

Mentions : De SAINT-Genols, Inventaire Rupelmonde, p. 182, $\mathrm{n}^{\circ} 622 .-$ C.S.L., t. 6, p. 38, n²02.- DuSSART, Jean de Flandre, p. 166.

C'est contes Lotin de Bruges daucun emprunt ki fut fais dou seut monsigneur Willeaume de Mortaingne, conté le mercredi devant le Saint Vinchant l'an LXXXXI, a Winendale ${ }^{309}$.

$[\ldots]$

Item donné par Lotin, k'on paia au castelain de Cornillon en rabat de che ke li eveskes lui devoit pour le warde dou chastel de Cornillon, 600 livres.

Item, par le commant mon signeur Willeaume de Mortaigne, doné a Namur a maistre Gherard de Fierlin, le jour k'on mut le cors l'eveske pour aler vers Flines $^{310}, 20$ livres tournois.

Item adont, par le commant mon signeur Willeaume de Mortaigne, donné au capelain mon signeur de Naviers pour faire le despens mon signeur de Naviers et ceaus ki alerent avoec le cors le eveske, 25 livres tournois.

Item a Lotins paié as prestres et as clers ki vellierent a Anheive ${ }^{311}$ dales l'eveske, 40 sols.

Item pour linsuiaus et candelers pour l'eveske, 33 sols.

$[\ldots]$

\footnotetext{
${ }^{309}$ Wijnendale (Belgique, pr. Flandre occidentale, arr Bruges, comm. Torhout).

${ }^{310}$ Cfr n. 162.

${ }^{311}$ Cfr n. 70 .
} 
Item pour porter chierges de Namur a Viesville ${ }^{312}, 2$ sols.

A celui qui tailla et ovri le cors l'eveske, 60 sols.

Item a Freremeneurs pour pitanche, 46 sols.

Pour mener un vallet a Anheve, 12 deniers.

Item pour les chierges et les candelles faire, 14 sols.

Item pour porter le harnas de Hanheve en le nef pour le naviage et pour porter ou castel, 16 sols.

Item as Freres croisies pour pitanche, 20 sols.

Item pour faire le litiere sour qoi li cors fu mis, 6 sols.

Item pour le despens le signeur de Spiere ${ }^{313}$, Jakemon le clers $^{314}$ et Lotin de

Bruges alant a Liege et en le terre de Namur 32 livres tournois, outre che

k'il rechurent de Henri le clerc dont Lotins doit conter. $[\ldots]$

Ce sunt divers despens ke Lotins de Bruges a paiet et donné hors puis k'il s'en parti de mon signeur d'Alost le mardi apres le tous sains, l'an LXXXXI, conteit a Winendale le mercredi devant le Saint Vinchant apres suiant.

Premierement le mardi, le merkerdi et le joesdi, pour le despens mon signeur Willeaume de Mortaigne, le seigneur de Spiere et Lotin, a Broussiele, 9 livres 7 sols 9 deniers tournois.

Item pour le despens le signeur de Spiere et Lotin, de Broissiele duskes a Liege, parmi un homme ki les mena par nuit, 3 livres 3 sols 2 deniers.

Item pour le despens Jakemin le clerc pour venir de Winendale duskes a Liege encontre le signeur de Spiere et Lotin, parmi parties k'il donna hors, ke de messagés ke d'autres coses, 5 livres 5 sols 6 deniers.

Item pour le despens le signeur de Spiere, Jakemin le clerc, mon signeur Nicholes le capelain ${ }^{355}$ et Lotin a Liege, a l'ostel le coustre pour 6 iours, nient car il n'en vaurent riens prendre pour chou ke nous les menames de Namur duskes a Winendale a no despens.

${ }_{312}$ Viesville (Belgique, pr. Hainaut, arr. Charleroi, comm. Pont-à-Celles).

313 Jean, seigneur d'Espierres (20 mai 1276-4 juillet 1294), chevalier (20 mai 1276), fils de Roger de Mortagne (1247- $\dagger$ 1275/6), seigneur d'Espierres, chevalier, et d'Helwidis de Seneffe. Cfr Warlop, Vlaamse adel, t. 1, p. 175; t. 2,1, p. 333, 341; t. 2,2, p. 441, 443.

${ }^{314}$ Maître, clerc de Béatrice de Brabant, veuve du comte de Flandre Guillaume de Dampierre $(\dagger 1251)(1280$-1283), puis son procufeur, clerc de Guy de Dampierre à partir de 1290, receveur général de Flandre entre aout 1292 et $\mathrm{ca} 1300$, détenteur de diverses prébendes et dignités, notamment à Bruges et peut-être également à Lille, Tournai et Liège. $\dagger$ [29 décembre 1299-1304]. Cfr surtout Queller-KITTELL, Jakemon of Deinze.KITTEL, Medieval bureaucraty, p. 207, 209, 213.- PyCKE, Répertoire, p. 380-382.

${ }^{315}$ Nicolas de Strée, chapelain de Guy de Dampierre (dès février 1290), chanoine prébendé de Furnes et de Saint-Géry de Cambrai, chargé de diverses missions par le comte, notamment en 1292, 1295, 1297 et peut-être en 1320. Cfr QUELLER, Diplomatic personnel, p. 399-400, 404.- GAILlARD, Inventaire, p. 112, $\mathrm{n}^{\circ} 777$.- DEHAISNES-FinOt, Inventaire, $t .9$, p. 95, 104, $\mathrm{n}^{\circ} \mathrm{B} 4049,4058$.- WyFFEL, Inventaris, p. 56, 139, n²01, 592.- PONCELET, Guy de Hainaut, p. 507 et n. 4. 
Item pour les kevaus ke signeur de Spiere, Jakemin le clerc, mon signeur Nicholes, Lotin et Guiot de Namur ${ }^{316}$ par ches 6 iours, 8 livres, 10 deniers. Item pour l'instrument publike fait pour le testament mon signeur de Liege, 50 sols.

Item pour le despens le signeur de Spiere, Lotin et Jakemin le clerc, de Liege a Namur, si fu une vesprece avoek eaus me sires Gerars li Moirs ${ }^{377}, 49$ sols 3 deniers.

Item pour le despens le signeur de Spiere, Jakemin le clerc et Lotin a Namur par 2 iours et pour le despens Iakemin le clerc et Lotin par pluseurs iours demorant a Namur apres che ke li sires de Spiere s'en fu partis par mi harnas, cire et autres menues coses, 10 livres 3 sols 12 deniers.

Item au signeur de Spiere pour son despens de raler en Flandre de Namur, parmi pisson k'il en porta, 45 sols.

Item pour le despens Lotin, Jakemin le clerc, le coustre de Fosses, maistre Gerard de Fierlin, les quels il menerent sour leur despens de Namur duskes a Winendale 4 livres 5 sols.

$[\ldots]$

Extraits de comptes réalisés par Lotin de Bruges, receveur de Flandre, relatifs aux dépenses consenties en faveur de Jean, évêque de Liège.

Wijnendale, 16 janvier 1292

A. ORIGiNal sur parchemin, rôle constitué de quatre feuilles de parchemin (1) hauteur à gauche : $404 \mathrm{~mm}$, à droite : $410 \mathrm{~mm}$; largeur, en haut : $216 \mathrm{~mm}$, en bas : $216 \mathrm{~mm} ; 2$ ) hauteur à gauche : $511 \mathrm{~mm}$, à droite : $503 \mathrm{~mm}$; largeur, en haut : $212 \mathrm{~mm}$, en bas : $210 \mathrm{~mm}$; 3) hauteur à gauche : $426 \mathrm{~mm}$, à droite : $425 \mathrm{~mm}$; largeur, en haut : $208 \mathrm{~mm}$, en bas : $210 \mathrm{~mm}$; 4) hauteur à gauche : $245 \mathrm{~mm}$, à droite : $248 \mathrm{~mm}$; largeur, en haut : $210 \mathrm{~mm}$, en bas : $207 \mathrm{~mm}$ ), cousues, au fil bleu, sur la largeur; non scellé. Rôle conservé aux A.É.G., Chartes des comtes de Flandre, Fonds de Saint-Genois, n ${ }^{\circ} 623$.

316 Guyot de Namur est la fils de Guy de Dampierre et d'Isabelle de Luxembourg, décédé en octobre 1311, durant la Romfahrt d'Henry VII de Luxembourg. Cfr M. HuiSMAN, Guiot de Namur, notes biographiques, MÉlanges PaUl FredericQ. HoMmage DE LA

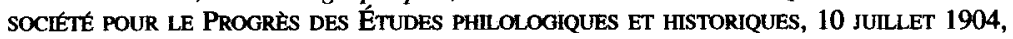
Bruxelles, 1904, p. 231-243.

317 Gérard, dit le Moer, seigneur de Wassenghien, chevalier de Robert de Béthume, mentionné en 1298-1299, 1306, 1307 et 1311. Cfr DeHAISNES-Finor, Inventaire, t. 9, p. 105-106, $n^{\circ} B$ 4058.- De SAINT-GenoIs, Inventaire Rupelmonde, p. $318,333,355, \mathrm{n}^{\circ} 1112,1165$, 1234. 
Mentions : De SAINT-Genols, Inventaire Rupelmonde, p. 182, nº623.- C.S.L., t. 6, p. $38, n^{\circ} 203$.

La date est uniquement mentionnée au verso de la quatrième feuille de parchemin, de la même main que le recto : Contes Lotin des deniers k'il a rechut pour le conte de Ghelre et pour mon signeur de Liege. Fais a Wynendale le mercredi devant le Saint Vinchant, l'an LXXX.XI.

Ch'est contes Lotyn de Bruges des deniers k'il a rechiut pour le conte de Ghelre $^{318}$ et monsigneur de Liege.

$[\ldots]$

Somme de toute ceste rechout deseure dite

9399 livres 17 sols 6 deniers parisis.

De ce a Lotins donné premierement a mon signeur de Lyege 1600 livres parisis si en rechut le bitre ${ }^{a}$ mon signeur de Liege ki parolent k'il doit a mon signeur de Neviers 3000 livres de noirs tournois a paier a se volenteit parmi autre deniers k'il devoit a mon signeur de Neviers les queles lettres Lotins kerka en warde mon signeur Jehan de Messines ${ }^{319}$ les queles me sire Jehan rendi a Lotin et Lotin rend avant a mon signeur de Nevers.

[...]

Item le venredi devant le Behourdich pour le despens Lotin de Bruges alant de Bruges a Namur et fist porteir avent li 5600 livres parisis dont li veskes en eut une partie et li autre furent alleurs deluivreit. Et pour le despens des kars er des karettes ki ces deniers meneirent et pour se despens sourjournant a Namur, pour awarder novielles quant il s'en iroit ver le terre de Ghelre de celi venredi juskes a boin devenres k'il revint arriere en Flandres c'est par 6 semaines, 35 livres 7 sols 7 deniers parisis.

Item delivra Lotins au castelain de Hozemont ${ }^{320}$ en rabat de 1530 livres de tournois c'on li devoit pour mon signeur de Liege dont il eut le lettre mon signeur de Flandre 1287 livres 19 sols 4 deniers tournois, valent 1030 livres 7 sols 6 deniers parisis. Et le sourplus paia sire Hubins de

a Mot inconnu, peut-être une erreur pour titre.

318 Renaud $I^{\text {er }}(1271-\dagger$ octobre 1326), époux en secondes noces de Marguerite $(\dagger 1331)$, fille de Guy de Dampierre. Cfr Von Isenburg, Stammtafeln, t. 2, tabl. 2.- E.I. STRubbe, L. VOET, De chronologie van de middeleeuwen en de moderne tijden in de Nederlanden, Anvers-Amsterdam, 1960, p. 360-361.

319 Jean de Messines, clerc du comte de Flandre, mentionné en 1289, 1295 et 1299. Cfr Deshaisnes-Finot, Inventaire, t. 9, p. 91, n B 4046.- DE SAINT-GenoIs, Inventaire Rupelmonde, p. $144, \mathrm{n}^{\circ} 479 .-$ Gall

${ }^{320}$ Cfr n. 289. 
Saint-Martin ${ }^{321}$ et li recheveres de Namur si doit li recheveres ravoir le lettre [...] mon signeur de le dite dette.

Item donné a un messagé envoié de Ghelre a mon signeur de Liege et a recheveur de Namur, 10 sols.

Guy, comte de Flandre et marquis de Namur, s'engage à payer à Antonin de Fierain, la somme que lui devait Jean, évêque de Liège, au moment de sa mort, une moitié devant être acquitée à la Noël, la seconde, à Pâques de l'année suivante.

Petegem-aan-de-Schelde, 8 juin 1293

A. Original sur parchemin (hauteur, à gauche : $115 \mathrm{~mm}$, à droite, au-dessus de la queue de parchemin, très abimée : $85 \mathrm{~mm}$; largeur, en haut, $208 \mathrm{~mm}$, en bas, id. : $204 \mathrm{~mm}$ ), jadis muni, pendant sur simple queue de parchemin, d'un sceau aujourd'hui disparu, celui de Guy de Dampierre, comte de Flandre et marquis de Namur. Acte conservé aux A.É.G., Chartes des comtes de Flandre, Fonds Gaillard, $\mathrm{n}^{\circ} 527$.

MENTION : GAILLARD, Inventaire, p. $65, \mathrm{n}^{\circ} 527$.

Nous, Guys, cuens de Flandre et marchis de Namuir, fasons savoir a tous ke nous devons et summes tenut envers no boin ami Antonin de Fierain, pour nostre chier fil de boinne memore Jehan, par le grace de Diu jadis eveske de Liege, en le summe d'argent ke nos chiers fins devant dis li devoia devans au jour de sen trespas dont li dis Antonins a fet conte a Namur par devant nos gens, c'est asavoir sire Jehan, nostre aumagnier ${ }^{322}$, Lothin de Bruges, nostre siergant, Grigoire, cousteur de Foses, et mestre Gerart de Ferlin, nostre clerc, a rendre et a payier le moitiet de le dite summe telle ke nos gens recorderont au Noel ki vient et l'autre moytiet a Paskes apres ensivant. En tesmognayge de laquelle chose nous li avons donnees ces lettres sayelees de nostre syel ku furent fetes a Pethengem ${ }^{323}$, l'an de grace mil CCLXXX et treze le lundi apres les trois semaines de le Penthecoustes.

${ }^{321}$ Hubin de Saint-Martin, échevin de Huy (1284-1307), receveur de l'évêque à Huy en 1292. Cfr M. YANs, Les échevins de Huy. Biographies des échevins et des maires de HuyGrande, Liège, 1952, p. 18-19.

${ }^{322}$ Frère Jean, aumônier de Guy de Dampierre, est mentionné en 1296. Il déclare qu'un tiers a livré tourbe et sel à l'hôtel comtal. Cfr DE SAINT-GENoIs, Inventaire Rupelmonde, p. $247, \mathrm{n}^{\circ} 846$.

${ }^{323}$ Petegem (Wortegem-Petegem) (Belgique, pr. Flandre orientale, arr. Audenarde, comm. Petegem). 
Tirage à part du Bulletin de la Commission royale d'Histoire,

t. CLXIII, 1997, pp. 1-75. 